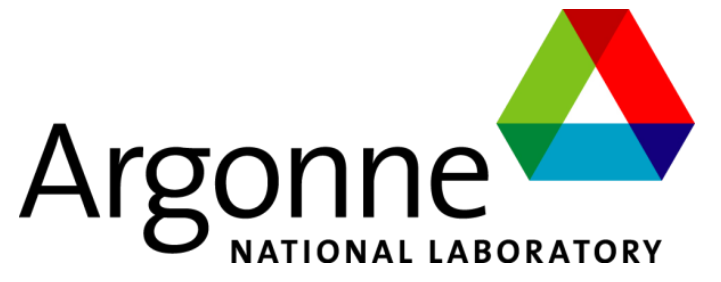

ANL/NED-18/1

\title{
CFD Simulations of Wind Tunnel Tests on Deer Isle - Sedgwick Bridge Model. Part 1. Static tests
}

January 2018 


\title{
About Argonne National Laboratory
}

Argonne is a U.S. Department of Energy laboratory managed by UChicago Argonne, LLC under contract DE-AC02-06CH11357. The Laboratory's main facility is outside Chicago, at 9700 South Cass Avenue, Argonne, Illinois 60439. For information about Argonne and its pioneering science and technology programs, see www.anl.gov.

\section{DOCUMENT AVAILABILITY}

Online Access: U.S. Department of Energy (DOE) reports produced after 1991 and a growing number of pre-1991 documents are available free via DOE's SciTech Connect (http://www.osti.gov/scitech/)

\author{
Reports not in digital format may be purchased by the public from the \\ National Technical Information Service (NTIS): \\ U.S. Department of Commerce \\ National Technical Information Service \\ 5301 Shawnee Rd \\ Alexandra, VA 22312 \\ www.ntis.gov \\ Phone: (800) 553-NTIS (6847) or (703) 605-6000 \\ Fax: (703) 605-6900 \\ Email: orders@ntis.gov \\ Reports not in digital format are available to DOE and DOE contractors from the \\ Office of Scientific and Technical Information (OSTI): \\ U.S. Department of Energy \\ Office of Scientific and Technical Information \\ P.O. Box 62 \\ Oak Ridge, TN 37831-0062 \\ www.osti.gov \\ Phone: (865) 576-8401 \\ Fax: (865) 576-5728 \\ Email: reports@osti.gov
}

Disclaimer

This report was prepared as an account of work sponsored by an agency of the United States Government. Neither the United States Government nor any agency thereof, nor UChicago Argonne, LLC, nor any of their employees or officers, makes any warranty, express or implied, or assumes any legal liability or responsibility for the accuracy, completeness, or usefulness of any information, apparatus, product, or process disclosed, or represents that its use would not infringe privately owned rights. Reference herein to any specific commercial product, process, or service by trade name, trademark, manufacturer, or otherwise, does not necessarily constitute or imply its endorsement, recommendation, or favoring by the United States Government or any agency thereof. The views and opinions of document authors expressed herein do not necessarily state or reflect those of the United States Government or any agency thereof, Argonne National Laboratory, or UChicago Argonne, LLC. 


\section{CFD Simulations of Wind Tunnel Tests on Deer Isle - Sedgwick Bridge Model. \\ Part 1. Static tests}

by

M.A. Sitek, and S.A. Lottes

Transportation Research and Analysis Computing Center (TRACC)

Nuclear Engineering Division, Argonne National Laboratory

January 2018 
Table of Contents

1. Introduction and research objectives .......................................................................

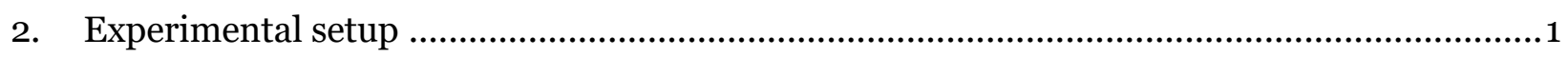

3. Development of the computational model ................................................................... 2

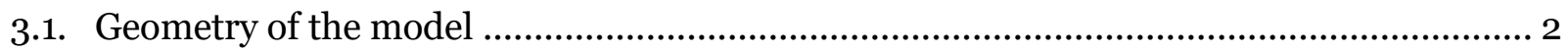

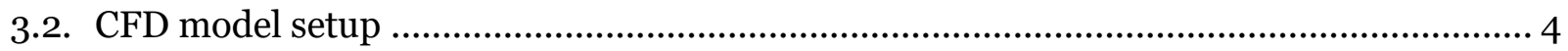

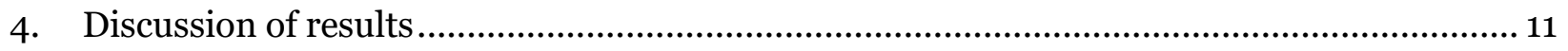

4.1. Initial considerations on the geometry of the bridge deck ..........................................12

4.2. Velocity field around the deck .............................................................................. 17

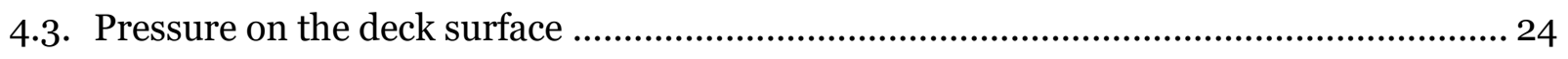

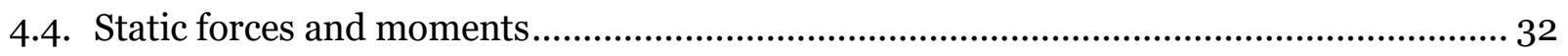

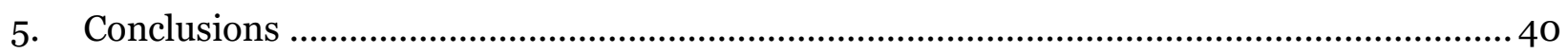

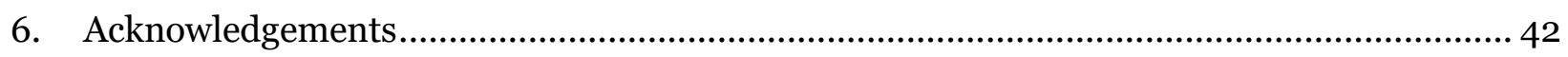

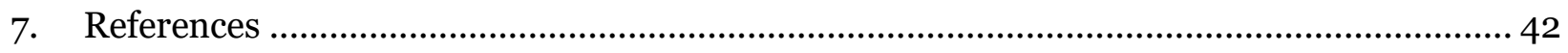




\section{List of Figures}

Figure 2-1: An example current wind tunnel test setup for force measurements ....................... 2

Figure 3-1: Top view of the model with details: a) outer side girder stiffeners and b) the deck, inner side of a girder and a narrow sidewalk; note the curb slot between the deck and the sidewalk

Figure 3-2: View of the bottom of the bridge section model with a detail of L-shape wind bracings

Figure 3-3: The CFD domain with the test section

Figure 3-4: General view of the bridge section model with end plates, with plane sections used for monitoring results

Figure 3-5: The distribution of the inlet velocity components, (a) along the flow direction, (b) across the flow, (c) in vertical direction.

Figure 3-6. The distribution of the inlet turbulence: (a) turbulence intensity, (b) turbulent viscosity ratio

Figure 3-7: Cross-sections through an example volume mesh around the bridge deck: (a) XZ plane 1, (b) plane XZ 2, (c) plane YZ (name convention according to Figure 3-4).................... 11

Figure 4-1: Wind flow direction and angle of attack .......................................................... 11

Figure 4-2: Orientation of force components ................................................................. 11

Figure 4-3: Drag force comparison between the experimental and computational models .........14

Figure 4-4: Lift force comparison between the experimental and computational models ...........15

Figure 4-5: Pitch moment comparison between the experimental and computational models ...15

Figure 4-6: Velocity vector distribution on XZ plane 1, at inlet velocity $3.3 \mathrm{~m} / \mathrm{s}$ and parallel flow in the model with (a) no sidewalks), (b) porous sidewalks, and (c) solid sidewalks. 16

Figure 4-7: Velocity vector field around the deck on XZ plane 1, at inlet velocity $3.3 \mathrm{~m} / \mathrm{s}$ and angle of attack zero degrees, (a) URANS k- $\varepsilon$ solver with uniform inlet boundary condition parameters, (b) URANS k- $\varepsilon$ solver with non-uniform inlet boundary condition parameters, (c) LES solver with uniform inlet boundary condition parameters.

Figure 4-8: Velocity magnitude field around the deck on XZ plane 1, at inlet velocity $3.3 \mathrm{~m} / \mathrm{s}$ and angle of attack zero degrees, (a) URANS k- $\varepsilon$ solver with uniform inlet boundary condition parameters, (b) URANS k- $\varepsilon$ solver with non-uniform inlet boundary condition parameters, (c) LES solver with uniform inlet boundary condition parameters. 20 
Figure 4-9: Pressure distribution on the top deck surface at (a) URANS k- $\varepsilon$ solver with uniform inlet boundary condition parameters, (b) URANS k- $\varepsilon$ solver with non-uniform inlet boundary condition parameters, (c) LES solver with uniform inlet boundary condition parameters, at inlet velocity $3.30 \mathrm{~m} / \mathrm{s}$ and angle of attack o degrees. The wind direction is marked with an arrow. . 25

Figure 4-10: Pressure distribution on the bottom deck surface at (a) URANS k- $\varepsilon$ solver with uniform inlet boundary condition parameters, (b) URANS k- $\varepsilon$ solver with non-uniform inlet boundary condition parameters, (c) LES solver with uniform inlet boundary condition parameters , at inlet velocity $3.30 \mathrm{~m} / \mathrm{s}$ and angle of attack o degrees. The wind direction is marked with an arrow.

Figure 4-11: Pressure distribution on the upwind girder surface at (a) URANS k- $\varepsilon$ solver with uniform inlet boundary condition parameters, (b) URANS k- $\varepsilon$ solver with non-uniform inlet boundary condition parameters, (c) LES solver with uniform inlet boundary condition parameters, at inlet velocity $3.30 \mathrm{~m} / \mathrm{s}$ and angle of attack o degrees. The wind direction is into the page.

Figure 4-12: Pressure distribution on the downwind girder surface at (a) URANS k- $\varepsilon$ solver with uniform inlet boundary condition parameters, (b) URANS k- $\varepsilon$ solver with non-uniform inlet boundary condition parameters, (c) LES solver with uniform inlet boundary condition parameters, at inlet velocity $3.30 \mathrm{~m} / \mathrm{s}$ and angle of attack o degrees. The wind direction is out of the page. 28

Figure 4-13: Drag force at different wind directions and inlet velocity $3.30 \mathrm{~m} / \mathrm{s}$................... 32

Figure 4-14: Drag force at different wind directions and inlet velocity $5.67 \mathrm{~m} / \mathrm{s}$.................. 33

Figure 4-15: Lift at different wind directions and inlet velocity $3.30 \mathrm{~m} / \mathrm{s}$............................ 33

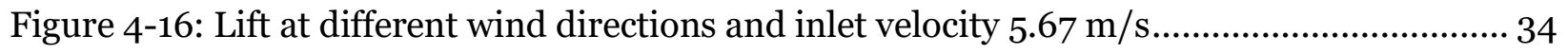

Figure 4-17: Pitch moment at different wind directions and inlet velocity $3.30 \mathrm{~m} / \mathrm{s}$................ 34

Figure 4-18: Pitch moment at different wind directions and inlet velocity $5.67 \mathrm{~m} / \mathrm{s}$................ 35

Figure 4-19: Change of the force components due to varying approach velocity at angle of attack -6 degrees. Comparison of experimental and computational results. 38

Figure 4-20: Change of the force components due to varying approach velocity at angle of attack 6 degrees. Comparison of experimental and computational results . 
List of Tables

Table 4-1: A comparison of static forces obtained in CFD simulations with wind tunnel results at angle of attack -6 degrees. For models with porous and solid sidewalks the total value and components on: deck, upstream sidewalk (us) and downstream (ds) sidewalk, are given. .13

Table 4-2: A comparison of static forces obtained in CFD simulations with wind tunnel results at parallel flow. For models with porous and solid sidewalks the total value and components on: deck, upstream sidewalk (us) and downstream (ds) sidewalk, are given...... .13

Table 4-3: A comparison of static forces obtained in CFD simulations with wind tunnel results at angle of attack 6 degrees. For models with porous and solid sidewalks the total value and components on: deck, upstream sidewalk (us) and downstream (ds) sidewalk, are given...........14

Table 4-4: Relative differences between the CFD results and experimental measurements ........ 17

Table 4-5: Velocity magnitude field around the deck on XZ plane 1, at inlet velocity $3.3 \mathrm{~m} / \mathrm{s}$ and angle of attack from -10 degrees to 10 degrees. URANS k- $\varepsilon$ solver with uniform inlet boundary condition parameters.

Table 4-6: Pressure distribution on the upwind surface of the girder at inlet velocity $3.30 \mathrm{~m} / \mathrm{s}$ and different angles of attack; URANS k- $\varepsilon$ with uniform inlet boundary condition parameters .

Table 4-7: Pressure distribution on the downwind surface of the girder at inlet velocity $3.30 \mathrm{~m} / \mathrm{s}$ and different angles of attack; URANS k- $\varepsilon$ with uniform inlet boundary condition parameters 29

Table 4-8: Pressure distribution on the top surface of the deck at inlet velocity $3.30 \mathrm{~m} / \mathrm{s}$ and different angles of attack; URANS k- $\varepsilon$ with uniform inlet boundary condition parameters ....... 30

Table 4-9: Pressure distribution on the bottom surface of the deck at inlet velocity $3.30 \mathrm{~m} / \mathrm{s}$ and different angles of attack; URANS k- $\varepsilon$ with uniform inlet boundary condition parameters .........31

Table 4-10: Relative differences between the computational and experimental results for the angle of attack -6 degrees. Case 1: URANS k- $\varepsilon$ solver with uniform inlet boundary condition parameters, Case 2: URANS k- $\varepsilon$ solver with non-uniform inlet boundary condition parameters, Case 3: LES solver with uniform inlet boundary condition parameters.

Table 4-11: Relative differences between the computational and experimental results for the angle of attack zero degrees. Case 1: URANS k- $\varepsilon$ solver with uniform inlet boundary condition parameters, Case 2: URANS k- $\varepsilon$ solver with non-uniform inlet boundary condition parameters, Case 3: LES solver.

Table 4-12: Relative differences between the computational and experimental results for the angle of attack 6 degrees. Case 1: URANS k- $\varepsilon$ solver with uniform inlet boundary condition parameters, Case 2: URANS k- $\varepsilon$ solver with non-uniform inlet boundary condition parameters, Case 3: LES solver. 36 
Table 4-13: Relative differences between the computational and experimental results at angles of

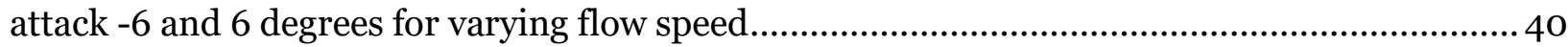




\section{Introduction and research objectives}

The Deer Isle - Sedgwick Bridge is a suspension bridge connecting the mainland to Little Deer Isle, Maine. The structure was completed in 1939 and from the beginning it encountered wind stability problems that were similar to those of the original Tacoma Narrows Bridge [1]. The problems led to numerous structural modifications during the construction and over the years of operation. In the 1980s the Aerodynamics Laboratory located in the Turner-Fairbank Highway Research Center was requested by the Maine Department of Transportation to investigate the bridge response under the existing wind conditions and suggest modifications to improve its aerodynamic characteristics. The results of the wind tunnel model studies were presented in an FHWA technical report [2]. The wind tunnel tests were conducted on a 1:25 scale section model in laminar flow conditions with varying inlet velocity and angle of attack. Static forces acting on the model were recorded and compared to the AASHTO design values. It was found that the existing shape exhibits undesirable tendencies for vortex induced response, galloping, and rotation in the torsional mode. The possible modifications of the cross-section enhancing the bridge response were proposed.

The present study focused on building a computational model of the experimental setup and validating it against the wind tunnel results with the goal of possible use in further research. A numerical representation of the original bridge model (without design enhancements) was built in LS-PrePost [3]. The computational domain of the experimental setup was built in the CFD software STAR-CCM+ [4]. A series of simulations with changing flow parameters were performed according to the laboratory setup. The computational results were then compared to the wind tunnel test results stated in the report and the analysis showed that they were in good agreement.

\section{Experimental setup}

The Deer Isle-Sedgwick Bridge is a girder-stiffened suspension bridge constructed mainly from steel, except for a reinforced concrete deck slab. The bridge section model is a copy of a typical length of the structure. Cables and hangers were not taken into account as their aerodynamic effects are considered negligible. The girders, floor beams, bracings, and stiffener elements were constructed from aluminum. Balsa wood was used to make the deck slab. A thin aluminum mesh was chosen to form the sidewalk grating.

The geometric length scale of 1:25 was used and the resulting main dimensions were:

- length inside-to-inside of the end plates $-5.0 \mathrm{ft}(1.5 \mathrm{~m})$

- width web-to-web - 11.25 in. $(28.6 \mathrm{~cm})$

- height of flanges out-to-out $-3.125 \mathrm{in}(7.9 \mathrm{~cm})$

- elliptic end plates -14.0 by 24.0 in. $(35.6 \mathrm{~cm}$ by $61.0 \mathrm{~cm})$

Neither the detailed design drawings nor the construction procedure for the model will be presented here. 
A series of wind tunnel tests was conducted under laminar flow conditions for wind speeds ranging from 0 to $40 \mathrm{fps}(12.2 \mathrm{~m} / \mathrm{s})$ and the vertical wind angles varying from -10 degrees to +10 degrees. Two sets of measurements were selected for validation of the CFD model, at flow velocity $3.30 \mathrm{~m} / \mathrm{s}$ (20 measurements at angles of attack from -10 degrees to 9 degrees) and $5.67 \mathrm{~m} / \mathrm{s}(17$ measurements at angles of attack from -10 degrees to 10 degrees). An example experimental setup is shown in Figure 2-1.

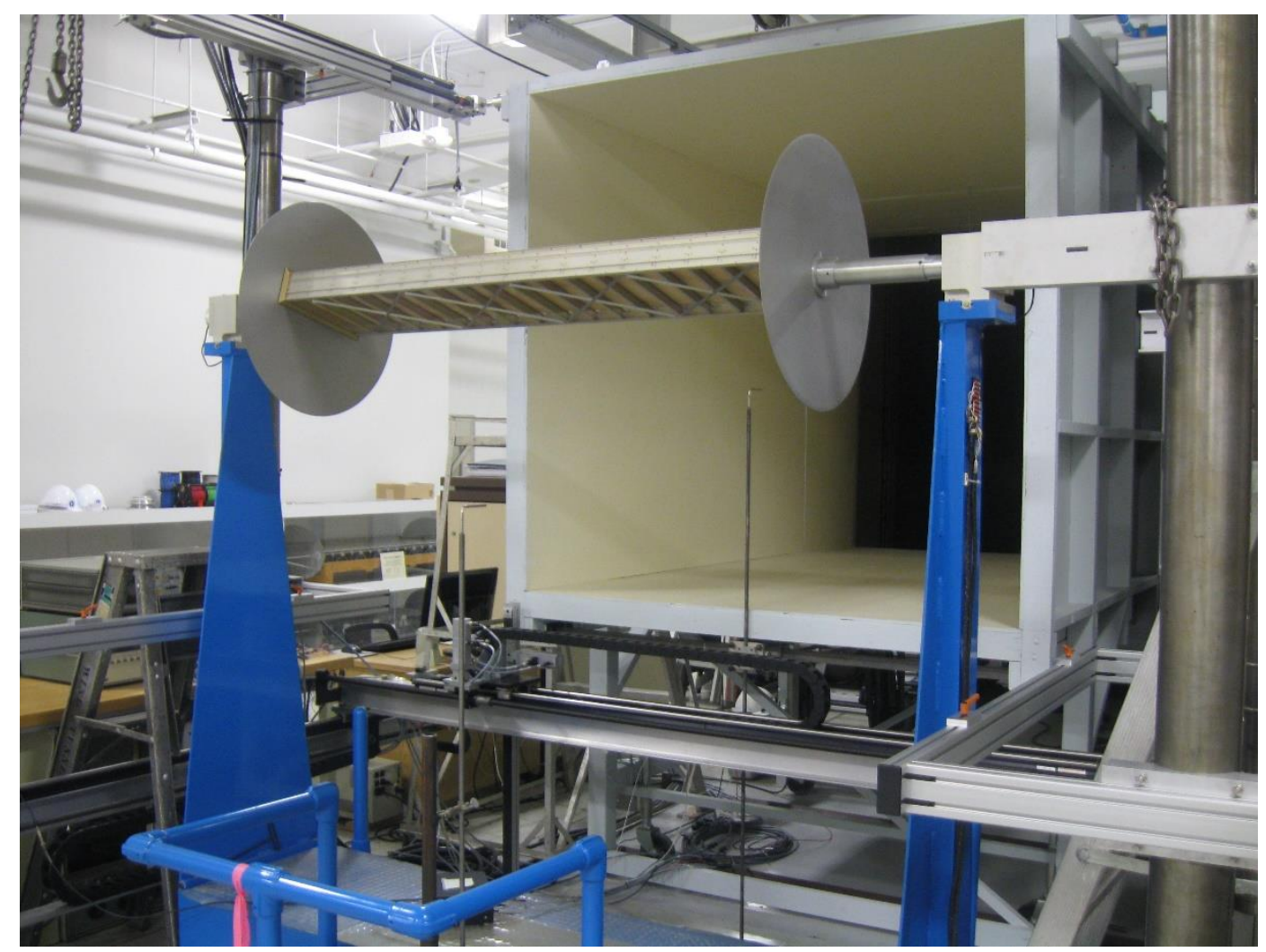

Figure 2-1: An example current wind tunnel test setup for force measurements

\section{Development of the computational model}

\subsection{Geometry of the model}

The geometry of the computational section model was developed taking into account all structural details, i.e. materials and dimensions, of the real model. Figure 3-1 shows the top view of a part of the model with two details: detail (a) shows a close-up of the girder, whereas detail (b) gives a better view of the sidewalk, which in the physical model was made of thin steel mesh with a gap between the sidewalk and the deck slab. In the numerical model it is represented with a zero- 
thickness porous shell with appropriate porosity. Figure 3-2 represents a view of the bottom of the bridge section model with a detail of L-shape wind bracings.

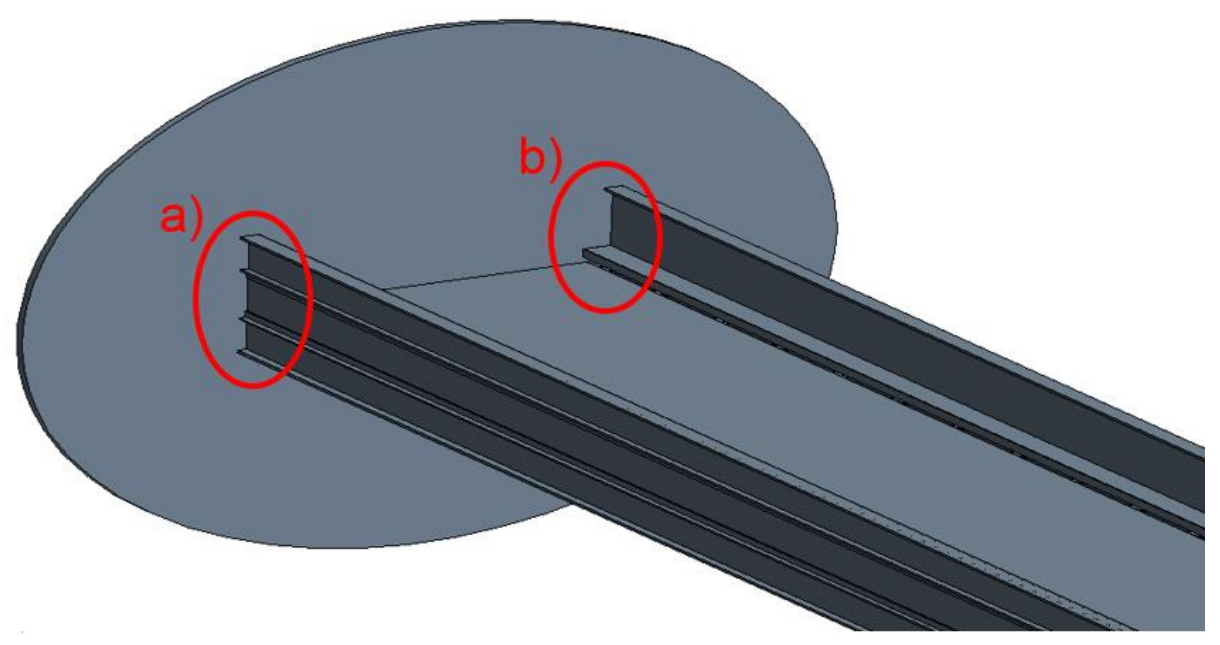

(a)

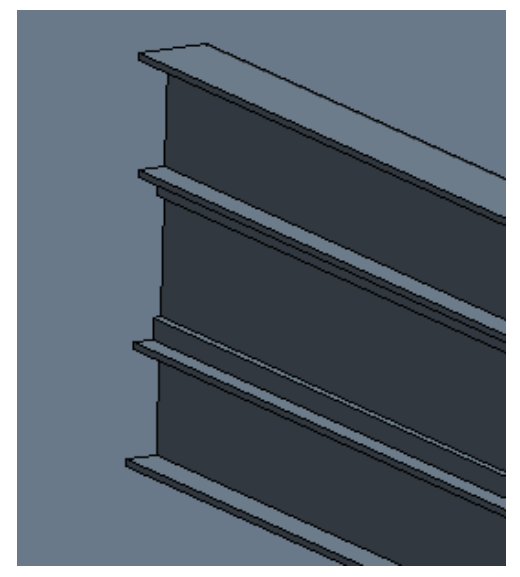

(b)

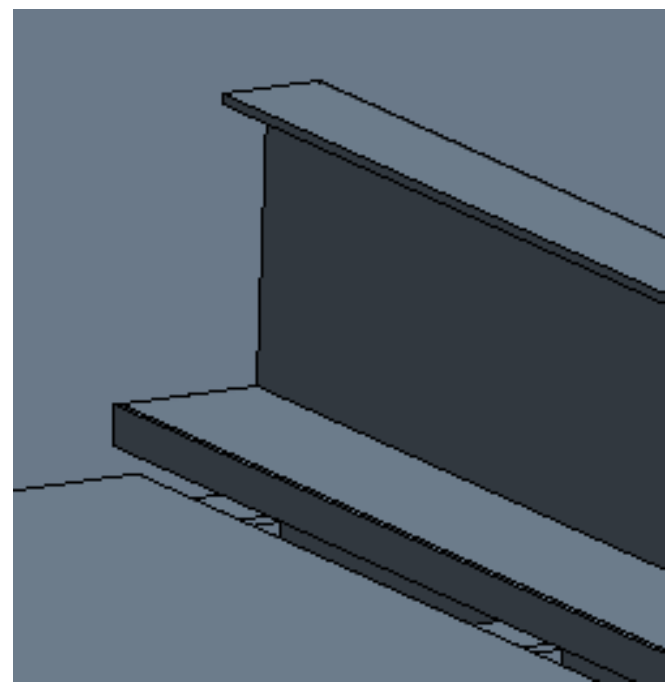

Figure 3-1: Top view of the model with details: a) outer side girder stiffeners and b) the deck, inner side of a girder and a narrow sidewalk; note the curb slot between the deck and the sidewalk 

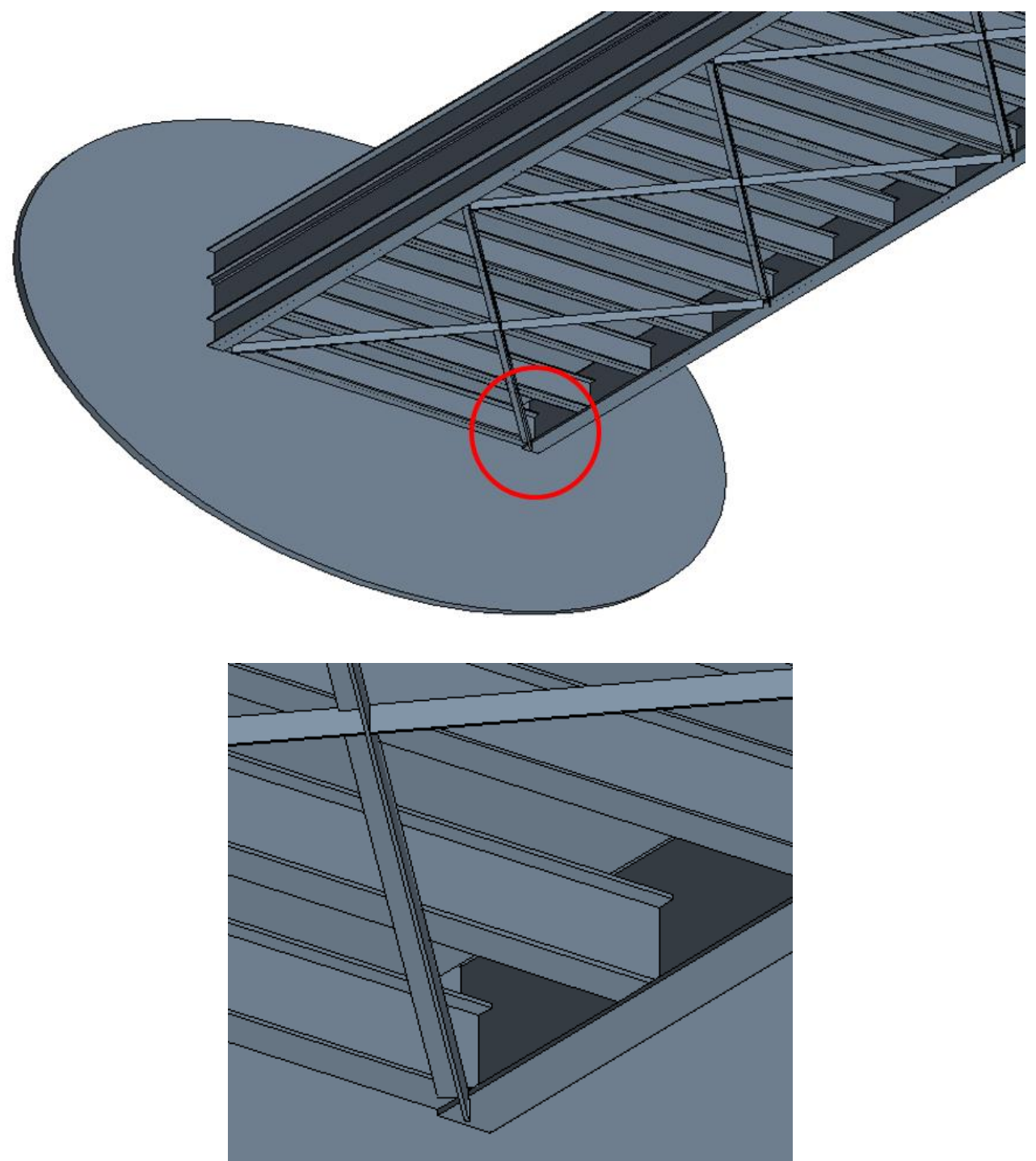

Figure 3-2: View of the bottom of the bridge section model with a detail of L-shape wind bracings

\subsection{CFD model setup}

The 3D turbulent flow was solved with STAR-CCM+ using two methods: unsteady ReynoldsAveraged Navier-Stokes (URANS) with k- $\varepsilon$ turbulence model and Large Eddy Simulation (LES) model. In the URANS simulations, an all $\mathrm{Y}+$ wall treatment using wall functions to determine wall shear was used, which means that for $\mathrm{Y}+<10$, wall shear is computed from the definition; for $\mathrm{Y}+$ $>30$, shear is computed using the standard wall function; and in the intermediate region, where $10<\mathrm{Y}+<30$, an additional hybrid wall treatment is used, which combines the high $\mathrm{y}+$ wall treatment for coarse meshes and the low $\mathrm{Y}+$ wall treatment for fine meshes. In the simulation with LES turbulence modeling, different mesh settings were used. The cell size was decreased in the first few layers of cells on the deck surface, to assure that wall $Y+$ is close to 1 . To model the turbulence of eddies smaller than those that can be resolved in the mesh, the Wale subgrid scale model is used. 
The CFD domain consists of a box that represents the space in front of the wind tunnel extension with dimensions of $2 \mathrm{~m}$ by $2 \mathrm{~m}$ by $4 \mathrm{~m}$, as displayed in Figure 3-3. The bridge section model was created in LS-PrePost and imported to Star-CCM+. It remains stationary throughout the simulation with no-slip wall boundary conditions on its surfaces. Figure 3-4 presents a general view of the bridge section model with end plates, with three plane sections used for monitoring results.

The flow was initiated in the domain in two ways. First, a constant velocity in the $\mathrm{X}$ direction and default turbulence parameter values, i.e. turbulent viscosity ratio $=10$ and turbulence intensity $=$ 0.01, were assigned at the surface. Next, a distribution of the aforementioned qualities was used, based on the flow in the Aerodynamics Laboratory modeled with a wind tunnel model with simplified geometry [5]. The distribution of the velocity components is presented in Figure 3-5, and the turbulence intensity and turbulent viscosity ratio distribution is shown in Figure 3-6. A pressure outlet boundary condition was applied on the other sides of the domain.

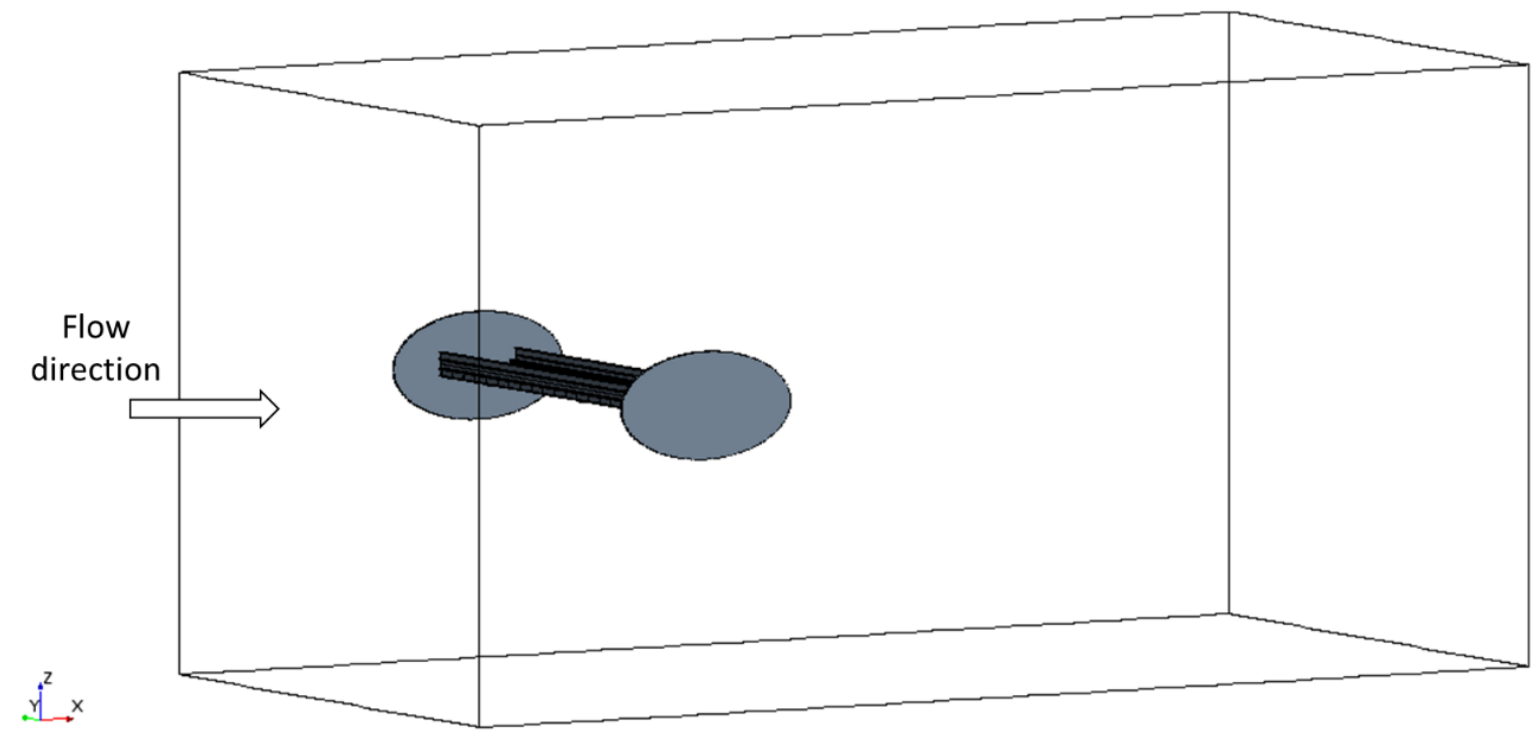

Figure 3-3: The CFD domain with the test section 


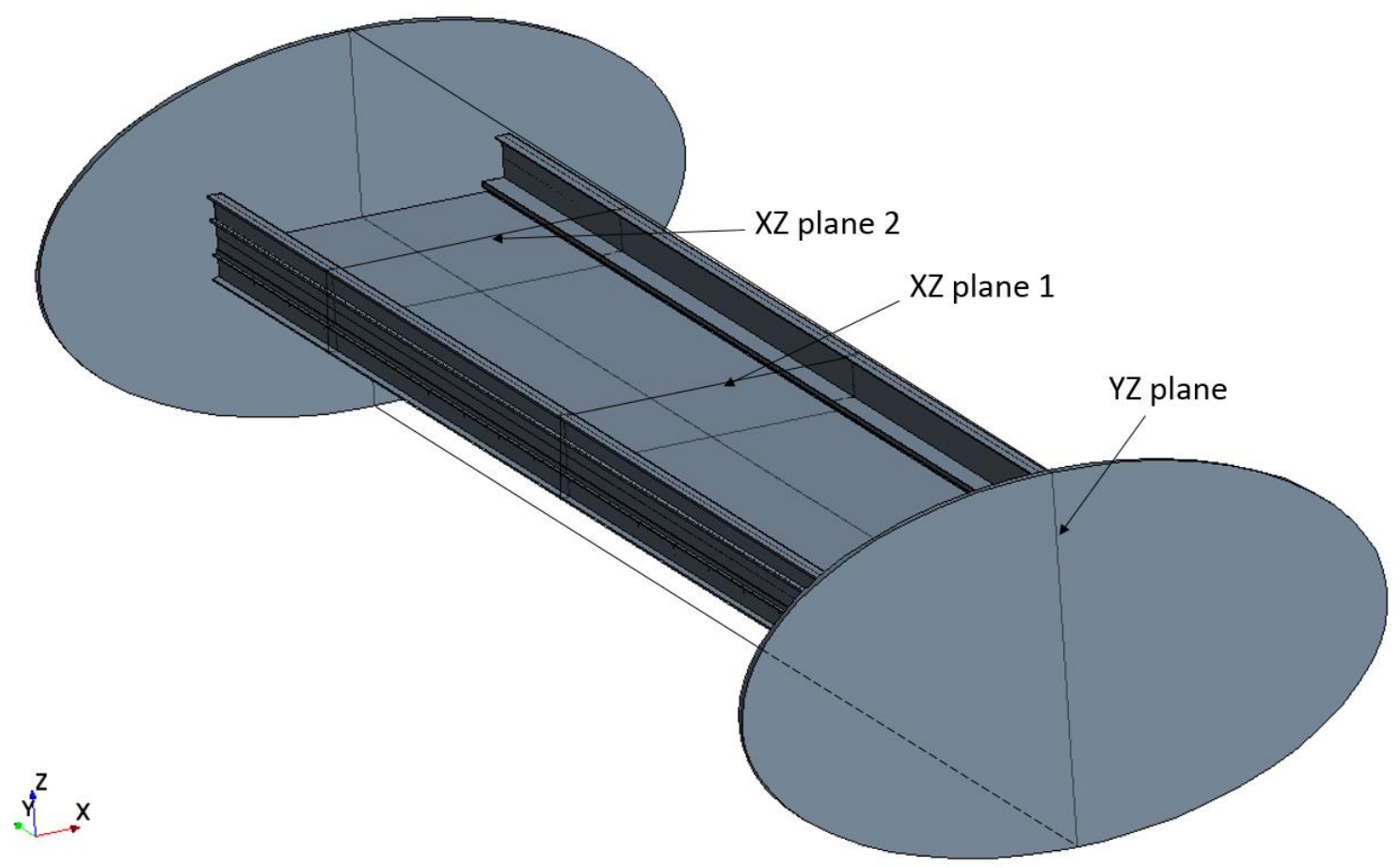

Figure 3-4: General view of the bridge section model with end plates, with plane sections used for monitoring results

(a)

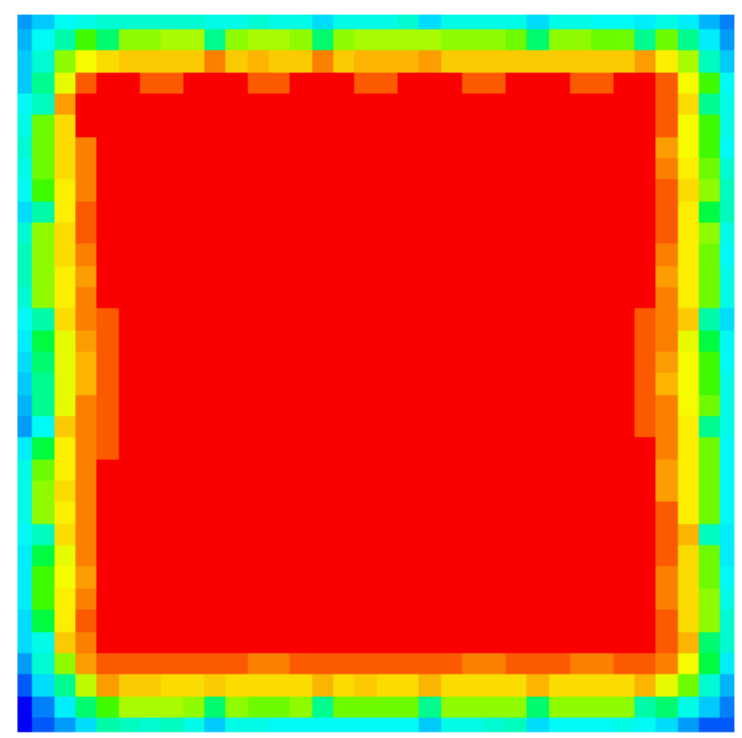

\begin{tabular}{cccccc}
\multicolumn{9}{c}{$\begin{array}{l}\text { Velocity }[\mathrm{i}](\mathrm{m} / \mathrm{s}) \\
-0.131\end{array}$} & 0.572 & 1.28 & 1.98 & 2.68 & 3.38 \\
\hline & & & & &
\end{tabular}


(b)

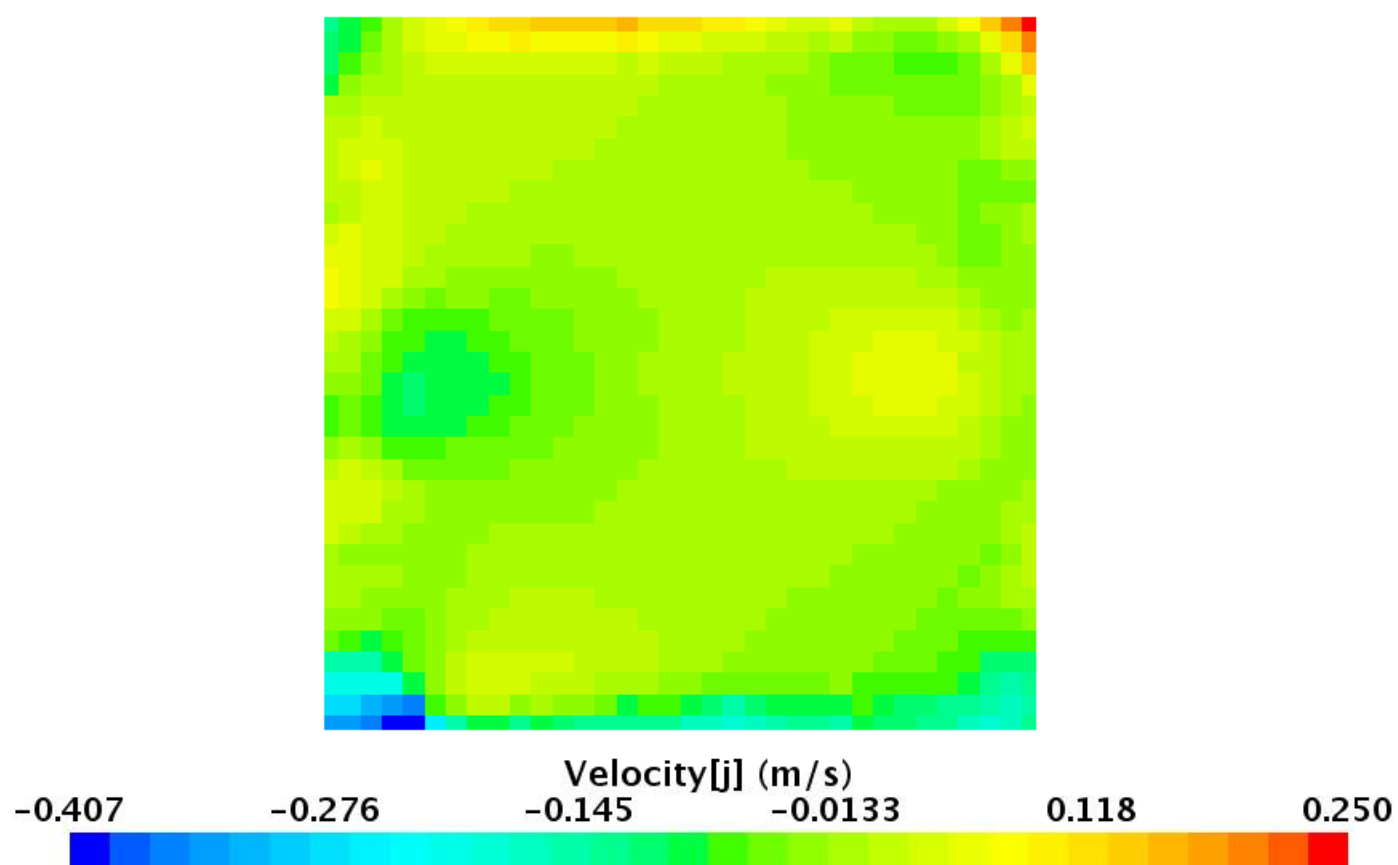

(c)

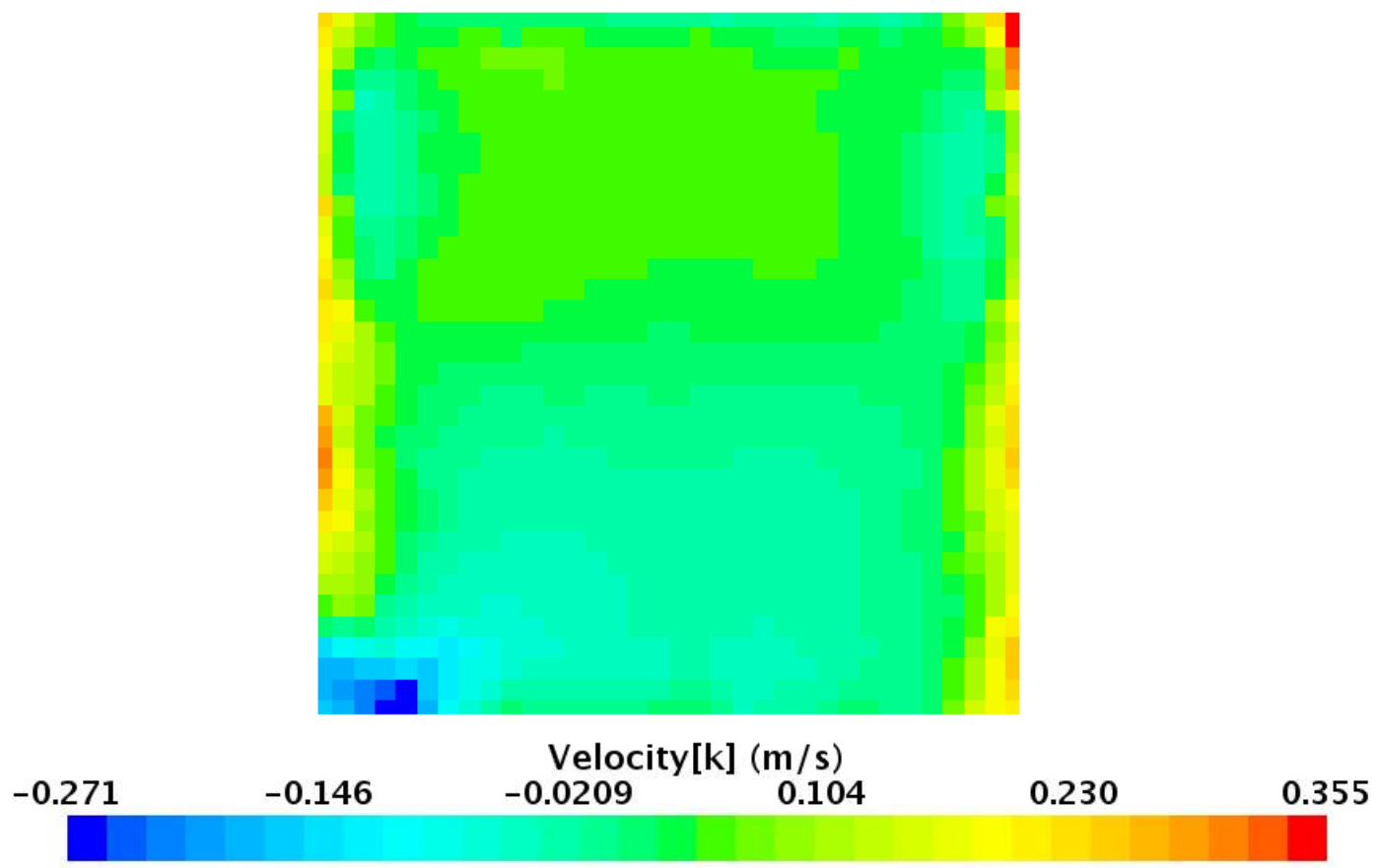

Figure 3-5: The distribution of the inlet velocity components, (a) along the flow direction, (b) across the flow, (c) in vertical direction 
(a)

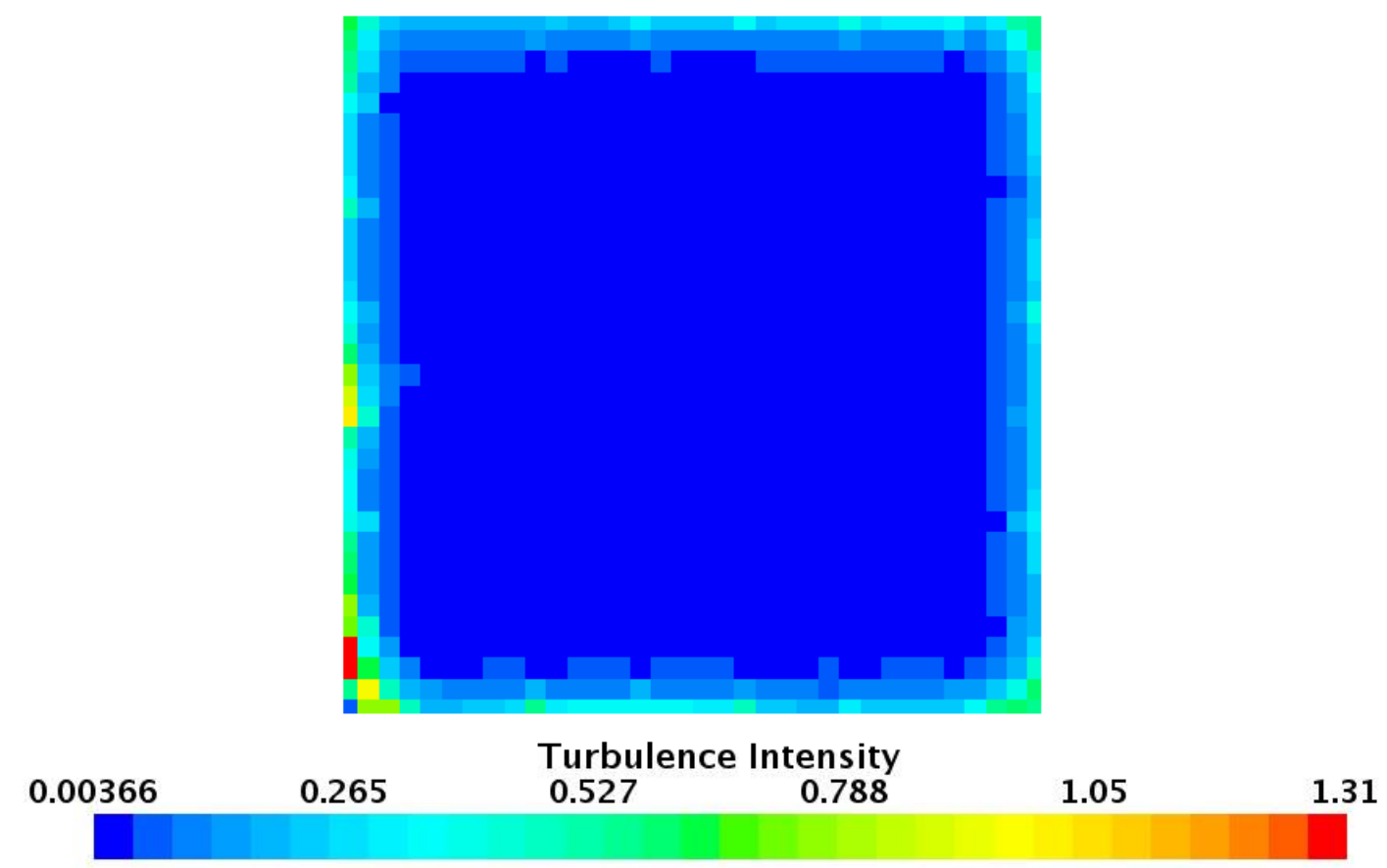

(b)

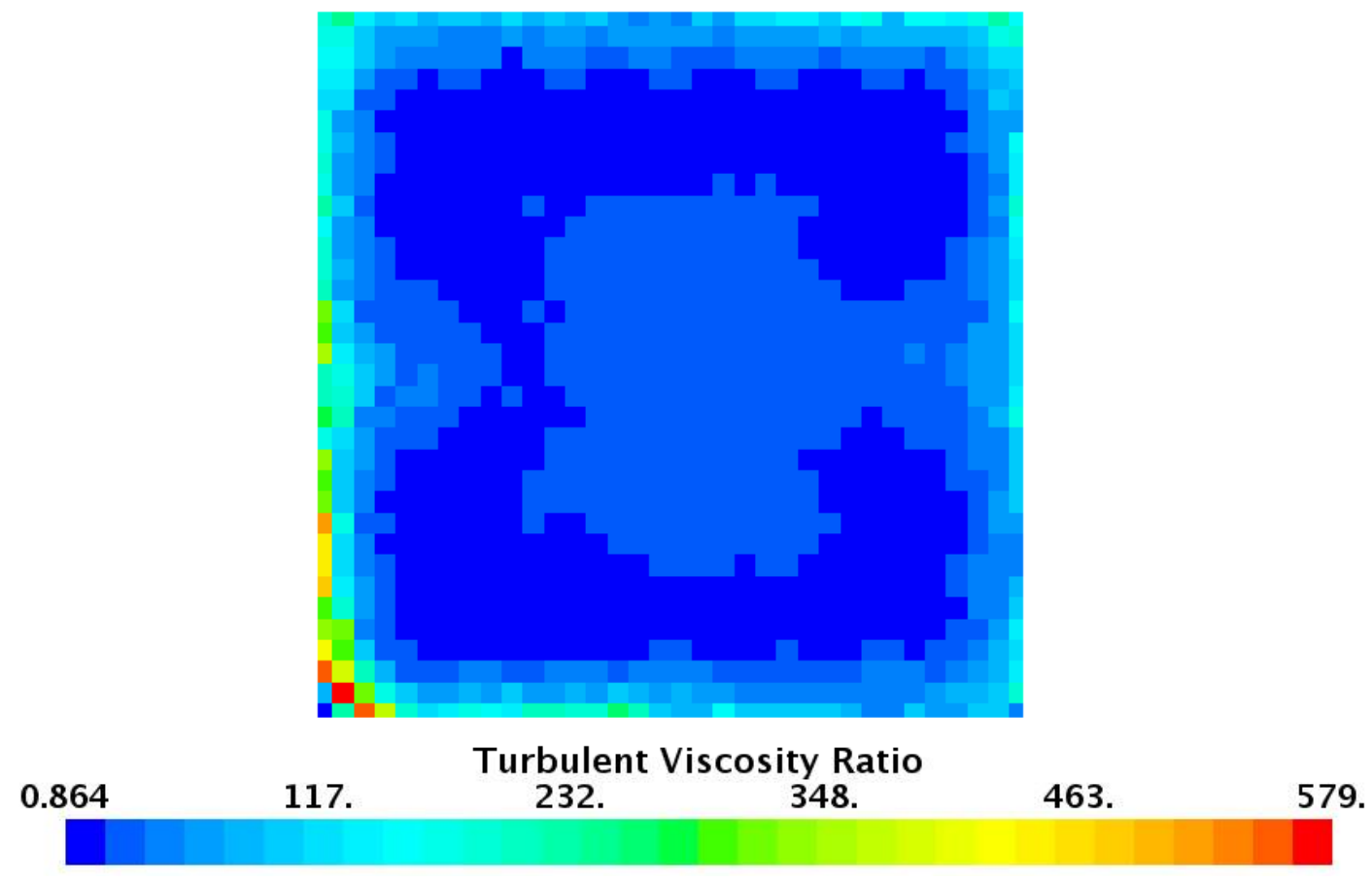

Figure 3-6. The distribution of the inlet turbulence: (a) turbulence intensity, (b) turbulent viscosity ratio

Wire mesh sidewalks in the experimental model allow air to move between the top and bottom of the deck in the space between the edges of the deck and side girders. The influence of the appropriate modeling of this part was verified in the initial phase of this study. The sidewalks were (i) omitted, (ii) represented as solid surfaces, and (iii) modeled by introducing porous baffle interfaces. The findings of this study are presented in the following chapter. 
A porous baffle interface model available in Star-CCM+ has three parameters: porosity, porous inertial resistance and porous viscous resistance. The design drawings (source: Turner Fairbank Aerodynamics Laboratory) provided information about the wire diameter and spacing. The wire diameter of the experimental scale model was equal $d=0.508 \mathrm{~mm}$ and the porosity, a ratio between the void surface to total surface, was determined to be equal to $\chi=0.762$.

The pressure drop across a porous baffle is described with the following formula in Star-CCM+ [4]

$$
\Delta p=-\rho\left(\alpha\left|\mathrm{v}_{n}\right|+\beta\right) \mathrm{v}_{n},
$$

where: $\rho$ is the fluid density at the interface, $\mathrm{v}_{n}$ is the superficial velocity normal to the surface, $\alpha$ is the porous inertial resistance and $\beta$ is the porous viscous resistance.

Mehta [6], defines a pressure drop coefficient for inclined flows, which is a ratio between the static pressure drop and dynamic pressure

$$
K_{\theta}=-\frac{\Delta p}{q},
$$

where $K$ is the pressure drop coefficient for normal flow

$$
\begin{gathered}
K_{\theta}=K \cos \theta, \\
K=6.5 \frac{1-\chi}{\chi^{2}}\left(\frac{\mathrm{v}_{n} d}{\chi^{2}}\right)^{-\frac{1}{3}},
\end{gathered}
$$

$\theta$ is the inclination angle, and the dynamic pressure is equal $q=\frac{1}{2} \rho \mathrm{v}^{2}$, with $\mathrm{v}$ as the resultant velocity. In this formulation there is no linear resistance term as a function of $\mathrm{v}$ and therefore $\beta$ is zero.

If we compare $\Delta p$ in the above equations, we will get a formula for porous inertial resistance

$$
\frac{1}{2} K_{\theta} \mathrm{v}^{2}=\alpha \mathrm{v}_{n}^{2} \Rightarrow \alpha=\frac{1}{2} K_{\theta} \frac{\mathrm{v}^{2}}{\mathrm{v}_{n}^{2}}=\frac{K}{2|\cos \theta|}
$$

The porous inertial resistance was programmed into Star-CCM+ as the following field function

$$
\alpha=1.33\left(42.55 \mathrm{v}_{n}\right)^{-0.33}\left|\frac{\mathrm{v}}{\mathrm{v}_{n}}\right| \text {, if } \mathrm{v}_{n}>0.0001 \text {, and } \alpha=8 \text {, if } \mathrm{v}_{n}<0.0001
$$

The above 'if' statement was necessary to avoid a division by zero, because $\mathrm{v}_{n}$ is in the denominator in the formula for $\alpha$, see equation (5). Whenever the normal velocity is equal zero, the software would issue an error and end the computations. For very low values of $v_{n}$ there is almost no flow through that portion of the porous baffle and its inertial resistance is set to a high number.

The complicated geometry of the model with a variety of thin structural elements resulted in small dimensions of volume cells in the CFD domain around the bridge section. The trimmed cell 
hexahedral mesh algorithm was used with cell dimensions varying from $0.12 \mathrm{~m}$ (in the areas far from the deck) to $6 \mathrm{~mm}$ (in its vicinity). Custom controls applied on the mesh on the deck surface decreased the cell dimensions to $3 \mathrm{~mm}$ (target size) with minimum size $1.5 \mathrm{~mm}$. Also, a volumetric control on the mesh around the deck and in the wake region was created. An anisotropic mesh was defined for this region by decreasing the dimensions by half in the $\mathrm{X}$ and $\mathrm{Z}$ directions, where the flow experiences major fluctuations. The resulting total number of cells was approximately 3.7 million. An example computational mesh is illustrated in Figure 3-7 for three planes (the YZ plane going through the center line of the deck, and two XZ planes - one at a deck symmetry plane and the other $0.5 \mathrm{~m}$ away from it, as depicted in Figure 3-4. The thickness of the near wall cell $(0.003 \mathrm{~m})$ was kept such that the value of Wall $\mathrm{Y}+$ was less than 10.

(a)

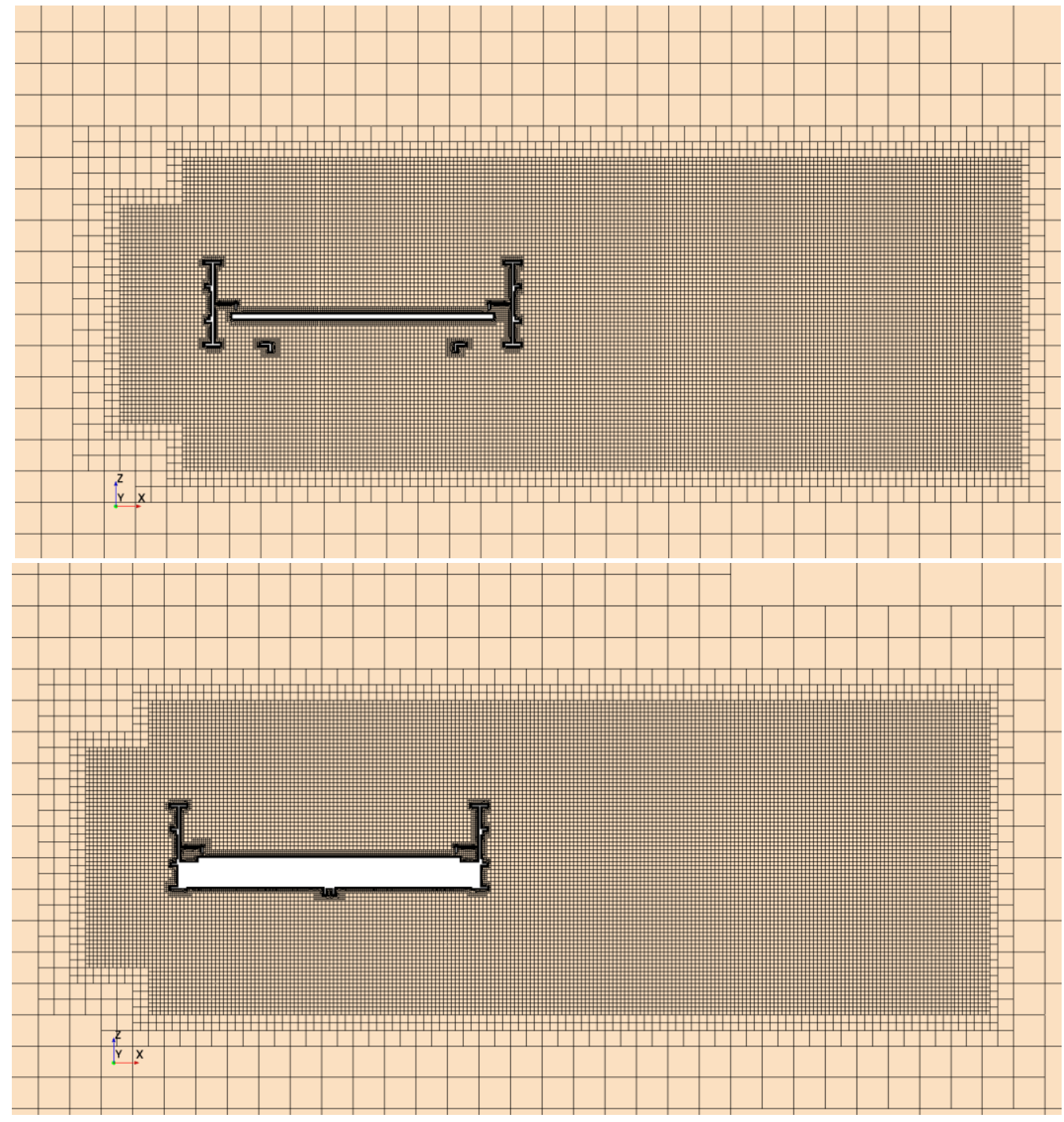


(c)

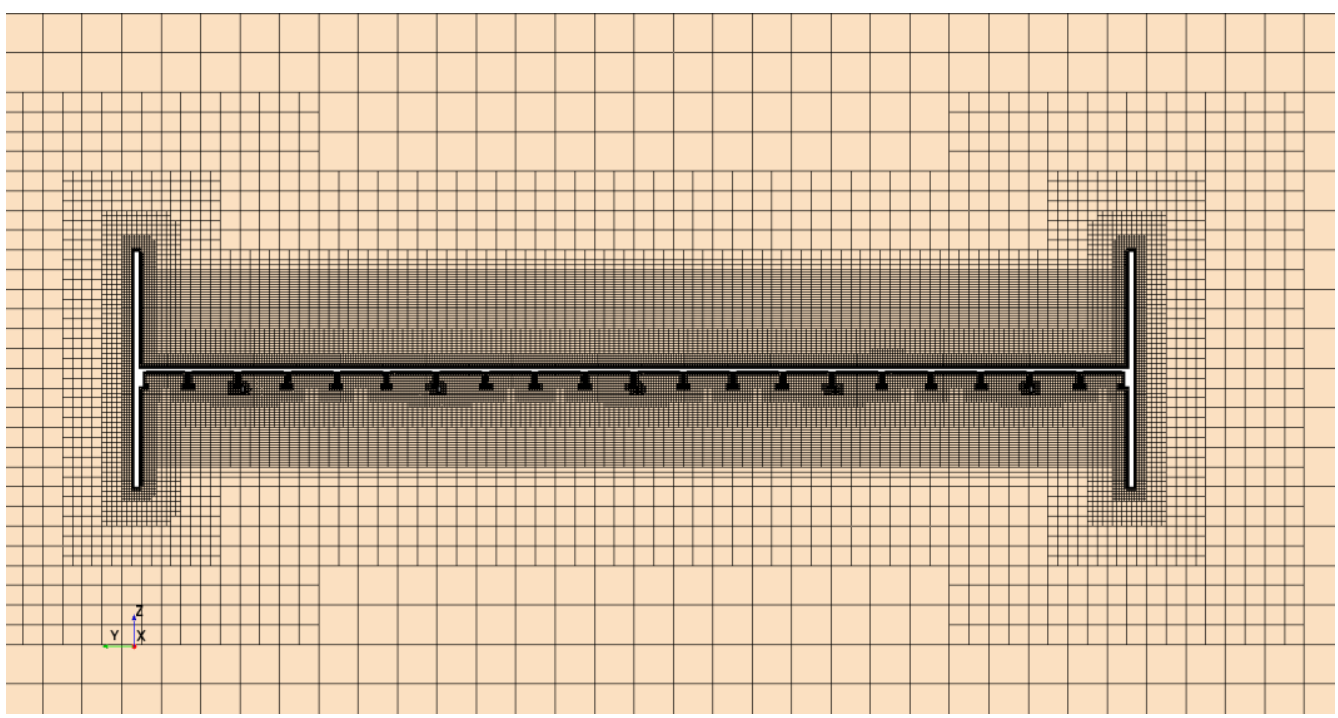

Figure 3-7: Cross-sections through an example volume mesh around the bridge deck: (a) XZ plane 1, (b) plane XZ 2, (c) plane YZ (name convention according to Figure 3-4).

\section{Discussion of results}

The main goal of this study was to validate the computational model against laboratory test results to determine the amount of geometric detail that needs to be included in the CFD model and mesh sizes that yield sufficiently accurate results in static tests. The studied bridge section shape was tested in a set of approach flow velocities ranging from $3.30 \mathrm{~m} / \mathrm{s}$ to $5.67 \mathrm{~m} / \mathrm{s}$ [2]. The range of the angle of attack in the wind tunnel was from -10 degrees to 9 degrees for approach velocity 3.30 $\mathrm{m} / \mathrm{s}$, and -10 degrees to 10 degrees for approach velocity $5.67 \mathrm{~m} / \mathrm{s}$. Figure 4-1 shows the assumed orientation of the angle of attack with respect to the wind direction.

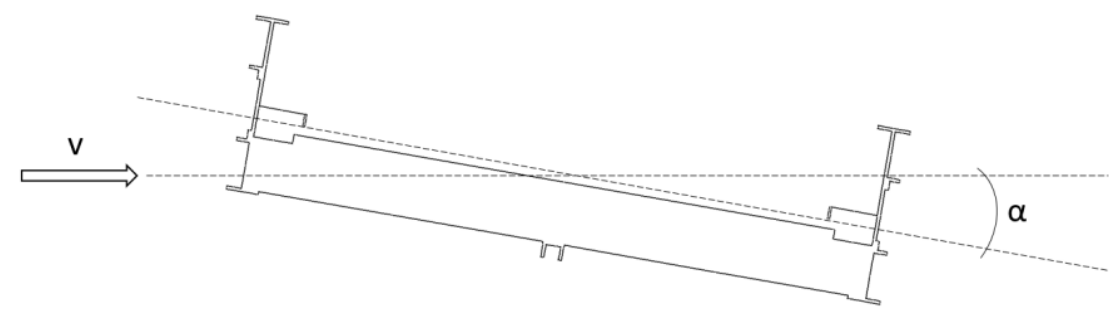

Figure 4-1: Wind flow direction and angle of attack

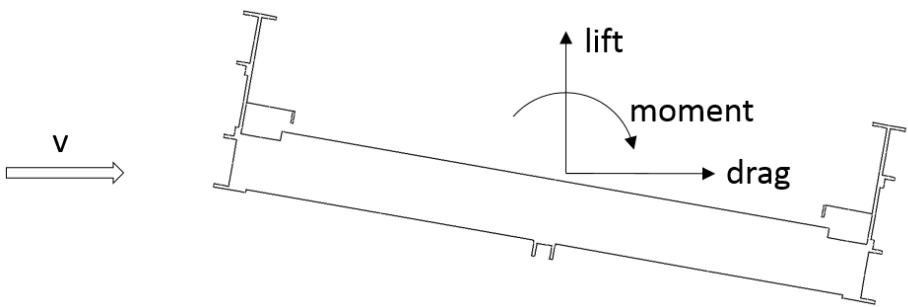

Figure 4-2: Orientation of force components 
The flow velocity field around the rigid deck was recorded to study the flow characteristics. Moreover, the pressure distribution on the deck was monitored and recorded. The static forces and moments, drag force $\left(F_{D}\right)$, lift force $\left(F_{L}\right)$ and moment $(M)$, obtained from CFD simulations were compared to wind tunnel results (note that the directions of forces coincide with the global Cartesian coordinate system). The orientation of the force components is presented in Figure 4-2.

\subsection{Initial considerations on the geometry of the bridge deck}

A comparative study was first performed to establish how the sidewalks should be modeled to obtain the most accurate solution. In the first model the sidewalks were omitted, in the second model the sidewalks were modeled as porous baffles, with porosity formulated as shown in Chapter 3.2, and in the third model the sidewalks were modeled as solid surfaces with no porosity.

Static force components acting on these section models for inlet velocity $3.3 \mathrm{~m} / \mathrm{s}$ and three angles of attack: -6, o, and 6 degrees are compared in Table 4-1, Table 4-2, and Table 4-3. The columns which combine the results for porous and solid sidewalks contain additional data, i.e. the components of the forces, acting separately on the upstream and downstream sidewalks as well as the deck, and their percentage contribution to the total force. Figure 4-3, Figure 4-4 and Figure 4-5 show a graphical interpretation of the analysis for the drag force, lift force, and pitch moment, respectively.

In all computational cases the drag forces yielded similar values, lower than the wind tunnel results. For a -6 degree angle, the relative difference varied from $-22 \%$ to $-26 \%$, it is approximately $-14 \%$ at $\mathrm{o}$ degrees, and at 6 degrees it was $-11 \%$. The model with porous baffles gave the closest approximation of the experimental values. The variation of lift forces was more pronounced depending on the model of the sidewalks. At -6 degrees the models without sidewalks and with solid sidewalks gave an overestimation of the force, by $20 \%$ and $43 \%$ respectively. The model with porous sidewalks gave a relative difference of only $-7 \%$. At o degrees, all models underestimated the measurements, but the model with porous sidewalks again gave the most accurate result, with $34 \%$ difference. At angle of attack 6 degrees, the lift force was underestimated for all models, by approximately $-10 \%$ for the models without the sidewalks and solid sidewalks, and by only $6 \%$ for the model with porous sidewalks. The experimental pitch moment was much lower than the other forces, with a near zero value. The CFD models underestimated it for 0 and 6 degree angles, and overestimated it for the -6 degrees.

Figure 4-6 presents a velocity vector distribution on XZ plane 1, at inlet velocity $3.3 \mathrm{~m} / \mathrm{s}$ and parallel flow in the model with (a) no sidewalks), (b) porous sidewalks, and (c) solid sidewalks. 
Table 4-1: A comparison of static forces obtained in CFD simulations with wind tunnel results at angle of attack - 6 degrees. For models with porous and solid sidewalks the total value and components on: deck, upstream sidewalk (us) and downstream (ds) sidewalk, are given.

\begin{tabular}{|c|c|c|c|c|}
\hline $\begin{array}{c}\text { Angle of } \\
\text { attack -6 deg }\end{array}$ & Experiment & No sidewalks & $\begin{array}{c}\text { Porous } \\
\text { sidewalks }\end{array}$ & Solid sidewalks \\
\hline \multirow{4}{*}{$\begin{array}{c}F_{D}[\mathrm{~N}] \\
\left(F_{D_{-} d e c k},\right. \\
F_{D_{-} u s} \\
\left.F_{D_{-} d s}\right)\end{array}$} & \multirow{4}{*}{1.253} & \multirow{4}{*}{0.983} & 0.958 & 0.923 \\
\hline & & & 0.956 (99.9\%) & $0.916(99.3 \%)$ \\
\hline & & & $0.001(0.1 \%)$ & $0.005(0.5 \%)$ \\
\hline & & & $0.001(0.1 \%)$ & $0.002(0.2 \%)$ \\
\hline \multirow{4}{*}{$\begin{array}{c}F_{L}[\mathrm{~N}] \\
\left(F_{L_{-} d e c k},\right. \\
F_{L_{-} u s}, \\
\left.F_{L_{-} d s}\right)\end{array}$} & \multirow{4}{*}{0.447} & \multirow{4}{*}{0.536} & 0.415 & 0.637 \\
\hline & & & $0.418(100.8 \%)$ & $0.706(110.8 \%)$ \\
\hline & & & $-0.005(-1.1 \%)$ & $-0.053(-8.3 \%)$ \\
\hline & & & $0.001(0.3 \%)$ & $-0.016(-2.5 \%)$ \\
\hline \multirow{4}{*}{$\begin{array}{c}M[\mathrm{Nm}] \\
\left(M_{d e c k},\right. \\
M_{u s} \\
\left.M_{d s}\right)\end{array}$} & \multirow{4}{*}{0.008} & \multirow{4}{*}{0.021} & 0.013 & 0.012 \\
\hline & & & $0.014(105.5 \%)$ & $0.017(143.5 \%)$ \\
\hline & & & $-0.001(-4.7 \%)$ & $-0.007(-58.3 \%)$ \\
\hline & & & $-1.1 \mathrm{e}-04(-0.8 \%)$ & $0.002(17.5 \%)$ \\
\hline
\end{tabular}

Table 4-2: A comparison of static forces obtained in CFD simulations with wind tunnel results at parallel flow. For models with porous and solid sidewalks the total value and components on: deck, upstream sidewalk (us) and downstream (ds) sidewalk, are given.

\begin{tabular}{|c|c|c|c|c|}
\hline $\begin{array}{c}\text { Angle of } \\
\text { attack o deg }\end{array}$ & Experiment & No sidewalks & $\begin{array}{c}\text { Porous } \\
\text { sidewalks }\end{array}$ & Solid sidewalks \\
\hline \multirow{4}{*}{$\begin{array}{c}F_{D}[\mathrm{~N}] \\
\left(F_{D_{-} d e c k},\right. \\
F_{D_{-} u s} \\
\left.F_{D_{-} d s}\right)\end{array}$} & \multirow{4}{*}{1.093} & \multirow{4}{*}{0.942} & 0.940 & 0.927 \\
\hline & & & $0.941(100.0 \%)$ & $0.927(100 \%)$ \\
\hline & & & $1.1 \mathrm{e}-04(0.01 \%)$ & $-2.5 \mathrm{e}-05(<1 \%)$ \\
\hline & & & $-1.7 \mathrm{e}-04(0.01 \%)$ & $-4.9 \mathrm{e}-05(<1 \%)$ \\
\hline \multirow{4}{*}{$\begin{array}{c}F_{L}[\mathrm{~N}] \\
\left(F_{L_{-} d e c k},\right. \\
F_{L_{-} u s}, \\
\left.F_{L_{-} d s}\right)\end{array}$} & \multirow{4}{*}{0.022} & \multirow{4}{*}{-0.008} & 0.015 & -0.025 \\
\hline & & & $0.015(103.5 \%)$ & $-0.023(90.8 \%)$ \\
\hline & & & $3.1 \mathrm{e}-04(2.1 \%)$ & $0.002(-8.9 \%)$ \\
\hline & & & $-0.001(-5.6 \%)$ & $-0.005(18.1 \%)$ \\
\hline \multirow{4}{*}{$\begin{array}{c}M[\mathrm{Nm}] \\
\left(M_{d e c k}\right. \\
M_{u s} \\
\left.M_{d s}\right)\end{array}$} & \multirow{4}{*}{-0.003} & \multirow{4}{*}{0.006} & 0.007 & 0.008 \\
\hline & & & $0.006(97.7 \%)$ & 0.007 (88.3\%) \\
\hline & & & $4.3 \mathrm{e}-05(0.6 \%)$ & $3.0 \mathrm{e}-04(3.9 \%)$ \\
\hline & & & $1.1 \mathrm{e}-04(1.6 \%)$ & $6.0 e-04(7.8 \%)$ \\
\hline
\end{tabular}


Table 4-3: A comparison of static forces obtained in CFD simulations with wind tunnel results at angle of attack 6 degrees. For models with porous and solid sidewalks the total value and components on: deck, upstream sidewalk (us) and downstream (ds) sidewalk, are given.

\begin{tabular}{|c|c|c|c|c|}
\hline $\begin{array}{c}\text { Angle of } \\
\text { attack } 6 \text { deg }\end{array}$ & Experiment & No sidewalks & $\begin{array}{c}\text { Porous } \\
\text { sidewalks }\end{array}$ & Solid sidewalks \\
\hline \multirow{4}{*}{$\begin{array}{c}F_{D}[\mathrm{~N}] \\
\left(F_{D_{-} d e c k},\right. \\
F_{D_{-} u s}, \\
\left.F_{D_{-} d s}\right)\end{array}$} & \multirow{4}{*}{1.235} & \multirow{4}{*}{1.096} & 1.093 & 1.094 \\
\hline & & & $1.091(99.8 \%)$ & $1.096(100.2 \%)$ \\
\hline & & & $0.0029(0.2 \%)$ & $0.003(0.3 \%)$ \\
\hline & & & $-7.76 \mathrm{e}-5(0.01 \%)$ & $-0.005(-0.5 \%)$ \\
\hline \multirow{4}{*}{$\begin{array}{c}F_{L}[\mathrm{~N}] \\
\left(F_{L_{-} d e c k},\right. \\
F_{L_{-} u s}, \\
\left.F_{L_{-} d s}\right)\end{array}$} & \multirow{4}{*}{-0.521} & \multirow{4}{*}{-0.469} & -0.487 & -0.477 \\
\hline & & & $-0.481(98.6 \%)$ & $-0.458(96.1 \%)$ \\
\hline & & & $0.003(-0.7 \%)$ & $0.03(-6.3 \%)$ \\
\hline & & & $-0.010(2.1 \%)$ & $-0.048(10.1 \%)$ \\
\hline \multirow{4}{*}{$\begin{array}{c}M[\mathrm{Nm}] \\
\left(M_{d e c k},\right. \\
M_{u s} \\
\left.M_{d s}\right)\end{array}$} & \multirow{4}{*}{-0.022} & \multirow{4}{*}{-0.009} & -0.012 & 0.001 \\
\hline & & & $-0.014(116.1 \%)$ & $-0.009(-727.2 \%)$ \\
\hline & & & $0.001(-4.4 \%)$ & $0.004(308.4 \%)$ \\
\hline & & & $0.001(-11.7 \%)$ & $0.006(518.9 \%)$ \\
\hline
\end{tabular}

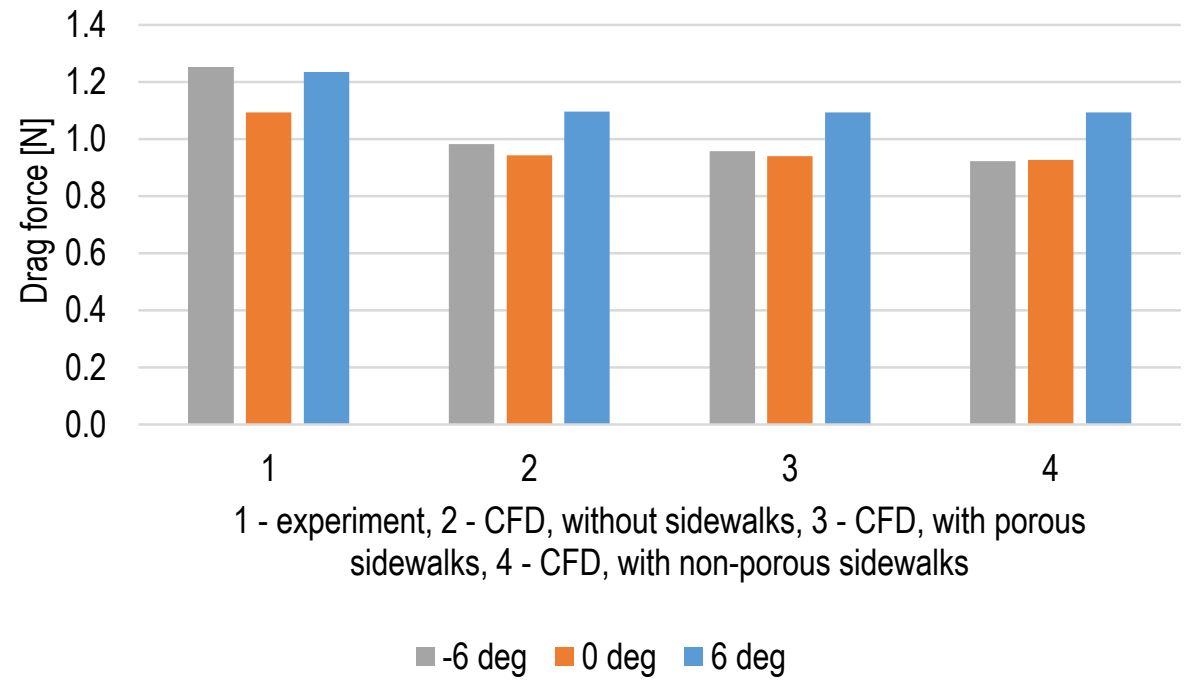

Figure 4-3: Drag force comparison between the experimental and computational models 


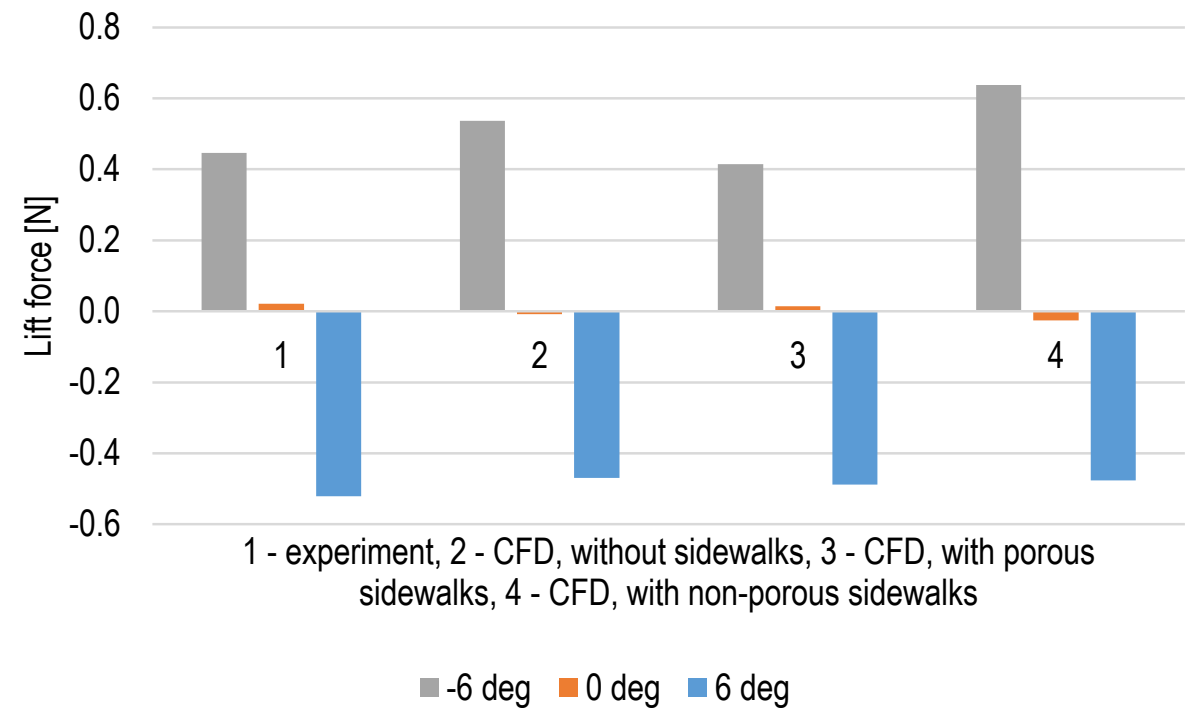

Figure 4-4: Lift force comparison between the experimental and computational models

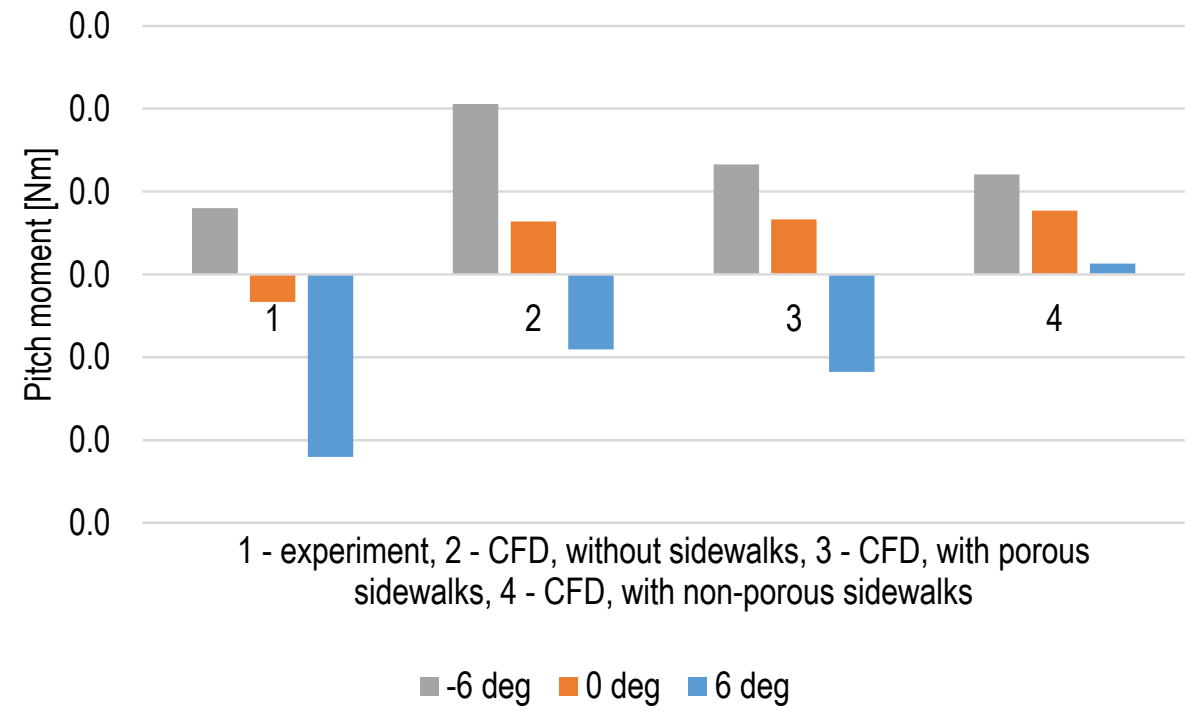

Figure 4-5: Pitch moment comparison between the experimental and computational models 
(a)

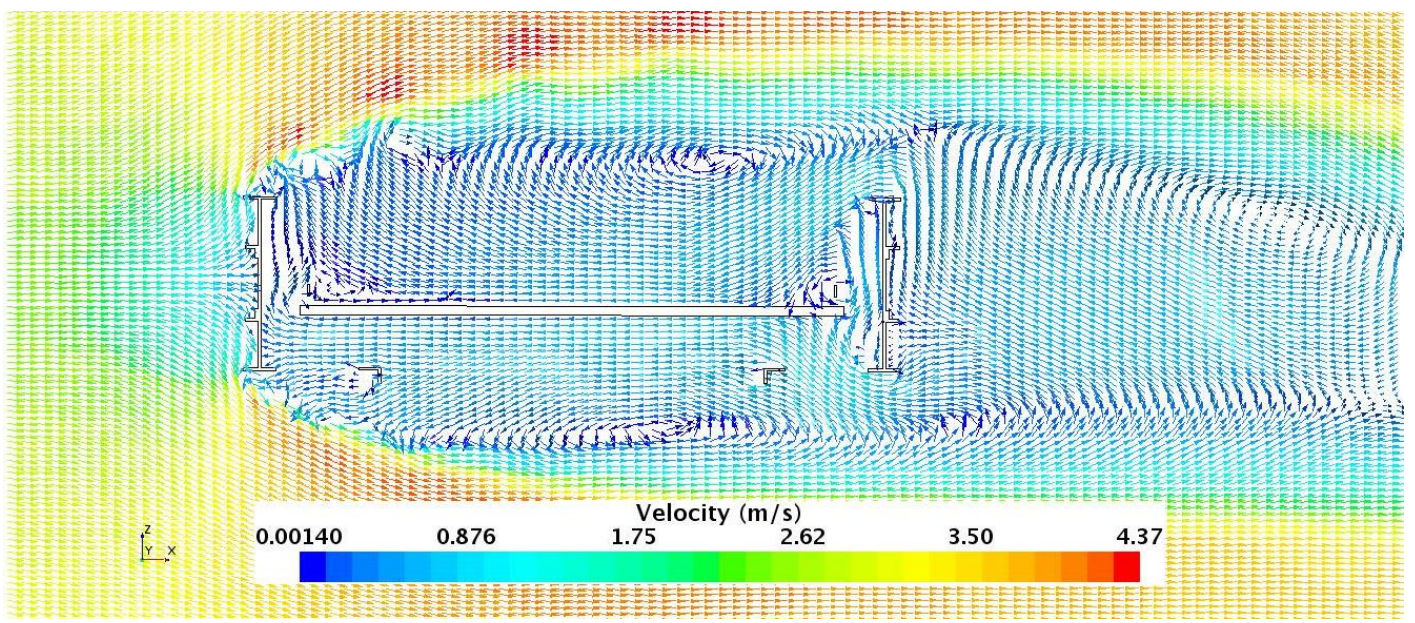

(b)

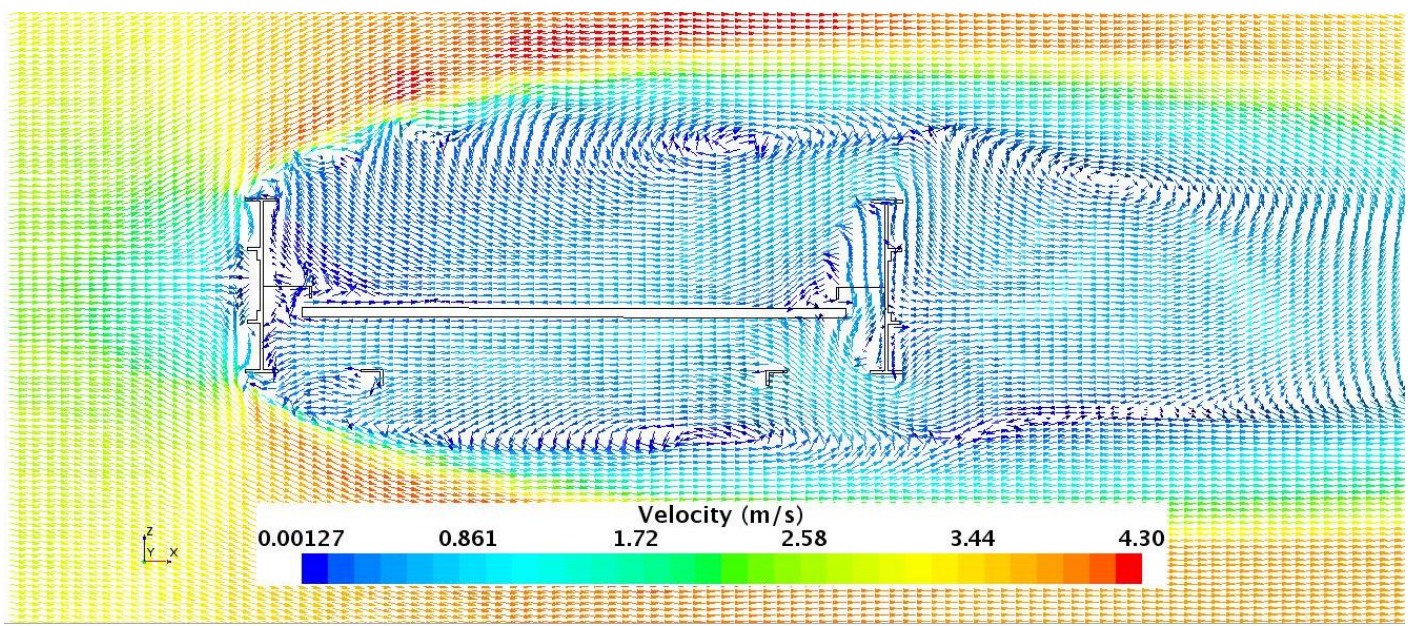

(c)

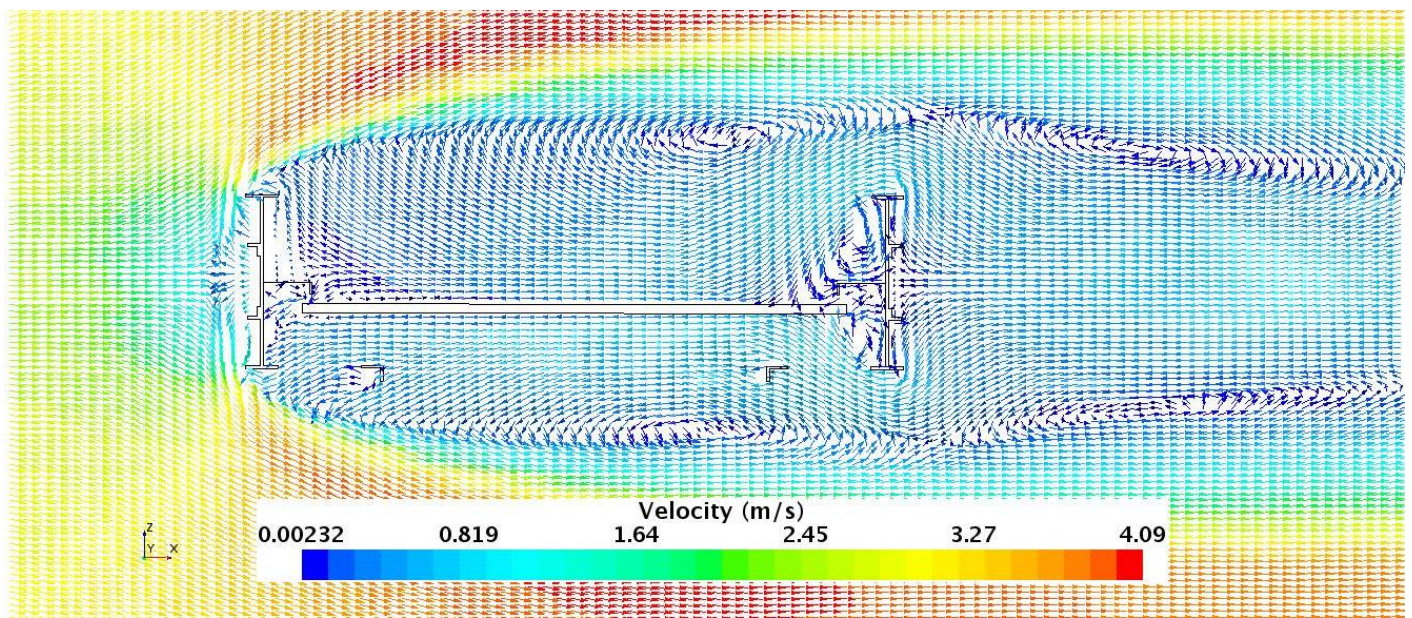

Figure 4-6: Velocity vector distribution on XZ plane 1, at inlet velocity $3.3 \mathrm{~m} / \mathrm{s}$ and parallel flow in the model with (a) no sidewalks), (b) porous sidewalks, and (c) solid sidewalks. 
Table 4-4: Relative differences between the CFD results and experimental measurements

\begin{tabular}{|c|c|c|c|c|}
\hline \multirow[b]{2}{*}{$\begin{array}{l}\text { Angle of } \\
\text { attack }\end{array}$} & \multirow[b]{2}{*}{$\begin{array}{c}\text { Force } \\
\text { component }\end{array}$} & \multicolumn{3}{|c|}{ Relative difference } \\
\hline & & $\begin{array}{c}\text { No } \\
\text { sidewalks }\end{array}$ & $\begin{array}{c}\text { Porous } \\
\text { sidewalks }\end{array}$ & $\begin{array}{c}\text { Solid } \\
\text { sidewalks }\end{array}$ \\
\hline \multirow{3}{*}{$-6 \mathrm{deg}$} & $F_{D}[\mathrm{~N}]$ & $-22 \%$ & $-11 \%$ & $-26 \%$ \\
\hline & $F_{L}[\mathbf{N}]$ & $20 \%$ & $-6 \%$ & $43 \%$ \\
\hline & $M[\mathrm{~N}]$ & $157 \%$ & $-47 \%$ & $51 \%$ \\
\hline \multirow{3}{*}{ o deg } & $F_{D}[\mathrm{~N}]$ & $-14 \%$ & $-14 \%$ & $-15 \%$ \\
\hline & $F_{L}[\mathbf{N}]$ & $-136 \%$ & $-34 \%$ & $-214 \%$ \\
\hline & $M[\mathrm{~N}]$ & $-291 \%$ & $-299 \%$ & $-331 \%$ \\
\hline \multirow{3}{*}{$6 \mathrm{deg}$} & $F_{D}[\mathrm{~N}]$ & $-11 \%$ & $-24 \%$ & $-11 \%$ \\
\hline & $F_{L}[\mathbf{N}]$ & $-10 \%$ & $-7 \%$ & $-9 \%$ \\
\hline & $M[\mathrm{~N}]$ & $-59 \%$ & $66 \%$ & $-106 \%$ \\
\hline
\end{tabular}

Table 4-4 presents the relative differences between the computational and experimental static forces. The lowest errors were obtained for the model with porous sidewalks, and therefore use of this more detailed model, the porous sidewalks, was needed to obtain reasonably accurate results. It was decided to model the grates forming sidewalks as a zero-thickness porous baffle interface. A porous baffle interface represents a porous membrane through which fluid passes and experiences a pressure drop. This approach keeps the model fairly simple, as no fine details (like flow through small openings between wires) need to be modeled. The porosity for the mesh used in laboratory tests was calculated to be equal to 0.762 (porosity is defined as a ratio of the area of the holes to the area of the surface and ranges from o to 1). Two other parameters which characterize this kind of interface are porous inertial resistance and porous viscous resistance. This model was used in all following analyses.

\subsection{Velocity field around the deck}

The velocity fields around the bridge deck on XZ plane 1 (see Figure 3-4) were monitored throughout the simulation. In this chapter, screenshots of the velocity field recorded at 10 seconds of simulated time are presented for the selected angles of attack, -6 degrees, zero degrees and 6 degrees, and solver settings: URANS k- $\varepsilon$ solver with uniform inlet boundary condition parameters, URANS k- $\varepsilon$ solver with non-uniform inlet boundary condition parameters, and LES solver with uniform inlet boundary condition parameters.

Velocity vector fields are illustrated in Figure 4-7 for zero degree angle of attack and inlet velocity $3.3 \mathrm{~m} / \mathrm{s}$, and Figure 4-8 presents the velocity magnitude fields. The three models gave similar maximum vector magnitudes, with slightly higher velocities obtained with LES. The separation points are very clear; they are located at the upwind corners of the flange of the left girder. In the URANS k- $\varepsilon$ simulations a reverse flow with low velocity can be observed in the area above the deck slab. In the LES simulation numerous vortices form in this region. 
Table 4-5 depicts the velocity magnitude contour plots for varying flow direction obtained from the URANS simulation with uniform inlet boundary condition parameters. The influence of the angle of attack on the flow is noticeable. The maximum instantaneous velocity increased with the increase of the absolute value of the angle, reaching $4.33 \mathrm{~m} / \mathrm{s}$ at -8 degrees and $4.35 \mathrm{~m} / \mathrm{s}$ at 8 degrees, and slightly decreases for the extreme angles. The lowest velocities were obtained at -4 degrees and 2 degrees, with values $4.18 \mathrm{~m} / \mathrm{s}$ and $4.19 \mathrm{~m} / \mathrm{s}$ respectively.

(a)

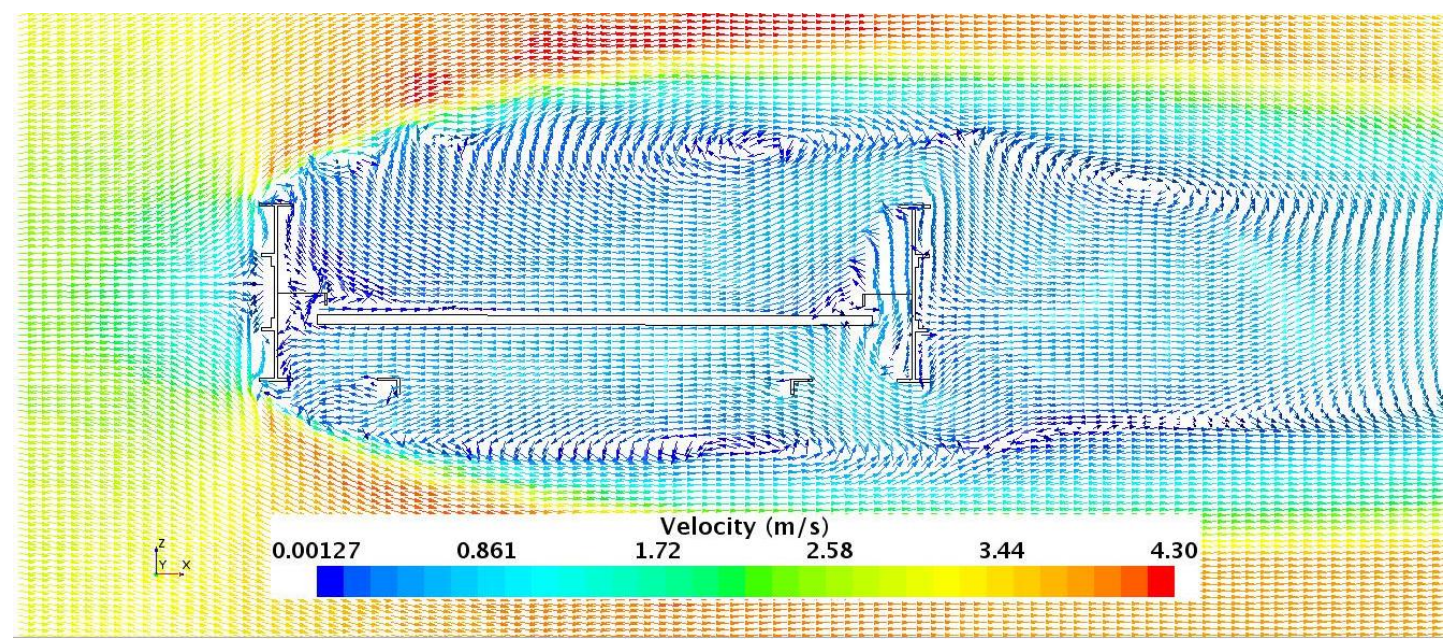

(b)

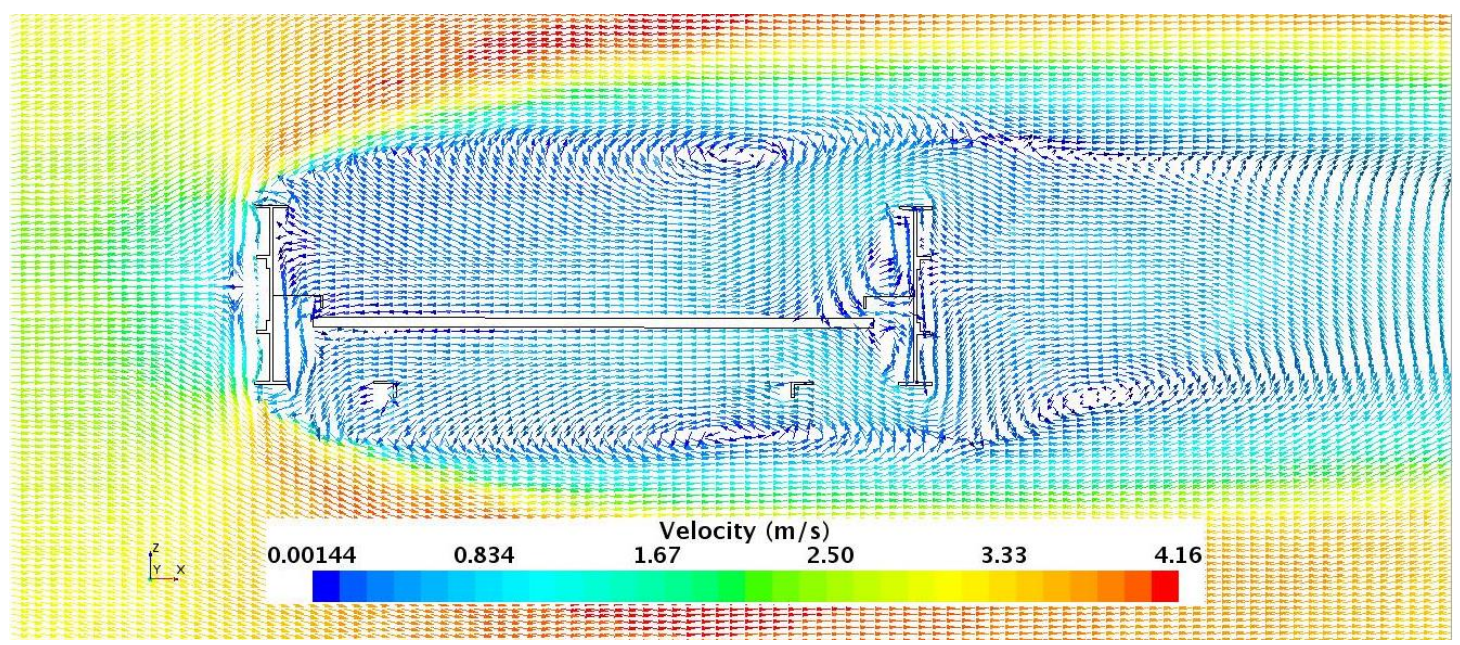


(c)

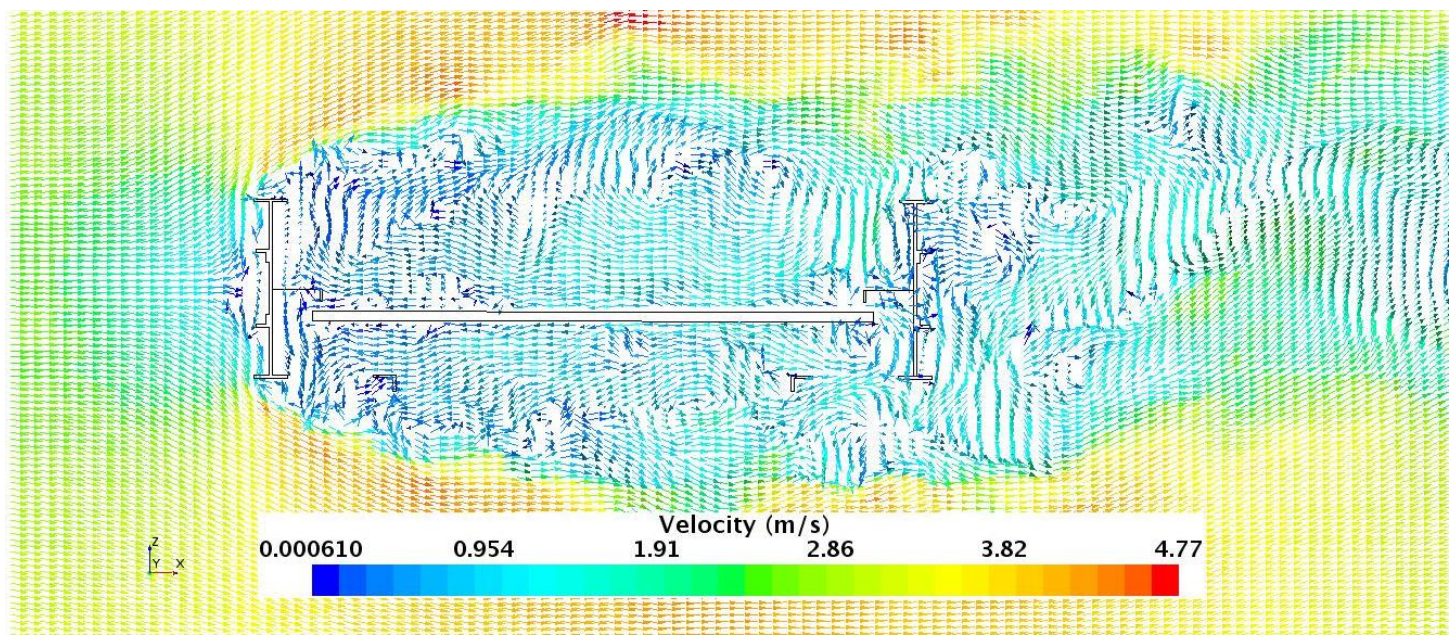

Figure 4-7: Velocity vector field around the deck on XZ plane 1, at inlet velocity $3.3 \mathrm{~m} / \mathrm{s}$ and angle of attack zero degrees, (a) URANS k- $\varepsilon$ solver with uniform inlet boundary condition parameters, (b) URANS k- $\varepsilon$ solver with non-uniform inlet boundary condition parameters, (c) LES solver with uniform inlet boundary condition parameters.

(a)

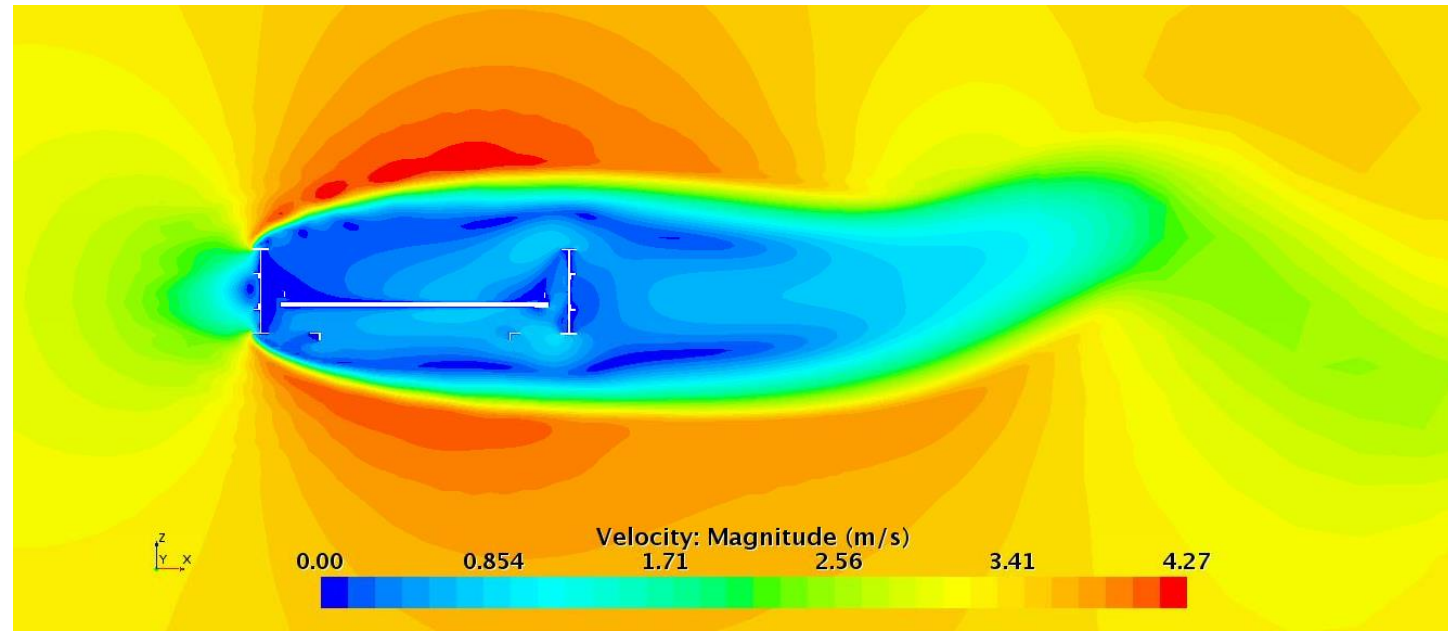

(b)

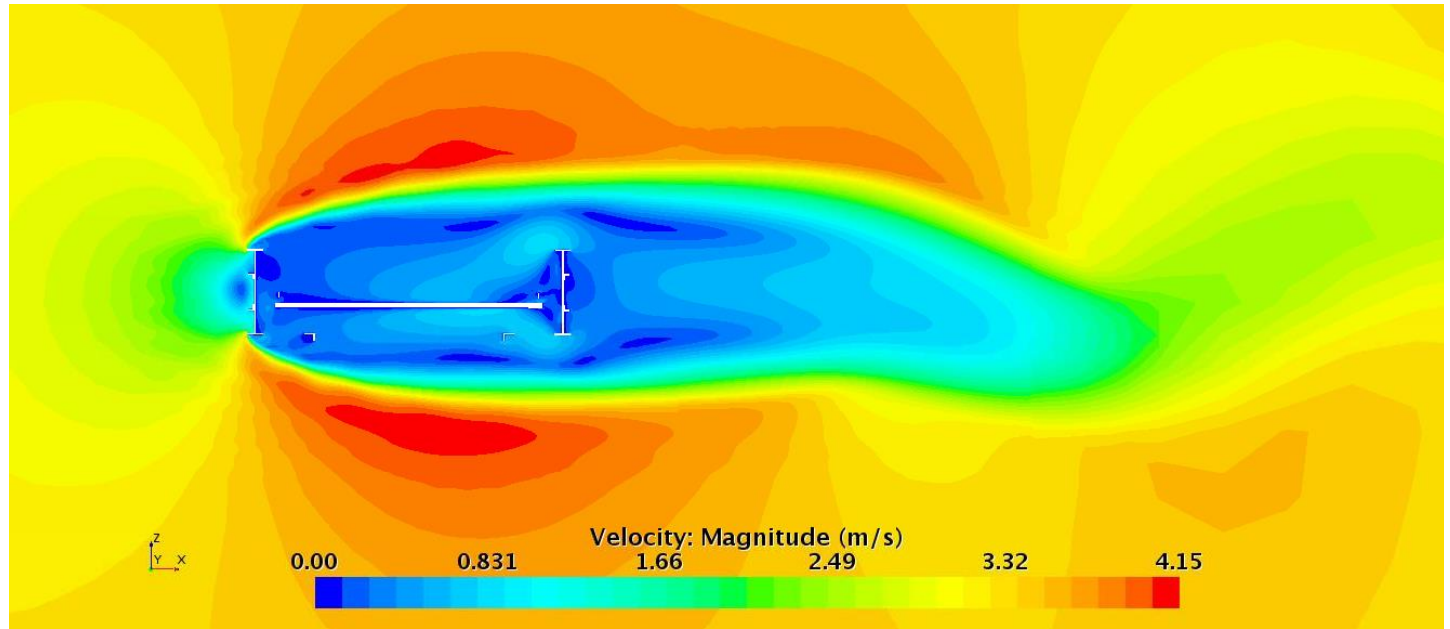


(c)

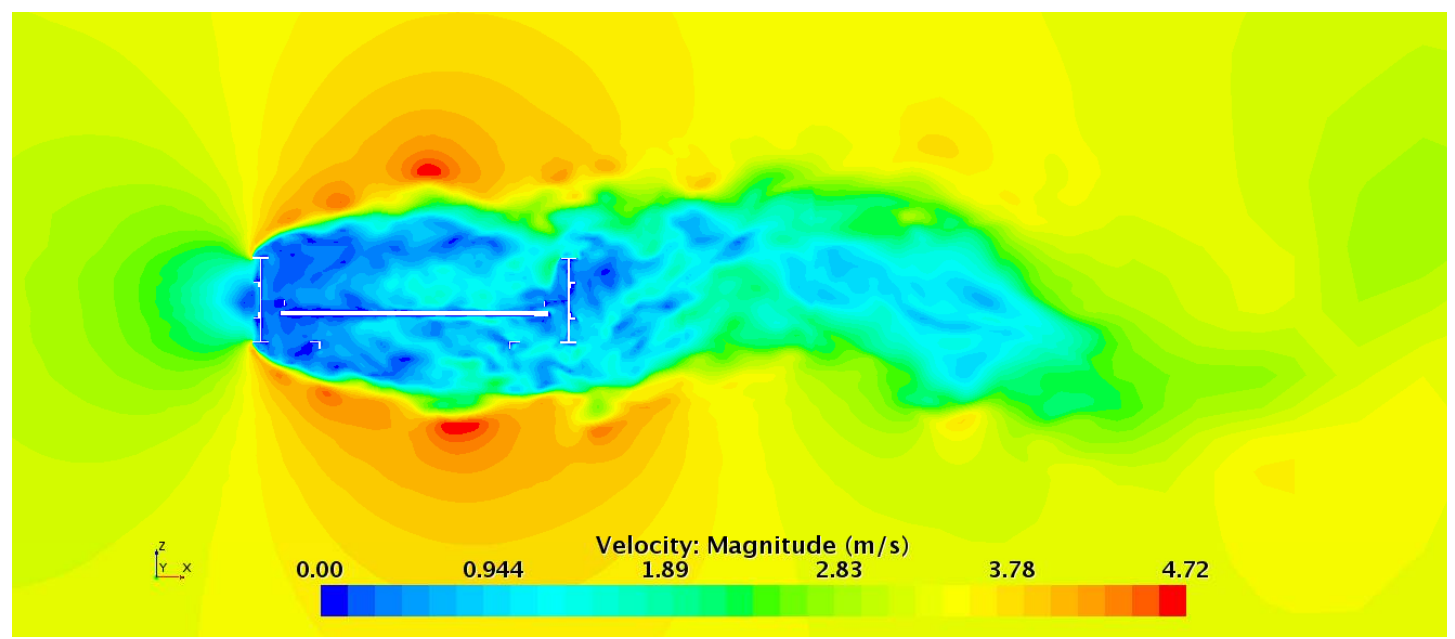

Figure 4-8: Velocity magnitude field around the deck on XZ plane 1, at inlet velocity $3.3 \mathrm{~m} / \mathrm{s}$ and angle of attack zero degrees, (a) URANS k- $\varepsilon$ solver with uniform inlet boundary condition parameters, (b) URANS k- $\varepsilon$ solver with non-uniform inlet boundary condition parameters, (c) LES solver with uniform inlet boundary condition parameters.

Table 4-5: Velocity magnitude field around the deck on XZ plane 1, at inlet velocity $3.3 \mathrm{~m} / \mathrm{s}$ and angle of attack from -10 degrees to 10 degrees. URANS k- $\varepsilon$ solver with uniform inlet boundary condition parameters.

\begin{tabular}{|c|ccc|}
\hline $\begin{array}{c}\text { Angle } \\
\text { of } \\
\text { attack }\end{array}$ & & Velocity magnitude field & \\
\hline-10 \\
deg
\end{tabular}




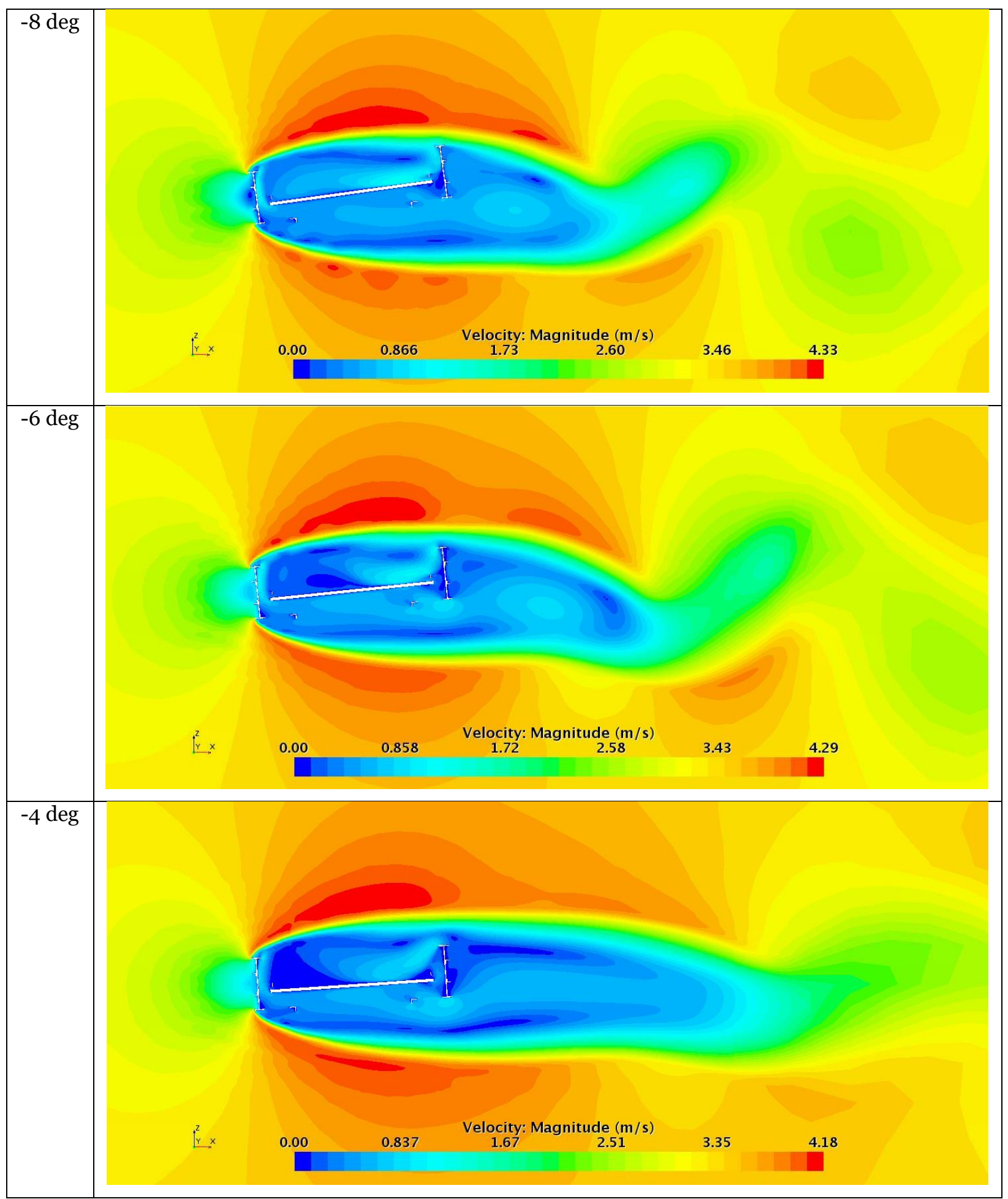




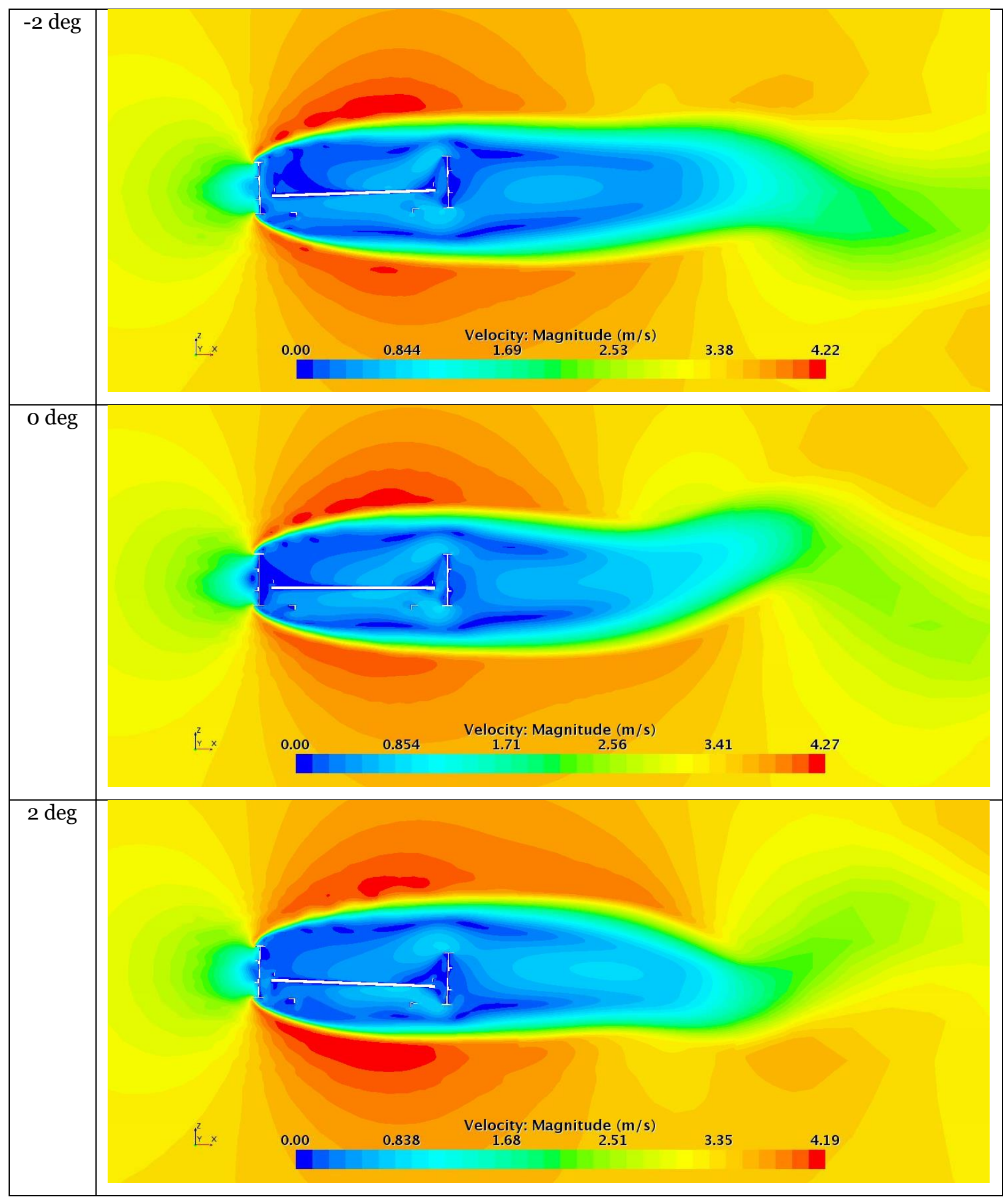




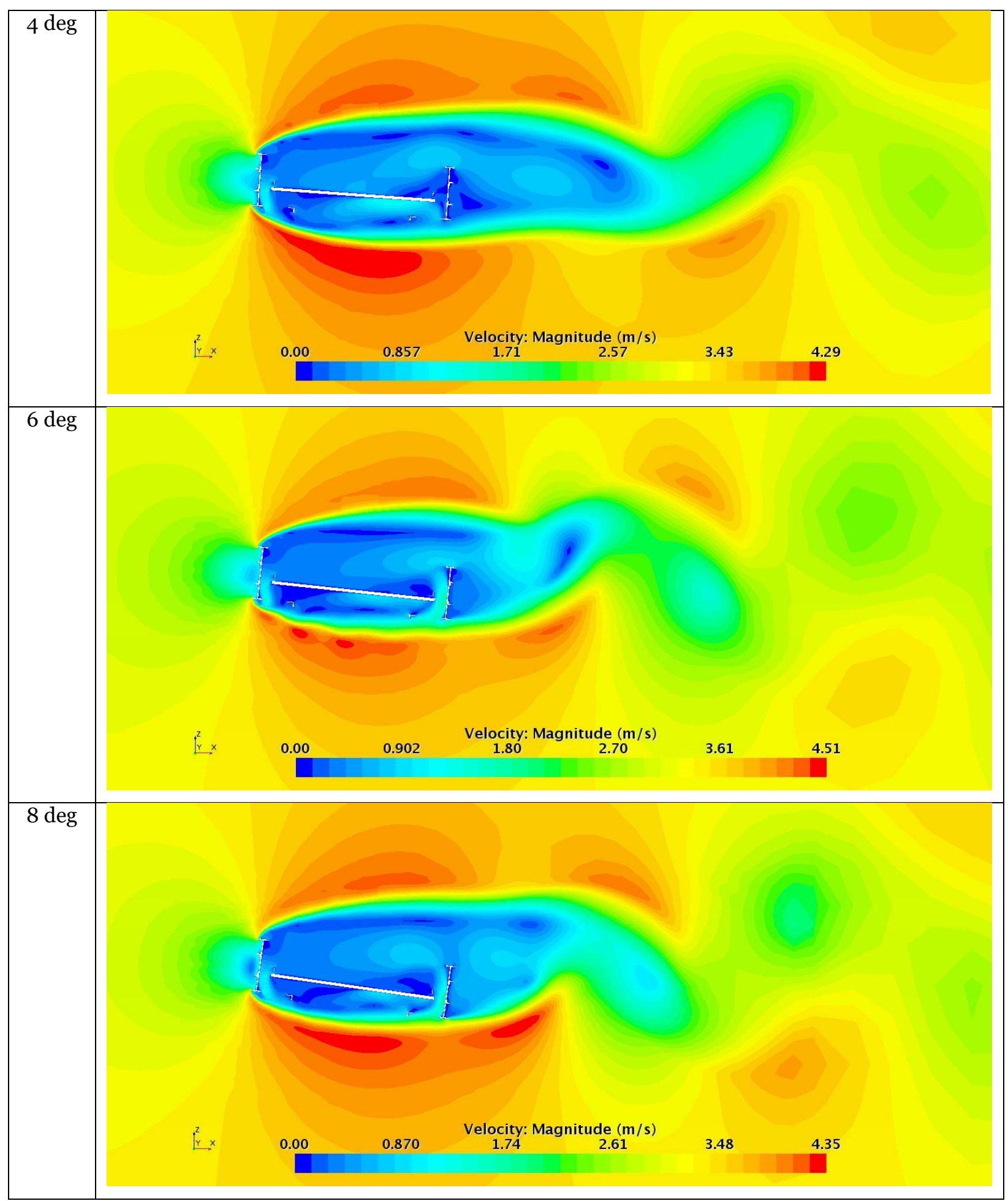




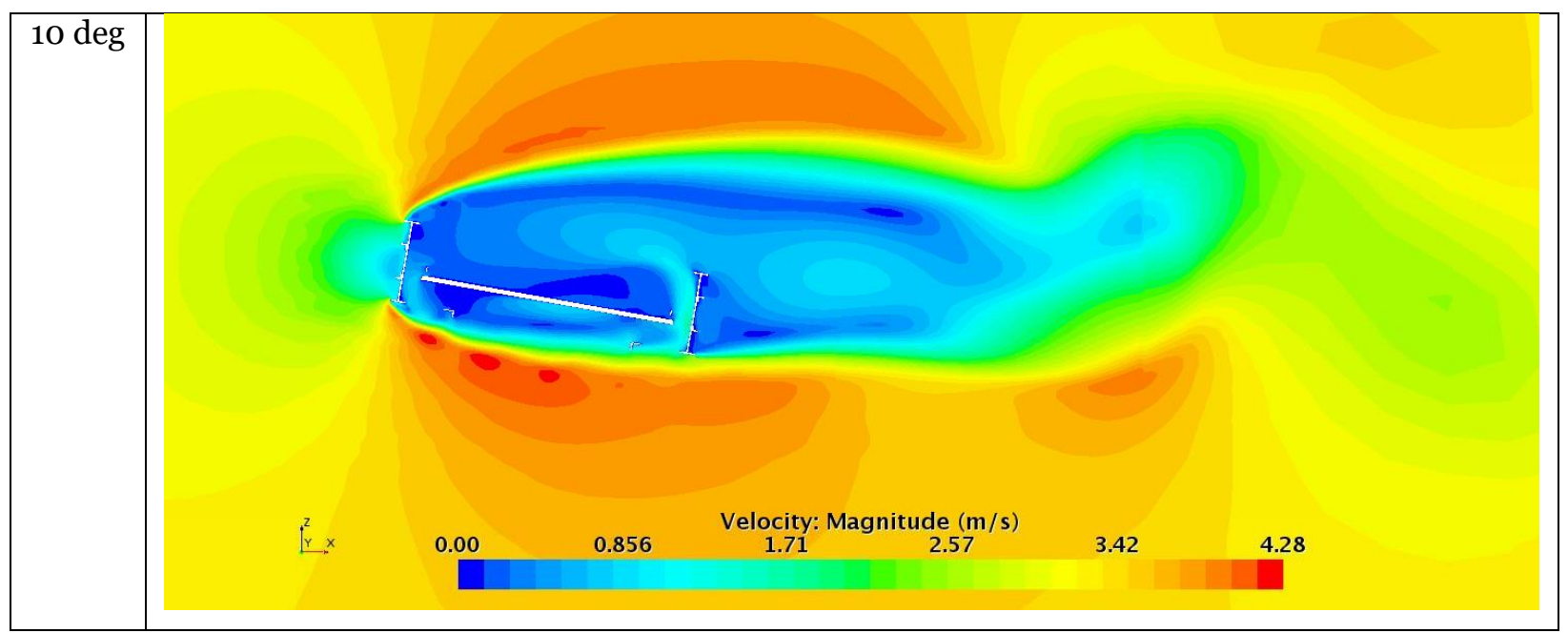

\subsection{Pressure on the deck surface}

Figures from Figure 4-9 through Figure 4-12 summarize the pressure distribution on the deck surfaces: top, bottom, upwind, and downwind, and they show a comparison of the results obtained with the use of different turbulence models and inlet conditions (with mean approach velocity $3.30 \mathrm{~m} / \mathrm{s}$ ) for parallel flow. The distribution resulting from the k- $\varepsilon$ modeling is smooth and the range of pressure values is narrower than that from LES computations. The deviations in values are more pronounced for the top and the bottom surfaces whereas pressure values on the upwind and the downwind surfaces are very similar. Flow fluctuations are noticeable for LES simulations, especially in the downwind area of the deck surfaces. Results for the inlet velocity of $5.67 \mathrm{~m} / \mathrm{s}$ are not presented in this report as they show the same characteristics.

(a)

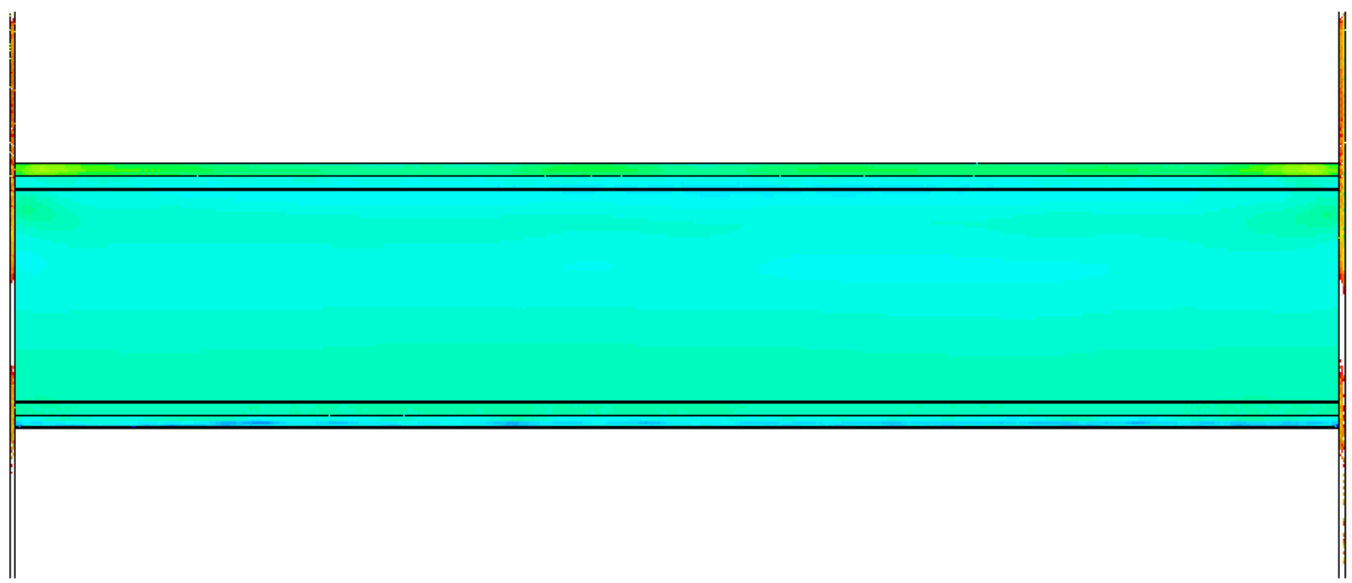


(b)

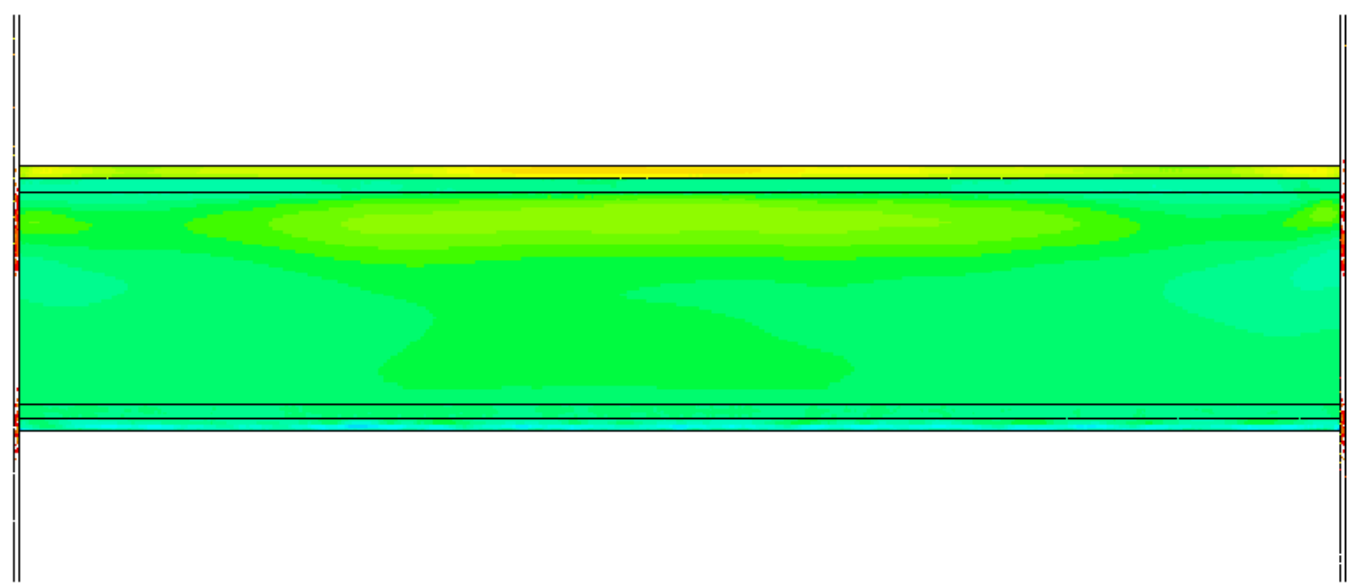

(c)

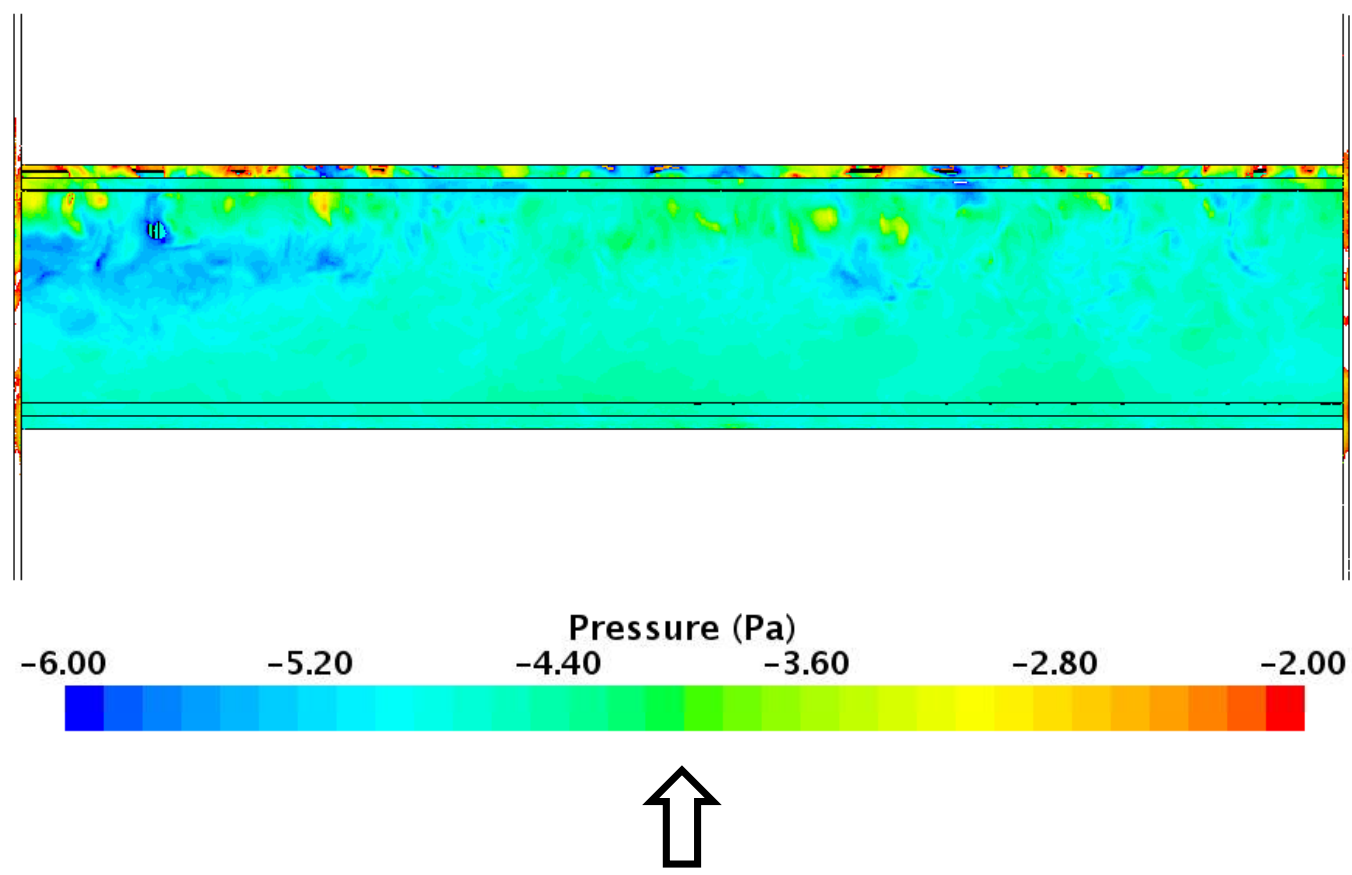

Figure 4-9: Pressure distribution on the top deck surface at (a) URANS k- $\varepsilon$ solver with uniform inlet boundary condition parameters, (b) URANS k- $\varepsilon$ solver with non-uniform inlet boundary condition parameters, (c) LES solver with uniform inlet boundary condition parameters, at inlet velocity $3.30 \mathrm{~m} / \mathrm{s}$ and angle of attack o degrees. The wind direction is marked with an arrow. 
(a)

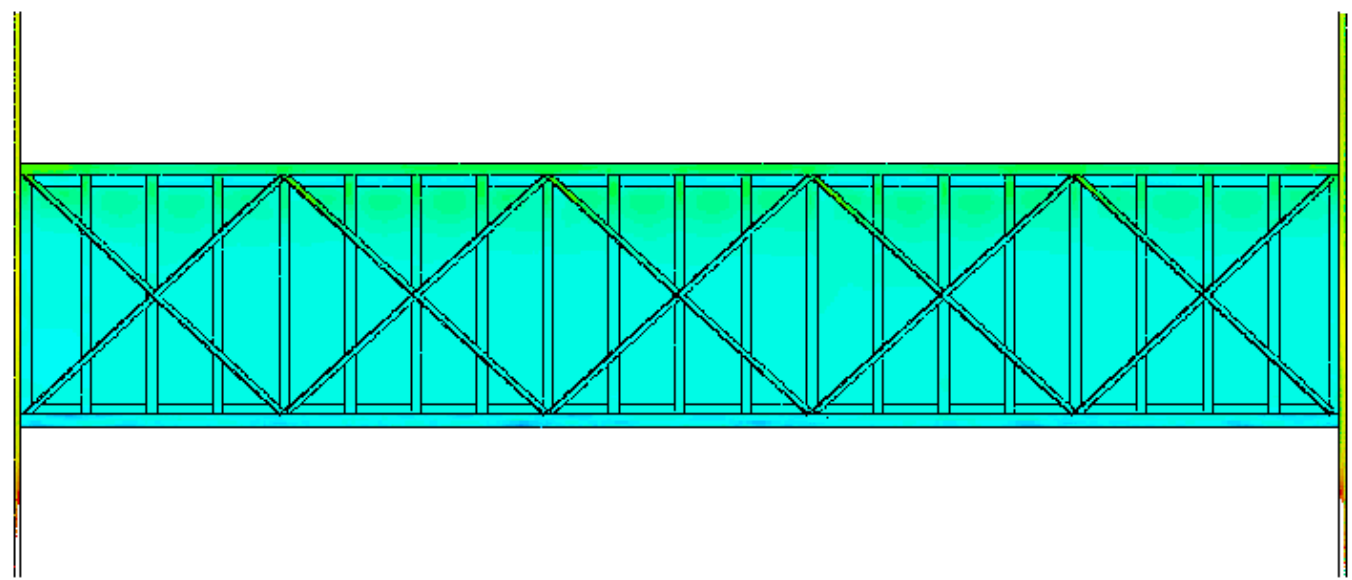

(b)

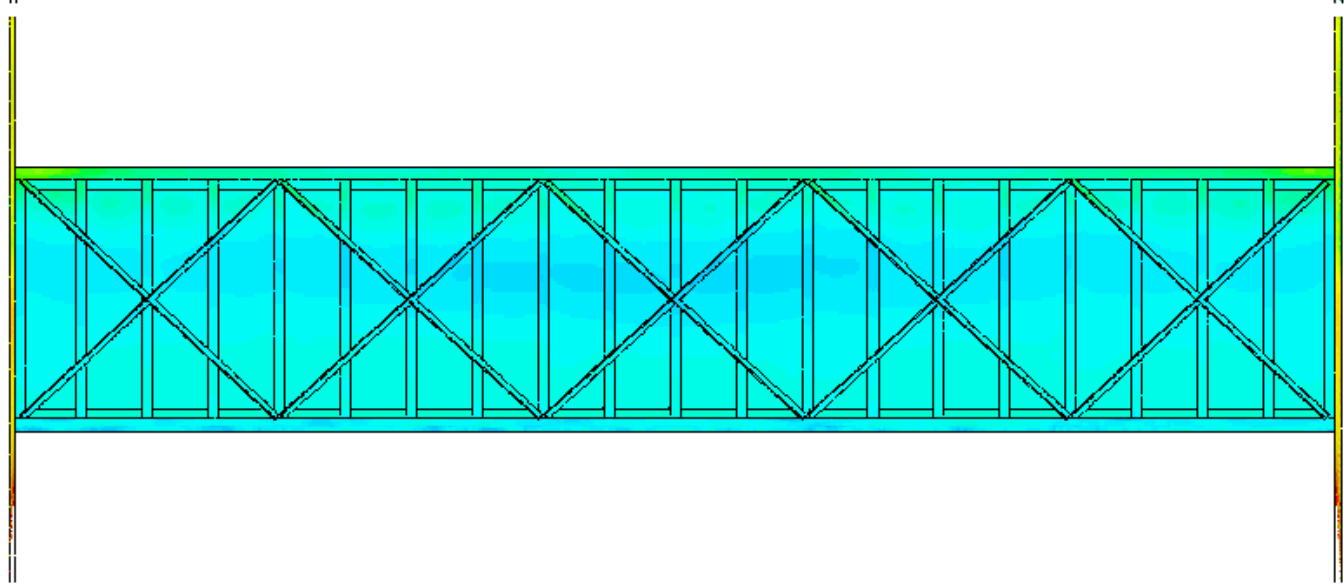

(c)

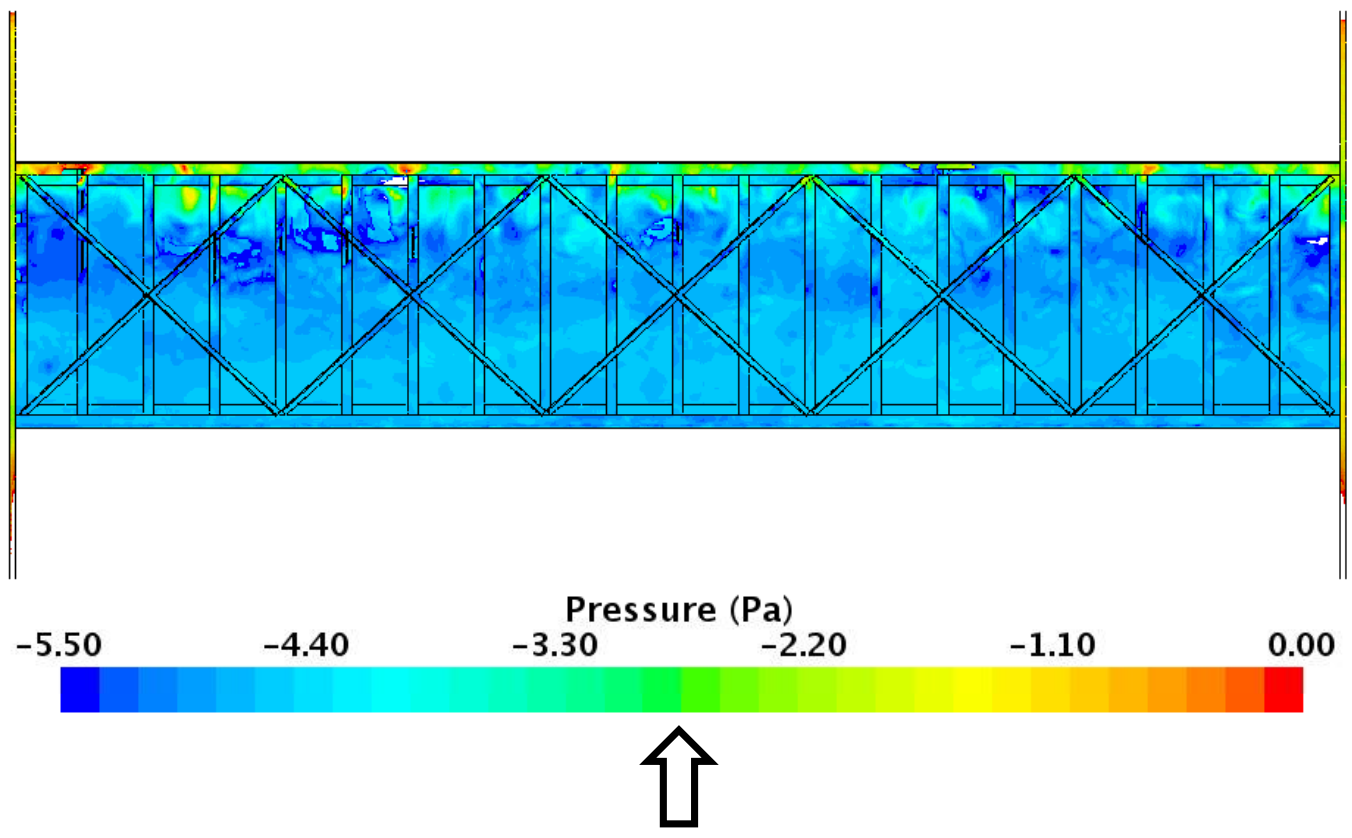

Figure 4-10: Pressure distribution on the bottom deck surface at (a) URANS k- $\varepsilon$ solver with uniform inlet boundary condition parameters, (b) URANS k- $\varepsilon$ solver with non-uniform inlet boundary condition parameters, (c) LES solver with uniform inlet boundary condition parameters , at inlet velocity $3.30 \mathrm{~m} / \mathrm{s}$ and angle of attack o degrees. The wind direction is marked with an arrow. 
(a)

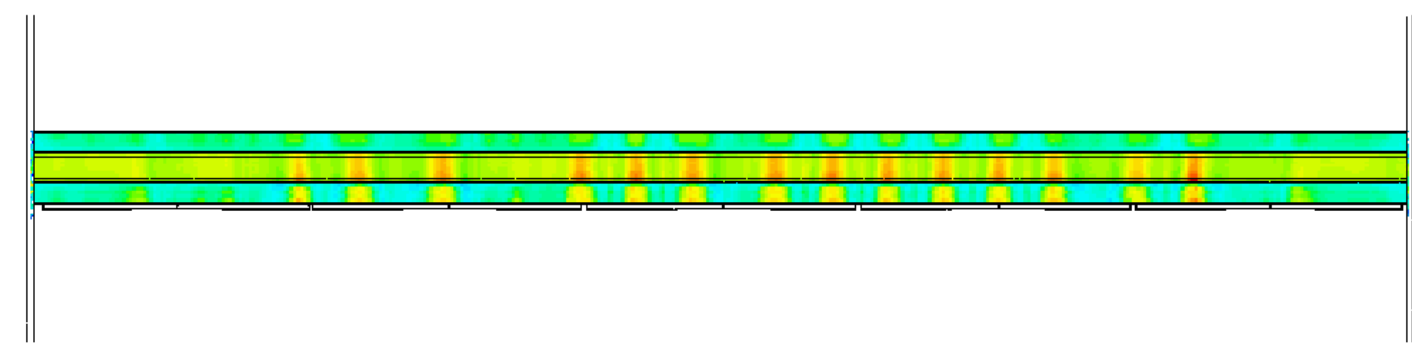

(b)

(c)
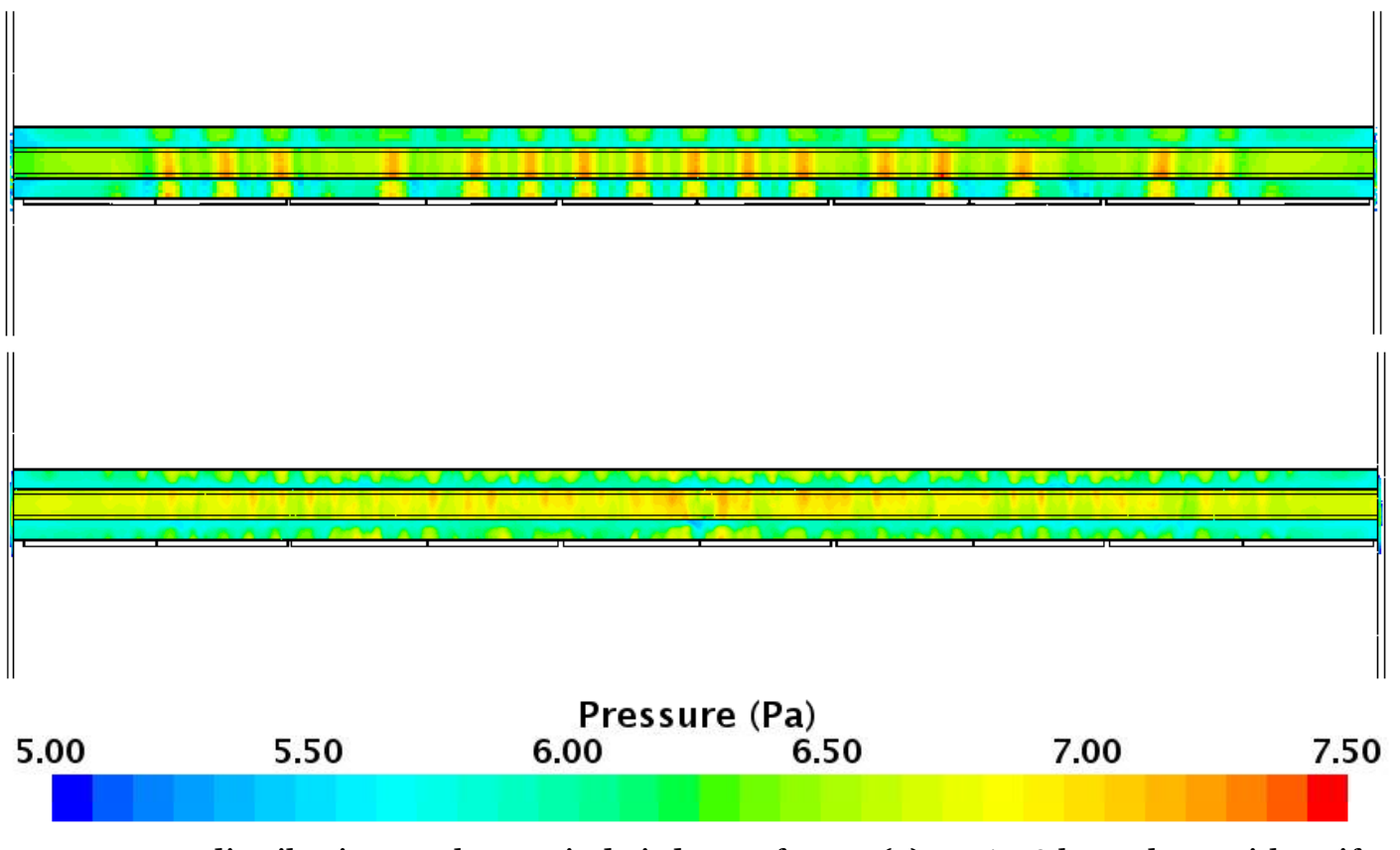

Figure 4-11: Pressure distribution on the upwind girder surface at (a) URANS k- $\varepsilon$ solver with uniform inlet boundary condition parameters, (b) URANS k- $\varepsilon$ solver with non-uniform inlet boundary condition parameters, (c) LES solver with uniform inlet boundary condition parameters, at inlet velocity $3.30 \mathrm{~m} / \mathrm{s}$ and angle of attack o degrees. The wind direction is into the page.

(a)

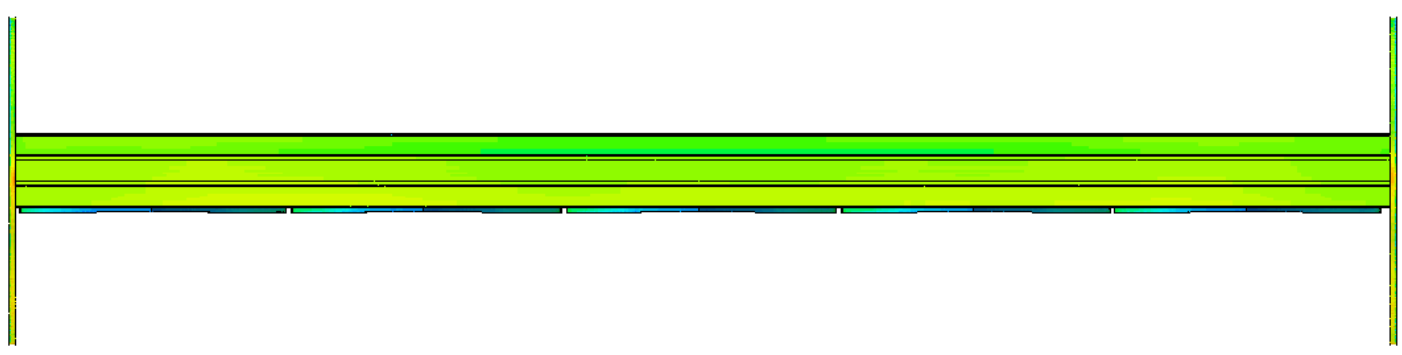

(b)

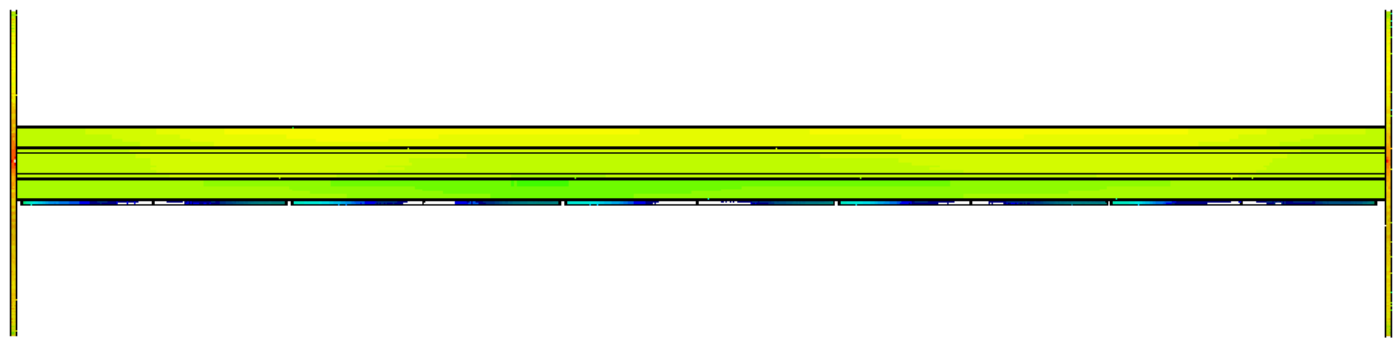


(c)

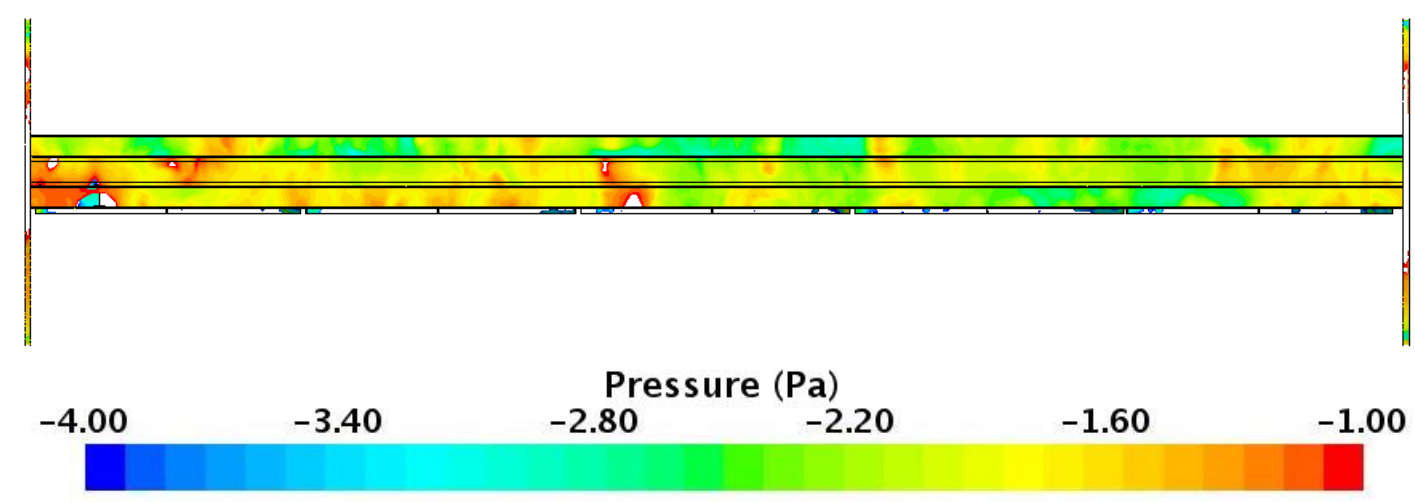

Figure 4-12: Pressure distribution on the downwind girder surface at (a) URANS k- $\varepsilon$ solver with uniform inlet boundary condition parameters, (b) URANS k- $\varepsilon$ solver with non-uniform inlet boundary condition parameters, (c) LES solver with uniform inlet boundary condition parameters, at inlet velocity $3.30 \mathrm{~m} / \mathrm{s}$ and angle of attack o degrees. The wind direction is out of the page.

A comparison of pressure fields on the deck surface at inlet velocity $3.3 \mathrm{~m} / \mathrm{s}$ and three representative values of angle of attack, -6, o, 6 degrees, is outlined in Table 4-6 to Table 4-9. The highest values were recorded for a positive value of the angle of attack and they were located in the central part of the upwind girder, in between the girder stiffeners, see Table 4-6. Pressure at the downwind girder surface was negative for the range of checked angles and varied from approximately -4 Pa to $-1 \mathrm{~Pa}$ (Table 4-7). The widest range of pressure values on top surface (Table 4-8) were encountered for angle of attack -6 degrees and for angle 6 degrees for the bottom surface (Table 4-9). The limit values were approximately -5.o Pa to 2.o Pa on top and -5.5 Pa to o.o Pa on the bottom surface. The positive values could be found only on the downwind girder.

Table 4-6: Pressure distribution on the upwind surface of the girder at inlet velocity $3.30 \mathrm{~m} / \mathrm{s}$ and different angles of attack; URANS k- $\varepsilon$ with uniform inlet boundary condition parameters .

\begin{tabular}{|c||c|}
\hline $\begin{array}{c}\text { Angle of } \\
\text { attack [deg.] }\end{array}$ & Pressure distribution on the upwind surface of the deck \\
\hline & \\
\hline
\end{tabular}




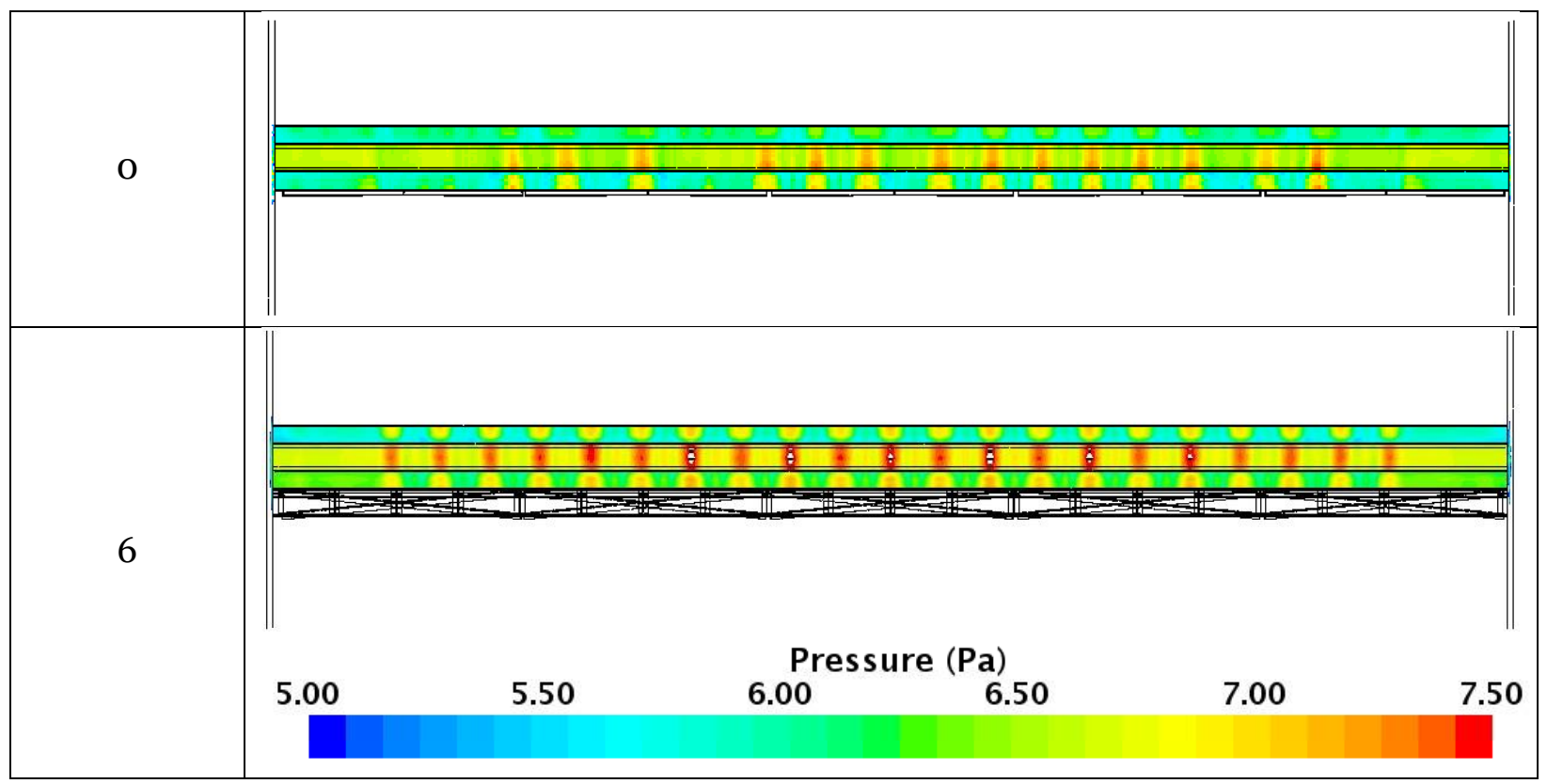

Table 4-7: Pressure distribution on the downwind surface of the girder at inlet velocity $3.30 \mathrm{~m} / \mathrm{s}$ and different angles of attack; URANS k- $\varepsilon$ with uniform inlet boundary condition parameters

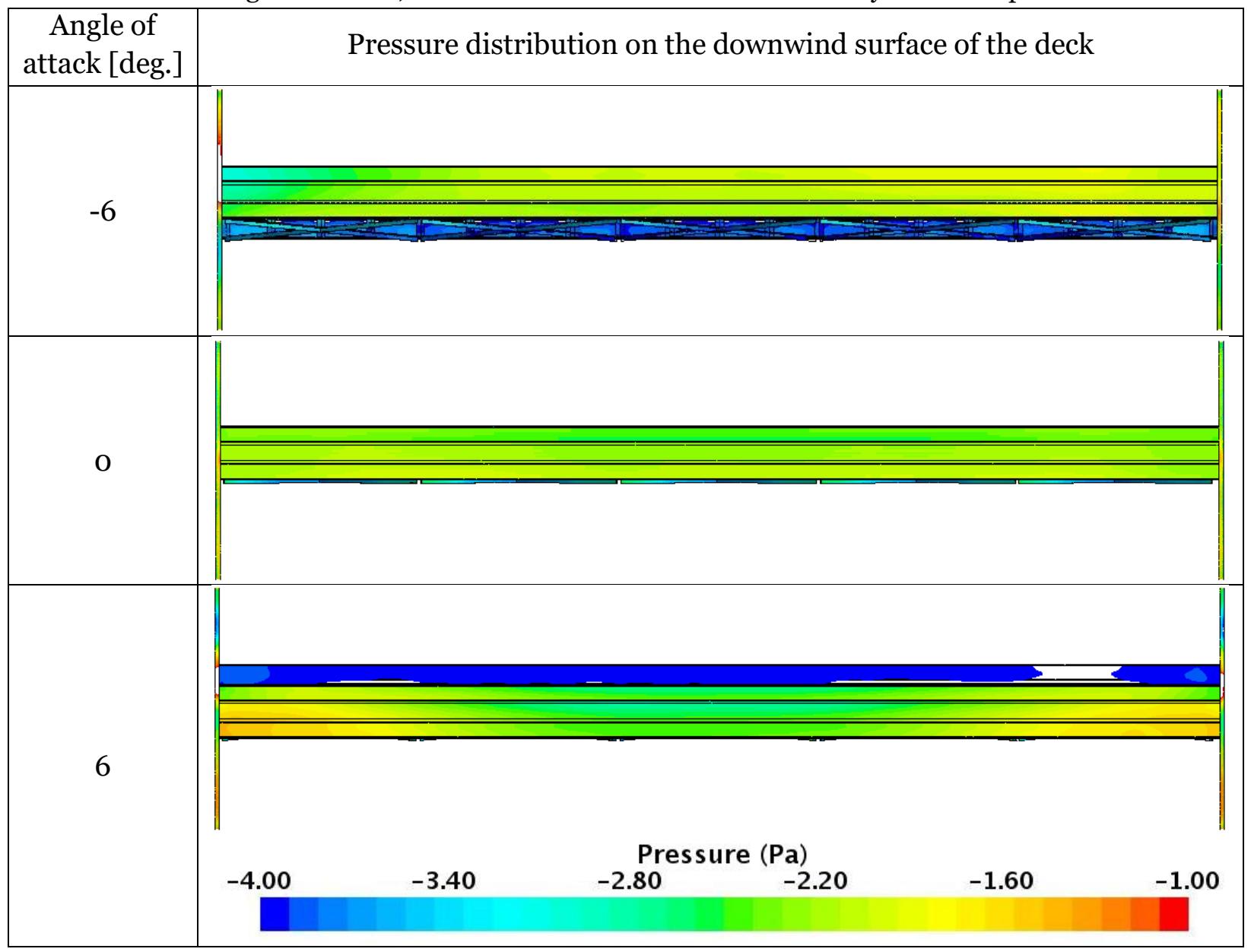


Table 4-8: Pressure distribution on the top surface of the deck at inlet velocity $3.30 \mathrm{~m} / \mathrm{s}$ and different angles of attack; URANS k- $\varepsilon$ with uniform inlet boundary condition parameters

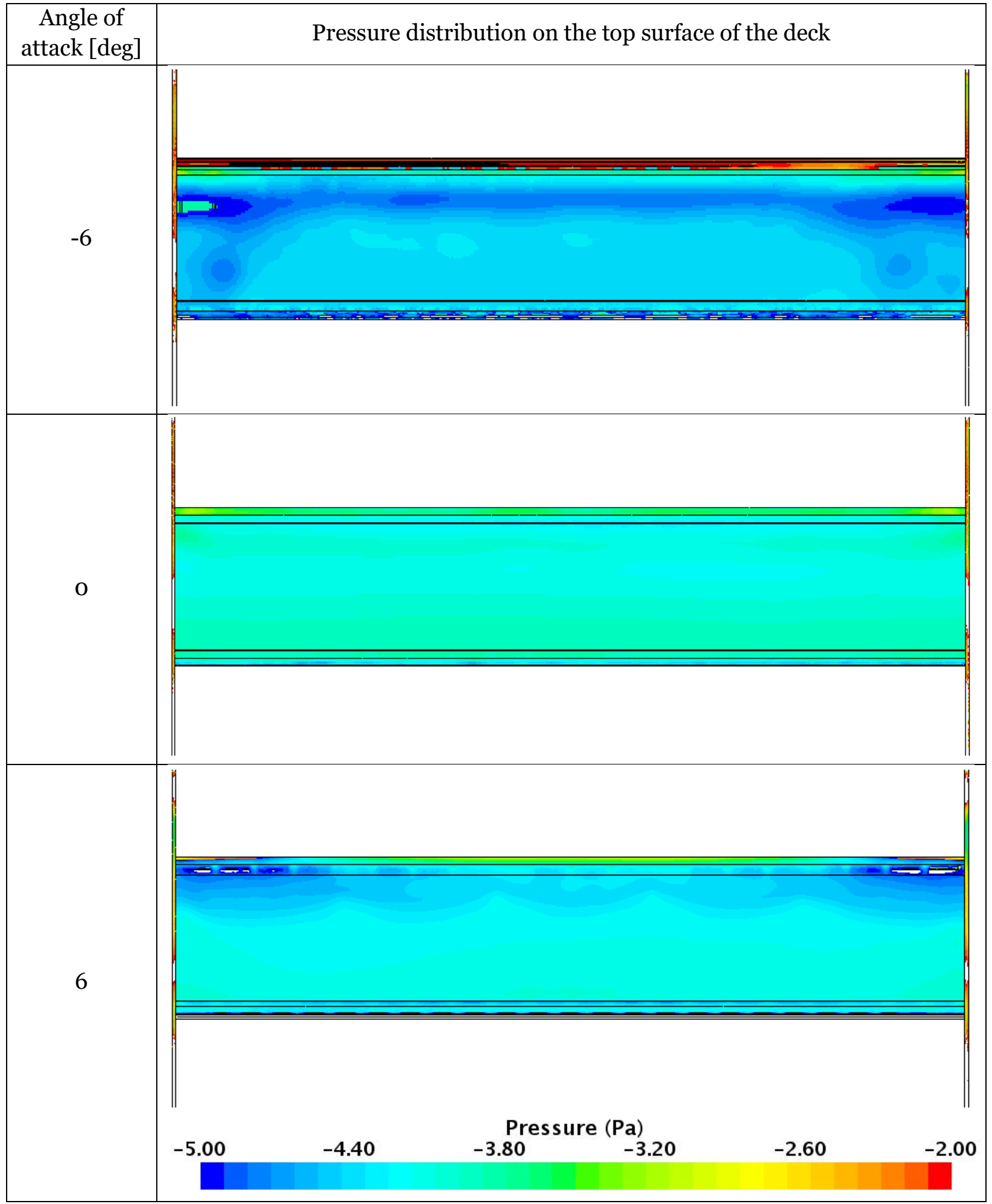


Table 4-9: Pressure distribution on the bottom surface of the deck at inlet velocity $3.30 \mathrm{~m} / \mathrm{s}$ and different angles of attack; URANS k- $\varepsilon$ with uniform inlet boundary condition parameters

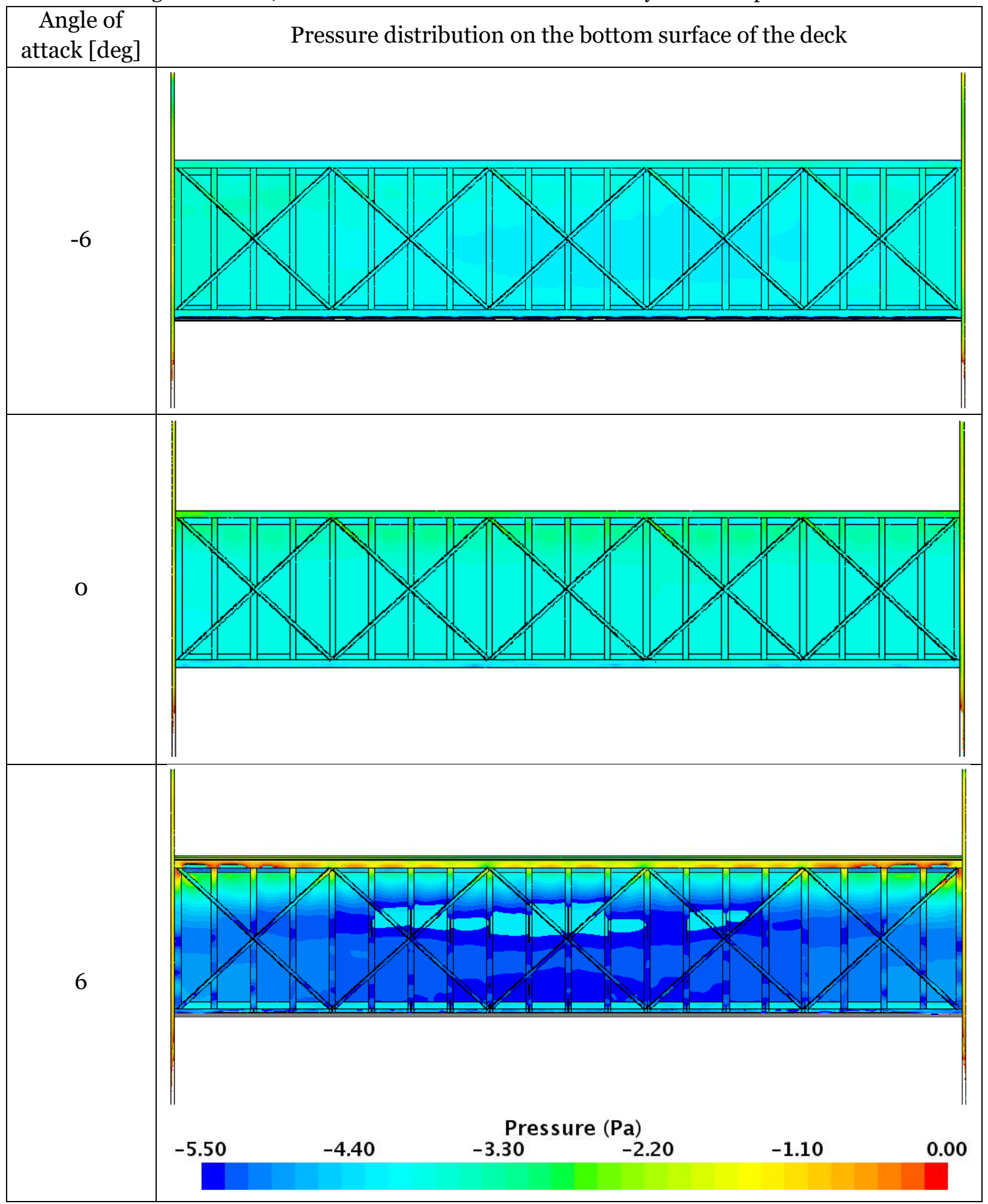




\subsection{Static forces and moments}

Static forces and moments acting on the rigid deck were calculated internally in the software from integration of pressure and shear over the deck surface. Initially in the computations, the URANS $\mathrm{k}-\varepsilon$ solver was used, and the domain was a box with a uniform distribution of inlet values on the inlet velocity boundary condition surface. The angle of attack varied from -10 degrees to 10 degrees, with 2 degree intervals. Two approach flow velocities were considered, equal to $3.30 \mathrm{~m} / \mathrm{s}$ and $5.67 \mathrm{~m} / \mathrm{s}$, which represent the lowest and the highest speeds tested in the laboratory. The mesh sidewalks were modeled as porous baffles. The porous inertial resistance was defined as a function of flow velocity normal to the baffle, according to the field function (5) in Chapter 3.2.

With the goal of improving the numerical results, the simulations were repeated for three representative angles of attack, -6 degrees, zero degrees, and 6 degrees, and both flow speeds, (i) with the use of URANS k- $\varepsilon$ solver, and a non-uniform distribution of inlet values (see Figure 3-5 and Figure 3-6), as well as (ii) with the use of LES solver and constant and uniform inlet velocity and turbulence parameters.

The results were compared with wind tunnel data and illustrated in the form of plots. Figure 4-13 and Figure 4-14 show the relationship between the drag force and wind direction at inlet velocity $3.30 \mathrm{~m} / \mathrm{s}$ and $5.67 \mathrm{~m} / \mathrm{s}$, respectively. Figure 4-15 and Figure 4-16 present the change of lift force, and Figure 4-17 and Figure 4-18 illustrate the change of the pitch moment due to the angle of attack.

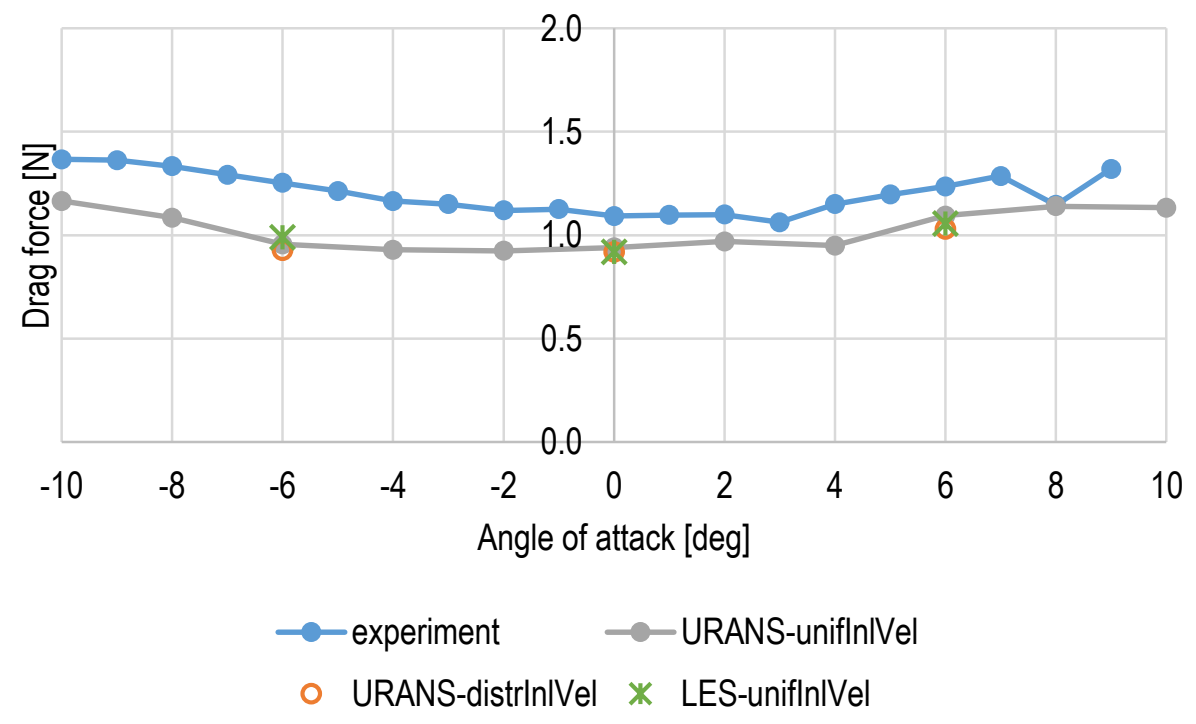

Figure 4-13: Drag force at different wind directions and inlet velocity $3.30 \mathrm{~m} / \mathrm{s}$ 


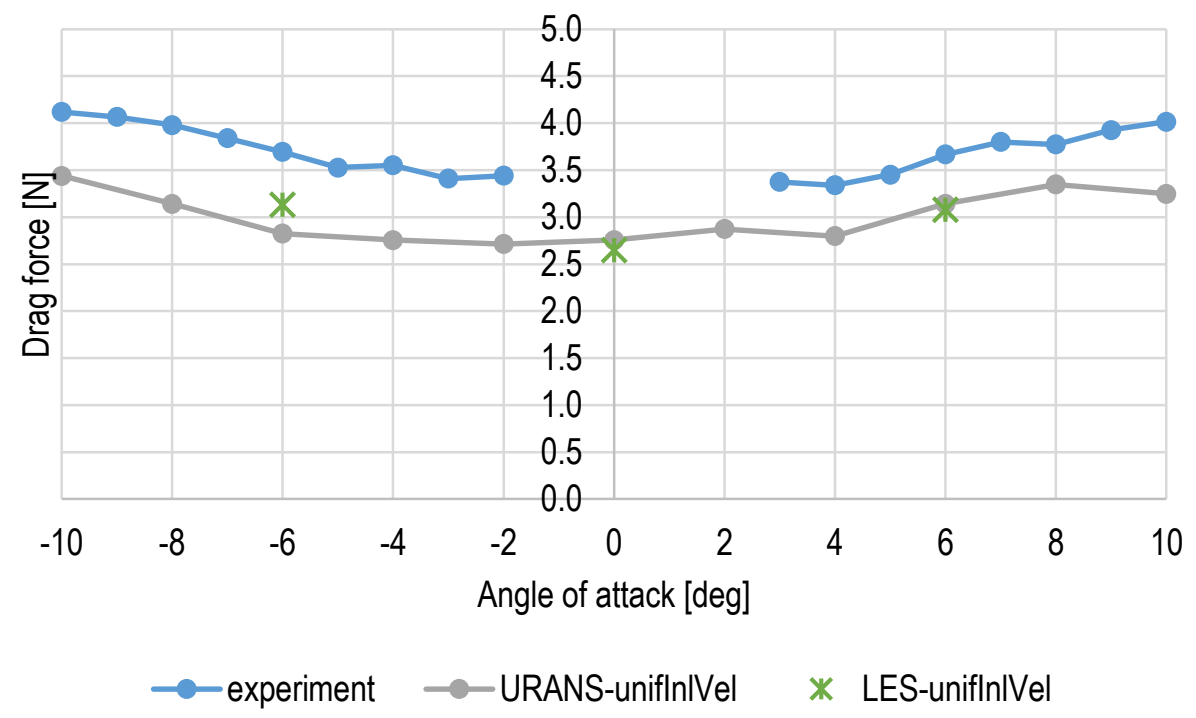

Figure 4-14: Drag force at different wind directions and inlet velocity $5.67 \mathrm{~m} / \mathrm{s}$

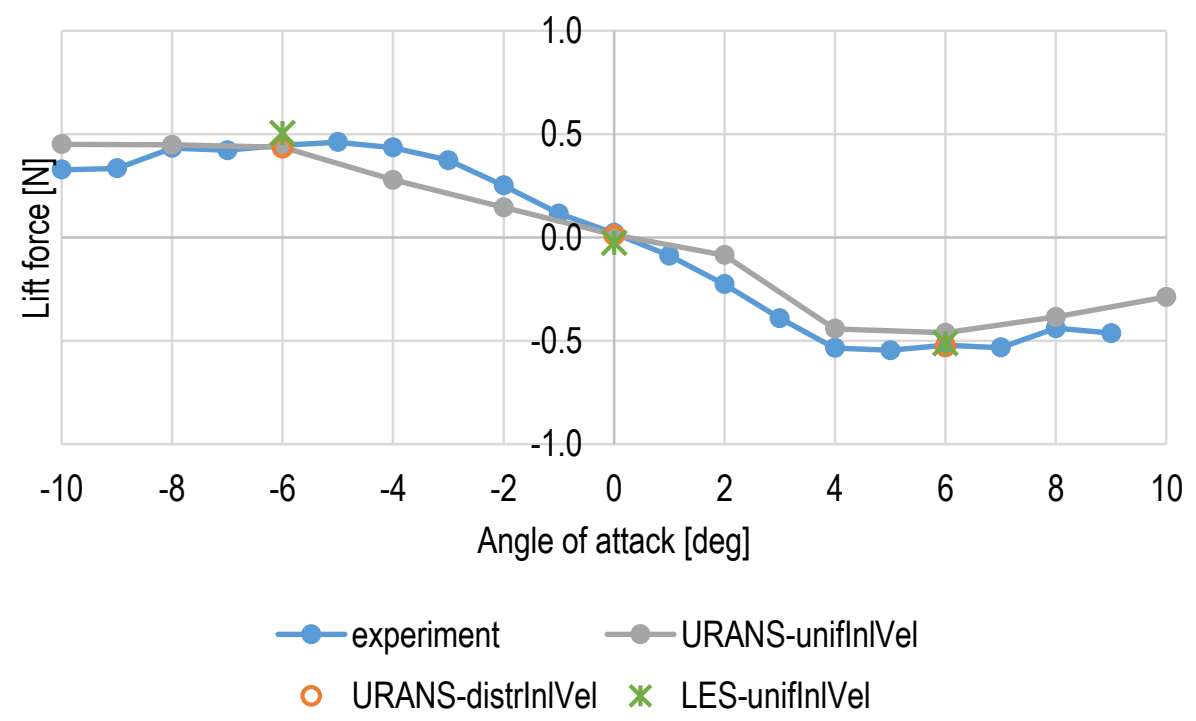

Figure 4-15: Lift at different wind directions and inlet velocity $3.30 \mathrm{~m} / \mathrm{s}$ 


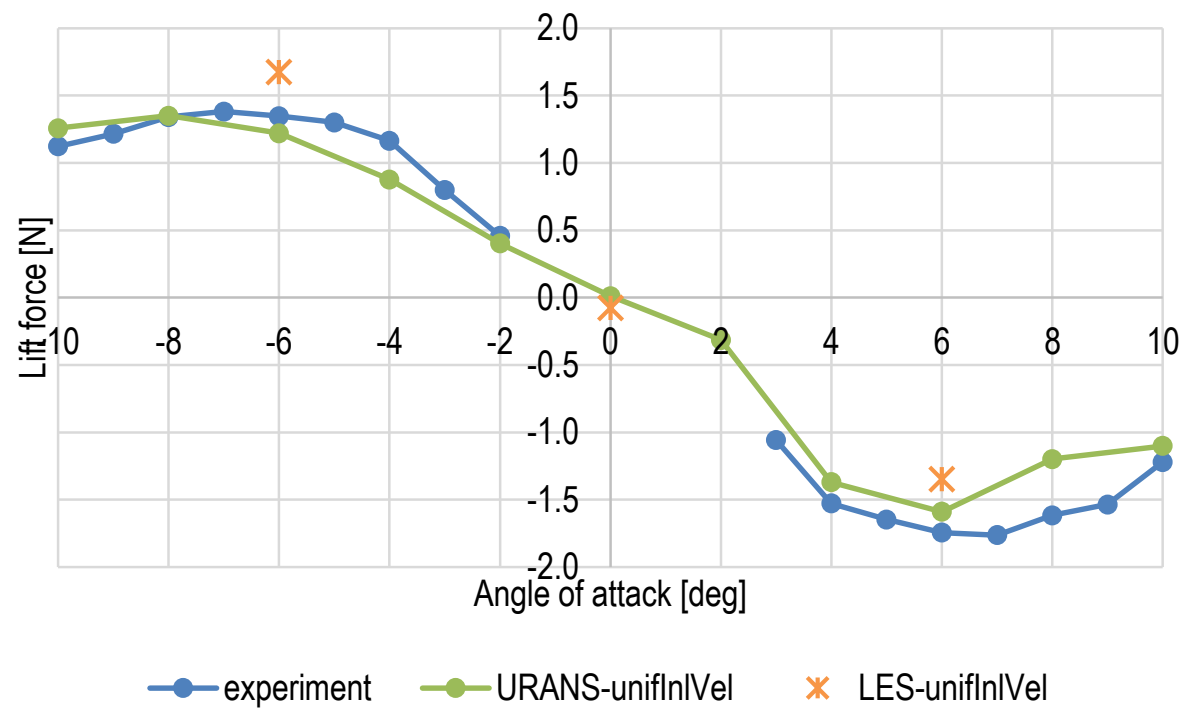

Figure 4-16: Lift at different wind directions and inlet velocity $5.67 \mathrm{~m} / \mathrm{s}$

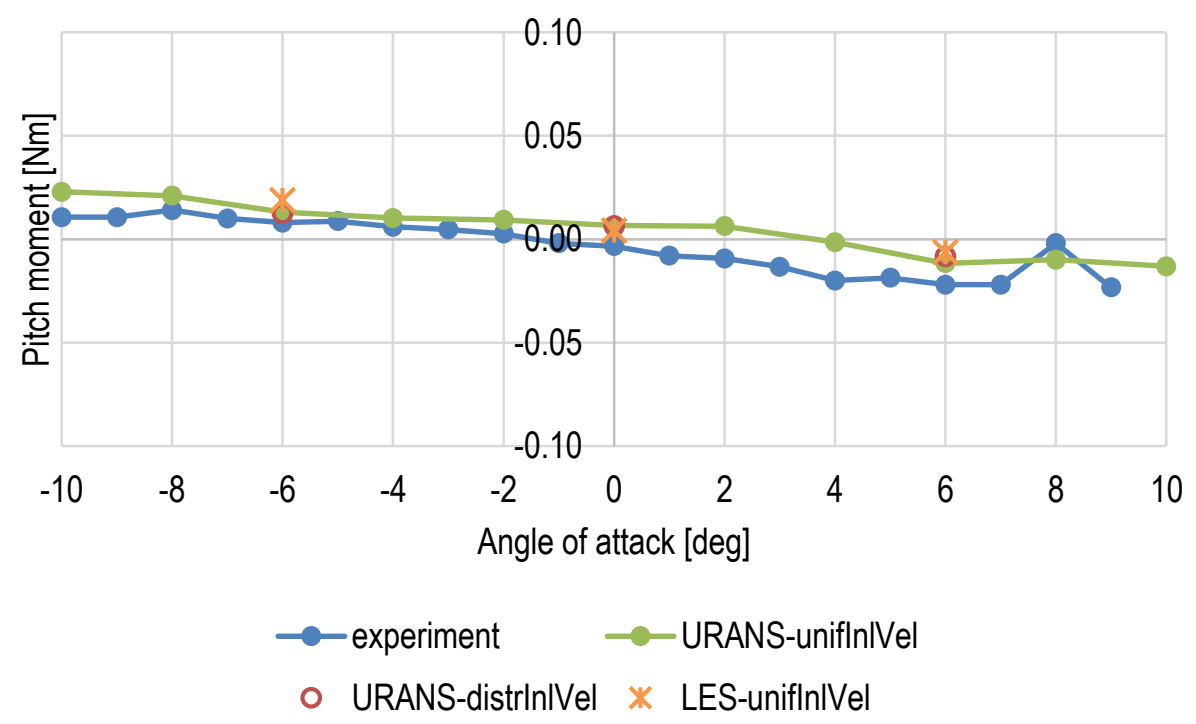

Figure 4-17: Pitch moment at different wind directions and inlet velocity $3.30 \mathrm{~m} / \mathrm{s}$ 


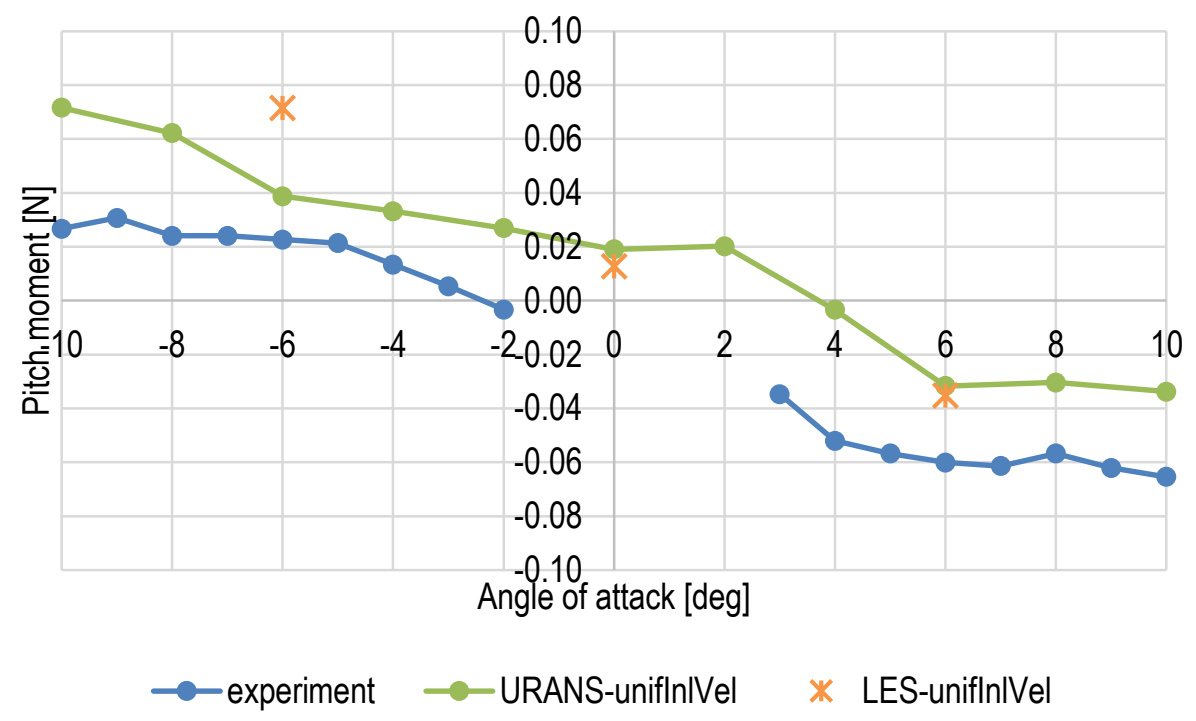

Figure 4-18: Pitch moment at different wind directions and inlet velocity $5.67 \mathrm{~m} / \mathrm{s}$

The study showed a good agreement of the force/moment vs. flow direction trends between the computational and experimental results. The drag force assumes all positive values with the lowest values for a parallel flow, and the highest values for the highest considered absolute values of the angle of attack. The lift force changes sign in the analyzed range of angles. It is positive for negative angles, goes through zero close to the zero angle of attack, and it is negative for the positive angles. It reaches the extreme values at approximately -6 to -4 degrees, and also at 4 to 6 degrees. The pitch moment decreases almost linearly in the examined range of flow directions.

Table 4-10: Relative differences between the computational and experimental results for the angle of attack -6 degrees. Case 1: URANS k- $\varepsilon$ solver with uniform inlet boundary condition parameters, Case 2:

URANS k- $\varepsilon$ solver with non-uniform inlet boundary condition parameters, Case 3: LES solver with uniform inlet boundary condition parameters.

\begin{tabular}{|c|c|c|c|c|}
\hline & $\begin{array}{c}\text { Flow } \\
\text { velocity } \\
{[\mathrm{m} / \mathrm{s}]}\end{array}$ & Case 1 & Case 2 & Case 3 \\
\hline \multirow{2}{*}{$\boldsymbol{e}_{\boldsymbol{F D}}$} & 3.30 & $-16 \%$ & $-13 \%$ & $-19 \%$ \\
\cline { 2 - 5 } & 5.67 & $-24 \%$ & n. a. & $-15 \%$ \\
\hline \multirow{2}{*}{$\boldsymbol{e}_{\boldsymbol{F L}}$} & 3.30 & $7 \%$ & $24 \%$ & $7 \%$ \\
\cline { 2 - 5 } & 5.67 & $-9 \%$ & n. a. & $24 \%$ \\
\hline \multirow{2}{*}{$\boldsymbol{e}_{\boldsymbol{M}}$} & 3.30 & $64 \%$ & $135 \%$ & $56 \%$ \\
\cline { 2 - 5 } & 5.67 & $71 \%$ & n. a. & $215 \%$ \\
\hline
\end{tabular}


Table 4-11: Relative differences between the computational and experimental results for the angle of attack zero degrees. Case 1: URANS k- $\varepsilon$ solver with uniform inlet boundary condition parameters, Case 2:

URANS k- $\varepsilon$ solver with non-uniform inlet boundary condition parameters, Case 3: LES solver

\begin{tabular}{|c|c|c|c|c|}
\hline & $\begin{array}{c}\text { Flow } \\
\text { velocity } \\
{[\mathrm{m} / \mathrm{s}]}\end{array}$ & Case 1 & Case 2 & Case 3 \\
\hline \multirow{2}{*}{$\boldsymbol{e}_{F D}$} & 3.30 & $-6 \%$ & $-8 \%$ & $-8 \%$ \\
\cline { 2 - 5 } & 5.67 & n.a. & n.a. & n.a. \\
\hline \multirow{2}{*}{$\boldsymbol{e}_{F L}$} & 3.30 & $-27 \%$ & $-227 \%$ & $-43 \%$ \\
\cline { 2 - 5 } & 5.67 & n.a. & n.a. & n.a. \\
\hline \multirow{2}{*}{$\boldsymbol{e}_{\boldsymbol{M}}$} & 3.30 & $-299 \%$ & $-221 \%$ & $-291 \%$ \\
\cline { 2 - 5 } & 5.67 & n.a. & n.a. & n.a. \\
\hline
\end{tabular}

Table 4-12: Relative differences between the computational and experimental results for the angle of attack 6 degrees. Case 1: URANS k- $\varepsilon$ solver with uniform inlet boundary condition parameters, Case 2:

URANS k- $\varepsilon$ solver with non-uniform inlet boundary condition parameters, Case 3: LES solver

\begin{tabular}{|c|c|c|c|c|}
\hline \multirow{2}{*}{$\boldsymbol{e}_{\boldsymbol{F D}}$} & $\begin{array}{c}\text { Flow } \\
\text { velocity } \\
{[\mathrm{m} / \mathrm{s}]}\end{array}$ & Case 1 & Case 2 & Case 3 \\
\cline { 2 - 5 } & 3.30 & $-3 \%$ & $-6 \%$ & $-9 \%$ \\
\hline \multirow{2}{*}{$\boldsymbol{e}_{\boldsymbol{F L}}$} & 3.67 & $-14 \%$ & n. a. & $-16 \%$ \\
\cline { 2 - 5 } & 5.67 & $-3 \%$ & $8 \%$ & $11 \%$ \\
\hline \multirow{2}{*}{$\boldsymbol{e}_{\boldsymbol{M}}$} & 3.30 & $-47 \%$ & $-71 \%$ & $-62 \%$ \\
\cline { 2 - 5 } & 5.67 & $-47 \%$ & n. a. & $-41 \%$ \\
\hline
\end{tabular}

The relative differences between the numerical and experimental results are collected in Table 4-10 for -6 degrees, Table 4-11 for zero degrees, and Table 4-12 for 6 degrees. The simulations with the URANS k- $\varepsilon$ solver with non-uniform inlet boundary condition parameters were run only for the $3.30 \mathrm{~m} / \mathrm{s}$ flow velocity, as no improvement of the solution was recorded. No differences were calculated for cases of parallel flow with velocity $5.67 \mathrm{~m} / \mathrm{s}$, as no experimental measurements were available.

The drag forces were underestimated for both free stream velocities, with an increase in the relative difference for the higher flow speed. In the simulations performed with the URANS solver with uniform inlet conditions, at $3.3 \mathrm{~m} / \mathrm{s}$ flow velocity, the relative difference equaled $-16 \%$ at -6 degrees, $-6 \%$ at zero degrees, and $-3 \%$ at 6 degrees. For the higher velocity of $5.6 \mathrm{~m} / \mathrm{s}$ the points on the curve were almost uniformly translated downward along the vertical axis, giving differences of $-24 \%$ at -6 degrees and $-14 \%$ at 6 degrees (zero angle of attack was not used in the experiment). The differences in the drag force between the computational models for the lower approach velocity were very small, of the order of a few percent. The only improvement of results, was noticed for -6 degrees where the relative difference dropped to $-13 \%$ for $3.3 \mathrm{~m} / \mathrm{s}$ when URANS 
solver was used with non-uniform inlet boundary condition parameters, and, to $-15 \%$ for $5.67 \mathrm{~m} / \mathrm{s}$ when LES solver was used.

The plots of the lift forces as a function of the angle of attack had characteristics similar to the experimental curves. At $3.3 \mathrm{~m} / \mathrm{s}$ free stream velocity, URANS k- $\varepsilon$ solver with uniform inlet boundary condition parameters were $7 \%,-27 \%$, and $-3 \%$ for angles -6 , 0 , and 6 degrees respectively. At $5.67 \mathrm{~m} / \mathrm{s}$ flow speed, the differences were $-9 \%$ for both -6 and 6 degrees. It is worth noting that at parallel flow, the lift forces, computational and measured, assumed values of the order of one hundredth of a Newton, nearly zero. In this case even though the percentage difference seemed to be high, the difference between the measured value and the model result was not significant. The model with LES solver gave higher lift forces than the experimental results, with increased relative differences, as compared to the aforementioned URANS k- $\varepsilon$ solver with the uniform inlet boundary condition parameters model. The URANS k- $\varepsilon$ solver with the nonuniform inlet boundary condition parameters gave the same or higher absolute values of the differences.

The experimental measurement of the pitch moment showed that it assumed values from -0.023 $\mathrm{Nm}$ to $0.014 \mathrm{Nm}$ at flow speed $3.30 \mathrm{~m} / \mathrm{s}$, and from -0.065 Nm to $0.031 \mathrm{Nm}$ at flow speed 5.67 $\mathrm{m} / \mathrm{s}$. The CFD solution underestimated these values, most likely as a result of the differences in the drag force value and pressure distribution on the deck surface. The model with URANS k- $\varepsilon$ solver and uniform inlet boundary condition parameters gave the lowest relative difference as compared to the experiment. The values of the computational pitch moment ranged from -0.012 $\mathrm{Nm}$ to $0.013 \mathrm{Nm}$ at $3.3 \mathrm{~m} / \mathrm{s}$, and from $-0.032 \mathrm{Nm}$ to $0.039 \mathrm{Nm}$ at $5.67 \mathrm{~m} / \mathrm{s}$.

Four additional simulations were performed for two other approach flow velocities used in the experiment, i.e. $3.9 \mathrm{~m} / \mathrm{s}$ and $5.06 \mathrm{~m} / \mathrm{s}$, with angles of attack -6 and 6 degrees. Zero angle of attack was omitted as no measurements were available. The simulation settings from Case 1, URANS k$\varepsilon$ solver with uniform inlet boundary condition parameters were used. Figure 4-19 presents a comparison of experimental and computational results for flow angle -6 degrees, and Figure 4-20 shows results for the 6 degree angle. 
(a)

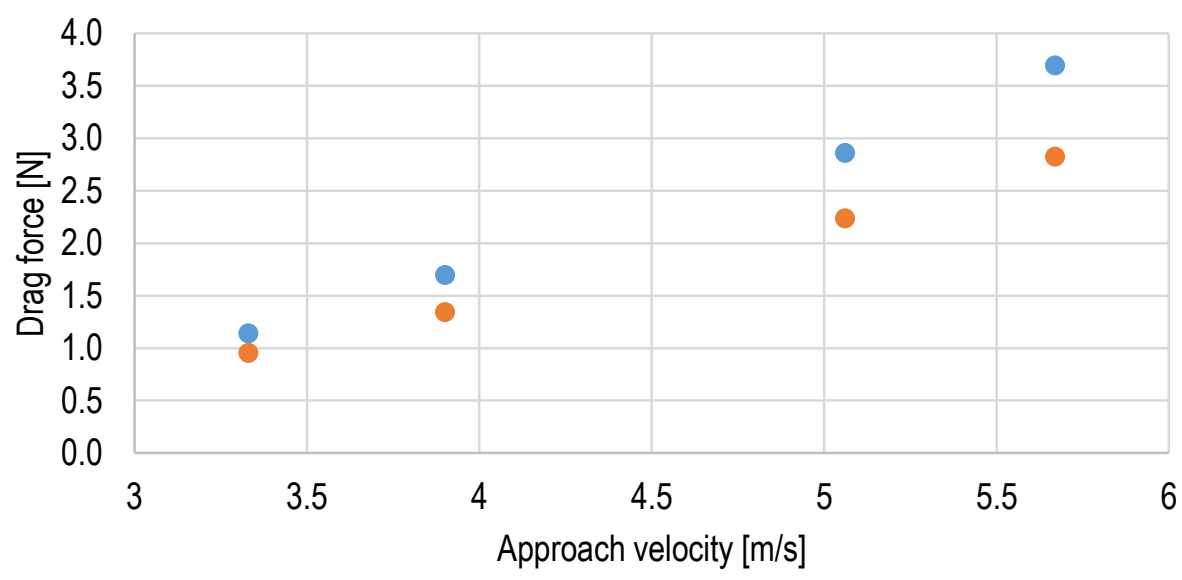

- experiment $\bullet$ CFD

(b)

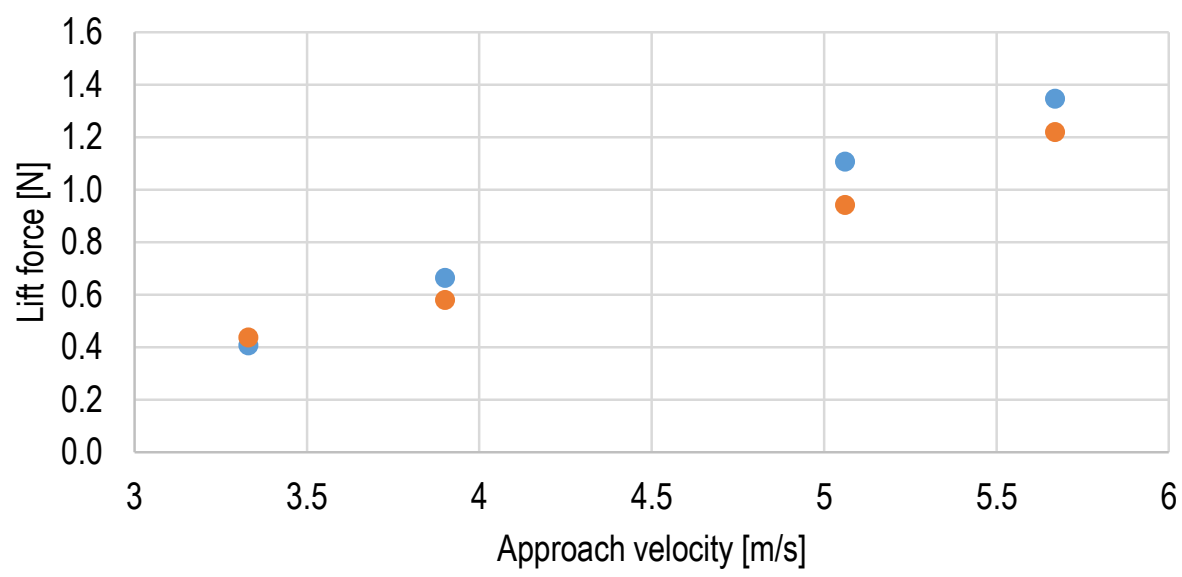

(c)

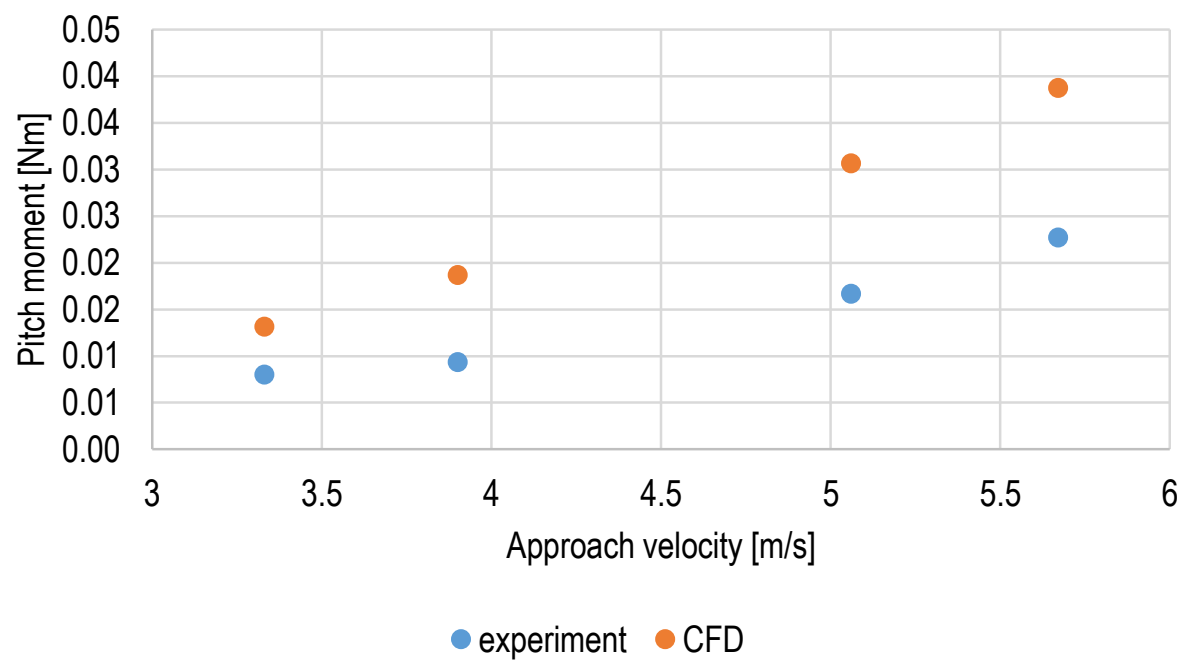

Figure 4-19: Change of the force components due to varying approach velocity at angle of attack -6 degrees. Comparison of experimental and computational results 
(a)

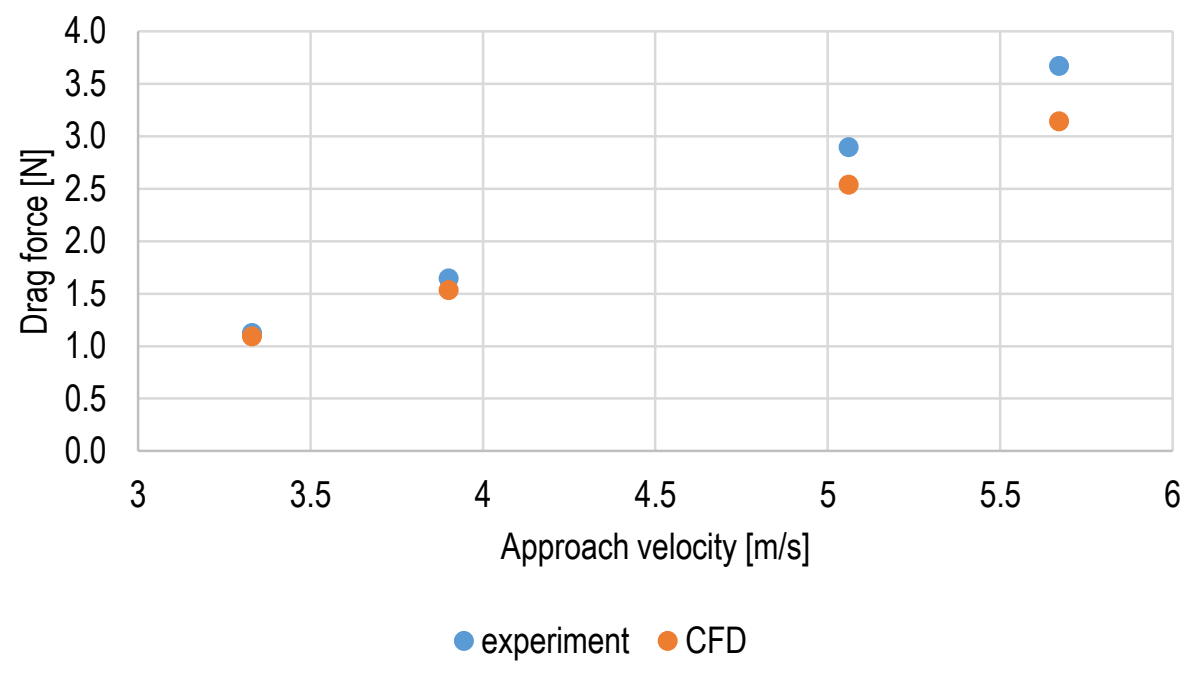

(b)

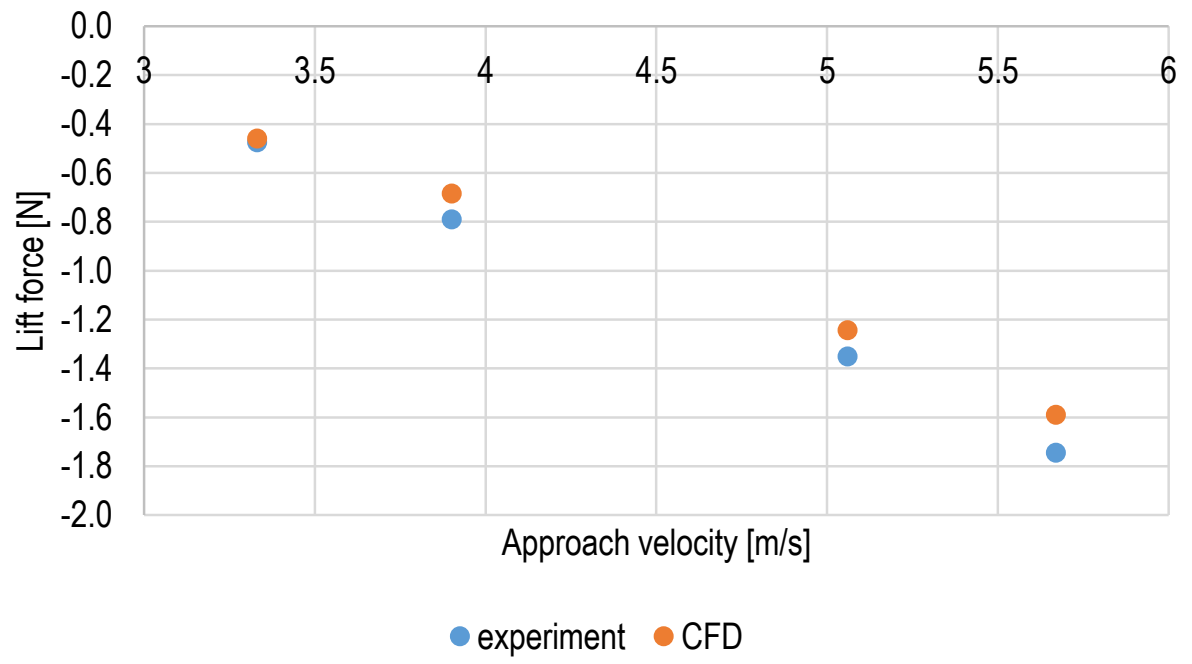

(c)

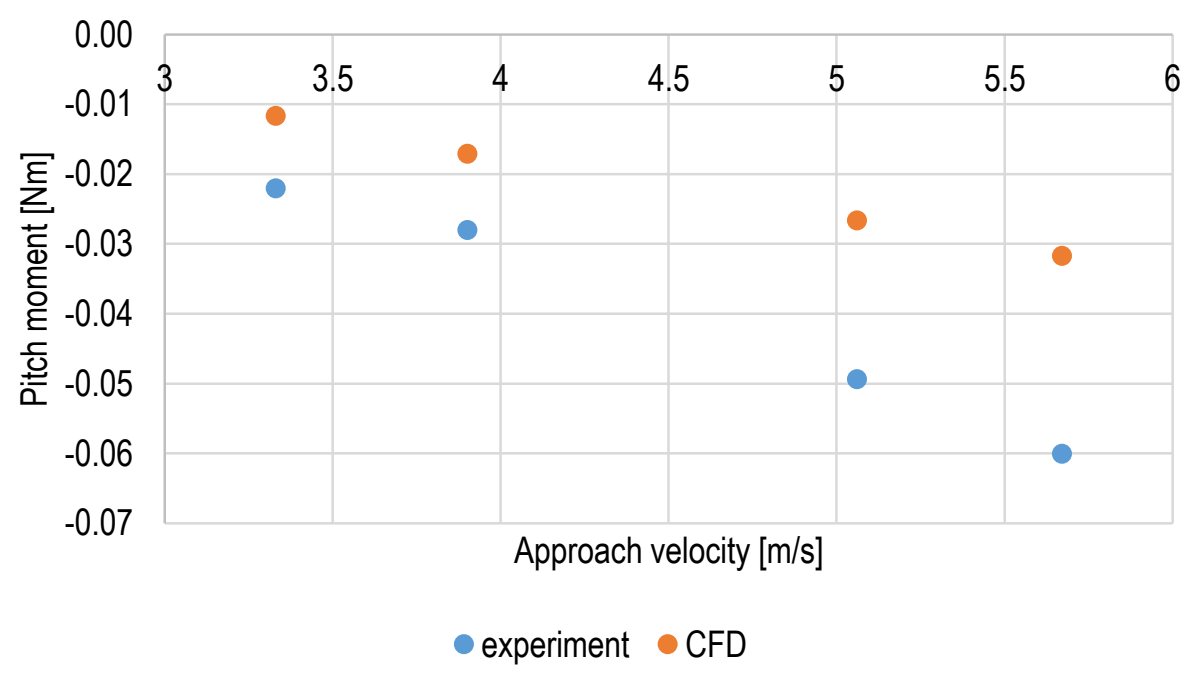

Figure 4-20: Change of the force components due to varying approach velocity at angle of attack 6 degrees. Comparison of experimental and computational results 
Table 4-13: Relative differences between the computational and experimental results at angles of attack -6 and 6 degrees for varying flow speed

\begin{tabular}{|c|c|c|c|c|}
\hline $\begin{array}{c}\text { Approach flow } \\
\text { velocity [m/s] }\end{array}$ & $\begin{array}{c}\text { Angle of } \\
\text { attack [deg] }\end{array}$ & $e_{F D}$ & $e_{F L}$ & $e_{M}$ \\
\hline \multirow{2}{*}{3.33} & -6 & $-16 \%$ & $7 \%$ & $64 \%$ \\
\cline { 2 - 5 } & 6 & $-3 \%$ & $-3 \%$ & $-47 \%$ \\
\hline \multirow{2}{*}{3.9} & -6 & $-21 \%$ & $-13 \%$ & $100 \%$ \\
\cline { 2 - 5 } & 6 & $-7 \%$ & $-13 \%$ & $-39 \%$ \\
\hline \multirow{2}{*}{5.06} & -6 & $-22 \%$ & $-15 \%$ & $84 \%$ \\
\cline { 2 - 5 } & 6 & $-12 \%$ & $-8 \%$ & $-46 \%$ \\
\cline { 2 - 5 } & -6 & $-24 \%$ & $-9 \%$ & $71 \%$ \\
\hline \multirow{2}{*}{5.67} & 6 & $-14 \%$ & $-9 \%$ & $-47 \%$ \\
\hline
\end{tabular}

Table 4-13 combines the relative differences between the experimental and computational results. The difference in drag force experiences an increase with increasing flow speed for both flow directions. It changes from $-16 \%$ to $-24 \%$ for -6 degree angle and changes from $-3 \%$ to $-14 \%$ at 6 degrees angle of attack. This trend was not noticed for the lift force. At -6 degrees, the difference is positive for $3.3 \mathrm{~m} / \mathrm{s}$, changes sign and increases in absolute value for the speed range of 3.9 to $5.06 \mathrm{~m} / \mathrm{s}$, and drops for the highest speed. At a 6 degree angle, it assumes values of $-3 \%,-13 \%$, $8 \%$, and $-9 \%$, with no noticeable trend. The pitch moment at -6 degree angle of attack has positive values, it increases for $3.9 \mathrm{~m} / \mathrm{s}$ as compared with $3.3 \mathrm{~m} / \mathrm{s}$, but decreases for higher speeds. At 6 degree angle it is almost constant, with values close to $-47 \%$, except for $3.9 \mathrm{~m} / \mathrm{s}$ speed, when it drops to $-39 \%$.

\section{Conclusions}

CFD computations were performed for a wind tunnel test of a bridge section model in smooth air flow with differing angles of attack, and flow velocity values. Also, different turbulence models and the inlet velocity boundary conditions were used. The deck model remains stationary throughout the simulation, which allows for an investigation of the static forces acting on it. The flow equations were solved with the use of two methods, unsteady RANS with k- $\varepsilon$ turbulence modeling and LES. Two cases of the inlet boundary conditions were assumed: a spatially uniform distribution and a non-uniform distribution of inlet parameters based on the flow modeled with a wind tunnel model with simplified geometry. Drag force, lift force, and pitch moment were computed and compared to the experimental results.

In the first phase of this study an investigation was performed to establish what approach should be taken in modeling the sidewalks. In the experimental setup, the model had sidewalks made of a wire mesh with constant porosity. Three computational models were developed: no sidewalks, porous sidewalks (grates) and non-porous, solid sidewalks. The model with sidewalks modeled as a full, non-porous surface gave the worst results. The sidewalks in the prototype are metal grates that allow the flow of the air through the structure between the bottom and top of the deck surface 
behind the girder webs at the edges of the deck. In the numerical model this element had to be represented in a way that did not require the large computational resources needed to include the wires of the metal grates to be resolved in the computational mesh. A porous baffle with porosity that matched that of the grates proved to give good results.

The numerical setup allows study and visualization of the model in wind in much more detail than what can be obtained from the limited set of available laboratory measurements. The flow velocity around the deck was visualized using color and vector plots, as well as color plotting the pressure distribution on the deck surfaces. The study of the velocity vector field showed that the flow in between the girders (above the deck) was turbulent with numerous vortices forming in this area. The flow separated at one of the corners of the upwind girder and reattached to the upper deck surface farther downstream.

The static forces were computed for the section model and compared with the experimental data. Results vary with change of the CFD solver, assumed inlet boundary conditions, and also flow direction and speed. Results closest to the measurements were obtained for the URANS solver with k-epsilon turbulence model and uniform velocity inlet boundary condition. For lower flow speed the model showed a better correspondence with the experiment than for higher velocities. Overall the CFD model gave the best match of the lift force for the considered range of parameters.

The existing differences may be attributed to several causes. In this type of structure, with so many thin structural elements, the flow becomes turbulent and capturing all separation points can become challenging. A much denser mesh surrounding the deck may be required to capture details of the flow that may be needed to significantly improve the results. The presented URANS models had 3.8 million cells, and the LES model was solved with 14 million cells. Increasing these numbers would mean much more computationally expensive CFD runs. 


\section{Acknowledgements}

The funding for this project came from the wind research program at Turner-Fairbank Highway Research Center, through Interagency Agreement Number DTFH61-14-X-300002 between DOT and DOE, and the work was performed under DOE's contract with UChicago Argonne, LLC, contract no. DE-ACo2-06-CH11357.

\section{References}

[1] http://www.wsdot.wa.gov/TNBhistory/

[2] Bosch H.R., A Wind Tunnel Investigation of the Deer Isle-Sedgwick Bridge (Phase I), Report No. FHWA/RD-87/027, Federal Highway Administration, Washington DC., August 1987

[3] Livermore Software Technology Corporation LS-PrePost Online documentation, http://lstc.com/lspp

[4] Star-CCM+ v.12.06 Documentation

[5] Sitek M.A., Lottes S.A., Bojanowski C., Air Flow Modeling in the Wind Tunnel of the FHWA Aerodynamics Laboratory at Turner-Fairbank Highway Research Center, ANL technical report ANL/NED/17/2, 2017

[6] Mehta, R.D., 1985. Turbulent Boundary Layer Perturbed by a Screen, AIAA Journal, Vol. 2, No. 9, 1335-1342 


\section{Argonne}

Nuclear Engineering Division

Argonne National Laboratory

9700 South Cass Avenue

Argonne, IL 60439-4815

www.anl.gov

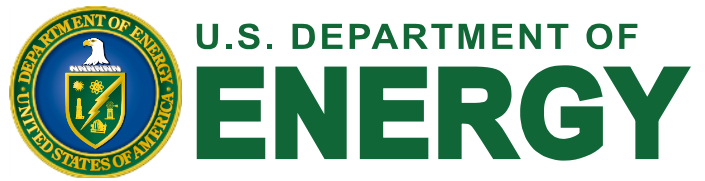

Argonne National Laboratory is a U.S. Department of Energy

laboratory managed by UChicago Argonne, LLC

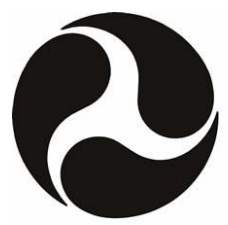

\section{U.S. Department \\ of Transportation}

\section{Federal Highway \\ Administration}

